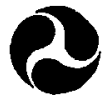

U.S. Department

of Transportation

National Highway

Traffic Safety

Administration

DOT HS 808321

October 1995

4

Final Report

$!$

\title{
Motivating Anti-DWI Behavior Using Existing Values
}

This document is available to the public from the National Technical Information Service, Springfield, Virginia 22161. 
This publication is distributed by the U.S. Department of Transportation, National Highway Traffic Safety Administration, in the interest of information exchange. The opinions, findings and conclusions expressed in this publication are those of the author(s) and not necessarily those of the Department of Transportation or the National Highway Traffic Safety Administration. The United States Government assumes no liability for its contents or use thereof. If trade or manufacturers' name or products are mentioned, it is because they are considered essential to the object of the publication and should not be construed as an endorsement. The United States Government does not endorse products or manufacturers. 
Technical Report Documentation Page

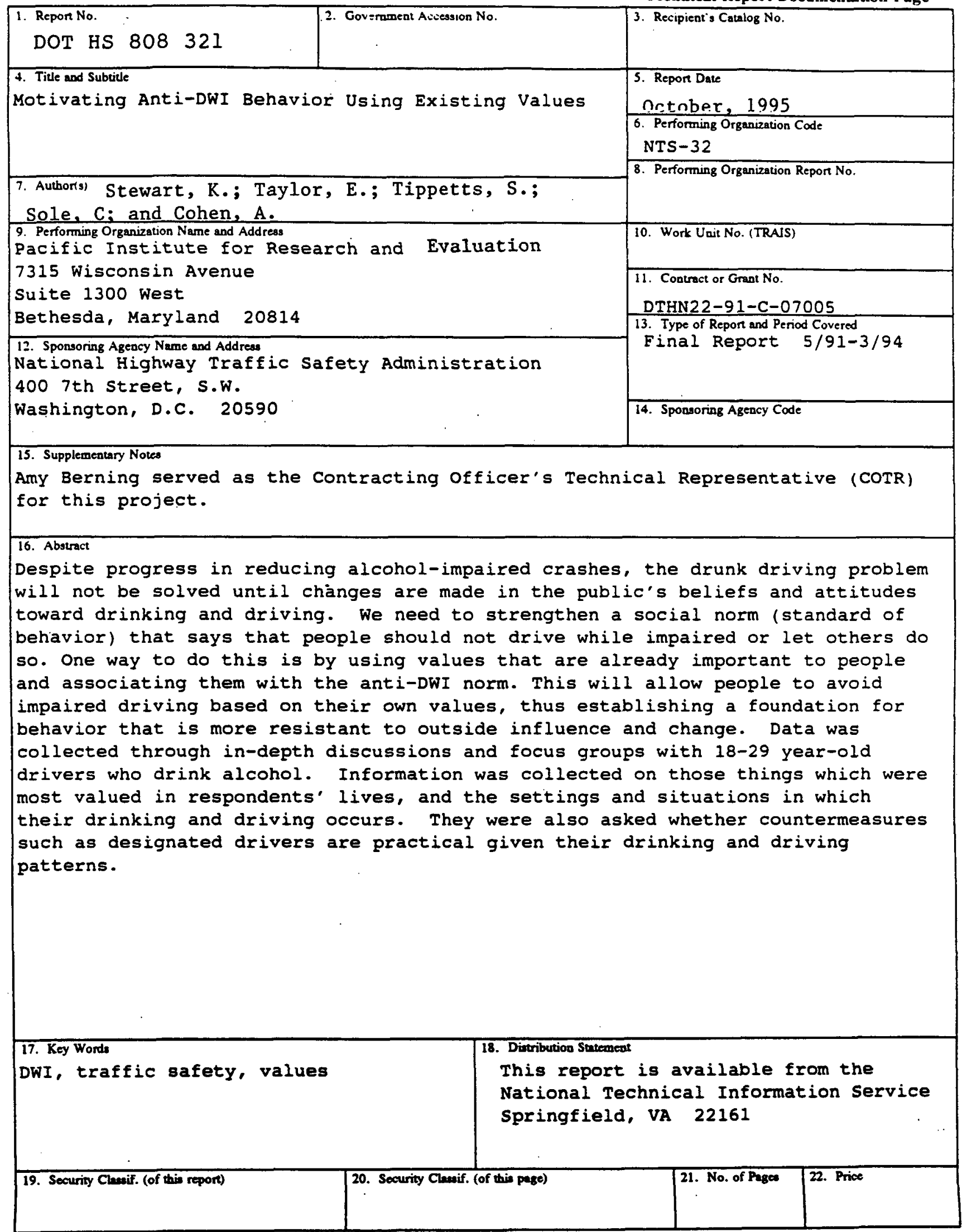

Form DOT F 1700.7 (8-72) Reproduction of completed page anthorized 


\section{TABLE OF CONTENTS}

I. SUMMARY $\ldots \ldots \ldots \ldots \ldots \ldots \ldots \ldots \ldots \ldots \ldots$

II. BACKGROUND ON THE RESEARCH $\ldots \ldots \ldots \ldots \ldots \ldots \ldots 13$

III. RESEARCH APPROACH AND METHODOLOGY $\ldots \ldots \ldots \ldots 15$

Target Groups .......................... 15

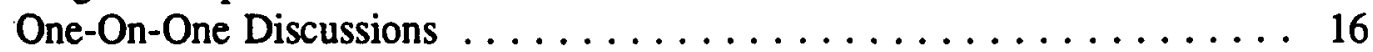

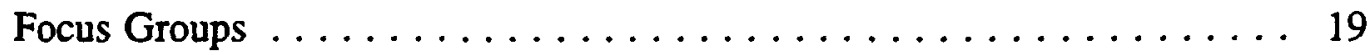

IV. ONE-ON-ONE DISCUSSIONS: 18-TO 29-YEAR OLDS $\ldots \ldots \ldots \ldots 21$

Results ............................ 21

Discussion ............................ 29

V. ONE-ON-ONE DISCUSSIONS: 13-TO 15-YEAR-OLDS $\ldots \ldots \ldots .31$

Results ............................. 31

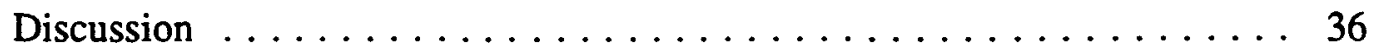

VI. FOCUS GROUPS $\ldots \ldots \ldots \ldots \ldots \ldots \ldots \ldots \ldots \ldots \ldots \ldots$

Results .............................. 37

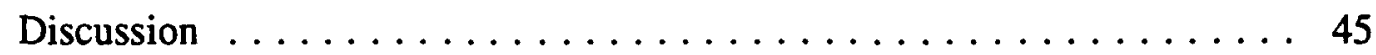

VII. VALUES-BASED COUNTERMEASURE CONCEPTS $\ldots \ldots \ldots \ldots 47$

Countermeasure Concepts .................... 47

Additional Countermeasures Needed . . . . . . . . . . . . . . . 49

Potential Channels for Countermeasure Messages ........... 50

Possible Countermeasure Message Scenarios .............. 51

Countermeasure Concepts for 13-to 15 -Year-Olds . . . . . . . . . 53

VIII. RECOMMENDATIONS FOR FURTHER RESEARCH $\ldots \ldots \ldots .55$

Testing Countermeasure Concepts ................ 55

Developing and Testing Countermeasures

for Other Target Groups . . . . . . . . . . . . . . . . . . 56

IX. REFERENCES $\ldots \ldots \ldots \ldots \ldots \ldots \ldots \ldots \ldots \ldots \ldots \ldots$ 


\title{
APPENDICES
}

\author{
APPENDIX A: Tables \\ APPENDIX B: $\quad$ Discussion Guides \\ APPENDIX C: $\quad$ Focus Group Discussion Guide and Pictures \\ APPENDIX D: $\quad$ Focus Group Detailed Summaries
}




\section{I \\ SUMMARY}

\section{BACKGROUND}

The last ten years have seen significant decreases in the deaths and injuries resulting from impaired driving. It is likely that a considerable part of the decrease has resulted from more vigorous and effective enforcement, more stringent prosecution of impaired driving offenses and more effective penalties applied to more offenders (Stewart and Voas, 1993). In addition, some decreases in crashes have resulted from changes in alcohol availability, especially the imposition of 21 as the uniform minimum purchase age throughout the country (NHTSA, 1993). This progress has been very encouraging but there are limits on deterrence and on control of availability of alcohol. Moreover, deterrence and enforcement-based countermeasures are costly to maintain. By contrast, if countermeasures can be based on intrinsic values and motivations, they have the potential to influence behavior even without the threat of apprehension and punishment. . The objectives of the current project were:

1) to identify existing values that are important influencers of behavior; and

2) to identify countermeasures based on the existing values and motivations of drivers at risk of impaired driving.

\section{RESEARCH APPROACH AND METHODOLOGY}

Information was collected through in-depth one-on-one discussions and through a series of focus groups. These data collection efforts were designed to provide detailed information concerning:

- The social and physical settings in which most drinking and driving occurs for the target groups;

- The types of strategies for avoiding impaired driving that are most practical given the settings in which drinking and driving most commonly occurs for the target groups;

- The countermeasures that would be most acceptable to the target groups;

- The ways that values can be applied to these countermeasures;

- The appropriate content and vocabulary for countermeasure messages for the target groups;

- Suggested channels for providing countermeasure messages. 
The primary target group selected for this research was 18- to 29-year-old drivers who drink at least occasionally. This group was selected because young drivers are at high risk of alcoholrelated crashes and it includes both drivers who can drink legally and those who cannot. A second target group was also selected: 13- to 15-year-olds. This group was selected because they do not yet drive legally. In addition, few in this age group drink regularly. This group was included in order to provide preliminary information that might lead to countermeasures to be used before the high-risk behavior begins. One-on-one discussions only were carried out with this group.

\section{ONE-ON-ONE DISCUSSIONS}

A semi-structured discussion guide was developed for each of the target groups to capture information and trends related to values, leisure time activities, and experiences and attitudes related to impaired driving.

Respondents were recruited from three geographic areas: Montgomery County, Maryland; Madison, Wisconsin; and Palo Alto, California. These areas were not selected to be representative of the population of the United States, but rather to present a range of demographic, geographic, economic and cultural features that would broaden the applicability of the findings of the study.

Recruitment of the 18- to 29-year-old sample was carried out through random digit dialing in each of the three sites. Recruitment for the 13- to 15-year-old respondents was carried out at four middle and high schools in and around Madison, Wisconsin.

All of the discussions were carried out face-to-face, one-to-one with project staff. Discussions with the older group lasted approximately one to one-and-one-half hours. For the younger group, the discussions lasted approximately 30 to 45 minutes. A total of 276 18- to 29-year old respondents participated in the one-on-one discussions (92 at each site) and 54 13-to 15-year-old respondents participated in the one-on-one discussions. The samples were roughly evenly divided by gender.

\section{Results: 18- to 29-year olds}

Demographic Characteristics: Respondents were primarily white ( 84 percent) and in whitecollar occupations (58 percent, with an additional 17 percent who were students, not otherwise employed). The large majority had at least some college education (83 percent).

Values: Family was named most frequently as one of the three things valued most in life (chosen by 72 percent of respondents). Friends were named next most frequently (by 48 percent). An additional 38 percent of respondents named spouse or significant other or children (which can also be viewed as "family"). From a list of values presented to the respondents, the values most frequently chosen as the five that were most important to respondents were health 
(57 percent), true friendship ( 57 percent), a sense of accomplishment ( 46 percent), family security (46 percent), and self-respect (44 percent.) From a second list of valued characteristics, the most frequently named as among the five that were most important to respondents were "honest" (70 percent), "responsible" (50 percent), and "broadminded" (43 percent).

Leisure Activities: Sports were named most frequently as among respondents' three favorite leisure activities (63 percent). Time with friends was mentioned by 39 percent of respondents and hobbies by 31 percent. Respondents reported that alcohol use commonly went along with sports and time with friends.

Drinking Patterns: Alcohol was reported as a central feature of the social life of a majority of the 18- to 29-year-old target group. Much of the heavy drinking reported takes place with groups of friends (often of the same sex). Bars appear to be the most common setting for heavy drinking. Celebrations, such as birthday parties and weddings are occasions of particularly heavy drinking.

A variety of forms of peer or social pressure to drink were reported. These included respondents' companions urging them to drink or teasing them if they declined, not wanting to appear without a drink in their hand, or a general sense that the occasion called for drinking.

Drinking and Driving: Most respondents admitted to driving while impaired. About two-thirds answered yes to the question: "Have you ever driven after drinking so much that you would have been in trouble with the police if you had been stopped?" Nine percent of the respondents had been arrested for drunk driving. Eighty-four percent of respondents were current "drinking drivers," defined as those who 1) admit to driving while impaired within the last year (thought they would have been in trouble with the police if stopped); 2 ) had been arrested for DUI in the last year; 3) usually drink on weekends and usually drive themselves; or 4) admit to having driven within 2 hours of consuming alcohol in the last year.

The reasons for impaired driving seemed to be simple: The respondents have a lifestyle that includes frequent drinking and at least occasional drinking to intoxication. On these occasions most respondents reported that the primary concern is to "get home." Potential negative consequences seem less important or unlikely. Rationalizations given by respondents include driving by saying that they only had to drive a short distance or that they were the least drunk person in a group. In many cases, respondents said that they only realized how drunk they were after they were already driving or the next day when they were sober.

Inconvenience seemed to be the most powerful deterrent to using alternatives to drunk driving. Respondents did not report being embarrassed to admit they were too drunk to drive, rather they just did not want the hassle or expense of other ways of getting home or avoiding driving. In most cases, they had driven to the drinking location and would not leave their cars behind to use alternative means of getting home. 
Concern about consequences of impaired driving focused for the most part on potential arrest and the resulting embarrassment, inconvenience and expense. (In fact, some respondents said that they preferred to have a companion -- even one more intoxicated than themselves -- drive them home so that they themselves would not take the risk of being arrested.)

Designated drivers were the preferred means of avoiding impaired driving. Over 80 percent of the respondents reported using a "designated driver" on a regular basis. About two-thirds of the respondents who reported using a designated driver said that the designated driver usually drank. Respondents reported many instances in which the designated driver became intoxicated.

With very few exceptions, respondents said that they believe that drinking and driving is wrong, bad, and dangerous. Drinking and driving is not positively valued for its own sake (at least respondents did not admit to valuing it). Most respondents reported that they had, at least on some occasions, stopped someone else from drinking and driving, used some means of avoiding driving while impaired themselves, and avoided riding with an impaired driver.

Differences among sub-groups: Statistical analyses were carried out to examine differences in values and lifestyles between current drinking drivers and non-drinking drivers. Non-drinking drivers $(\mathrm{N}=36)$ were more likely than current drinking drivers to be married and to have more children. They were also more likely to say that the amount they drink is affected by others. These respondents enjoy hobbies and spending time with their families in their spare time. Current drinking drivers $(\mathrm{N}=190)$ are more likely than non-drinking drivers to drink because of anger or frustration or to fit in with friends. In their leisure time, current drinking drivers were more likely than non-drinking drivers to go to parties or bars or to spend time with boyfriends or girlfriends. There were no major, consistent differences in values between the two groups.

Analyses were also conducted to determine the significant differences between other groups of interest: heavy versus light drinkers ${ }^{1}$; people who report driving while intoxicated versus those who do not?; people who have been arrested for DUI versus those who have not. The analyses demonstrate differences between the groups in a variety of realms:

- There are demographic differences between the groups. Heavy drinkers and arrested drunk drivers tend to be male; heavy drinkers tend to be younger, heavy drinkers are more likely than light drinkers to be single.

- There are lifestyle differences between the groups. Light drinkers are more likely than heavy drinkers to mention movies and travel as favorite activities.

\footnotetext{
' Heavy drinkers were defined as those respondents who report usually drinking five or more drinks at a time. Light drinkers were defined as those respondents who report usually drinking fewer than five drinks at a time.

${ }^{2}$ Respondents who reported that they had "driven after drinking so much that you would have been in trouble with the police if you had been stopped."
} 
- Other risky behavior tends to go along with heavy drinking or driving while intoxicated, including not wearing a seat belt, engaging in thrilling and risky activities, riding with an impaired driver, smoking and having friends who use drugs.

- Other indications of drinking problems are associated with heavy drinking and being arrested for drunk driving, including positive answers to questions about symptoms of problem drinking (i.e., drinking first thing in the morning and wanting to cut down on drinking).

\section{Discussion}

The discussions established that family and friends were the values most common to everyone in the sample. In addition, health and a sense of accomplishment were frequently named. Thus, these values are likely to be potential points of motivation for most members of the 18- to 29year-old target group. Little systematic difference in values was detected between members of the sample most likely to be at high risk of drinking and driving as compared to members of the sample who would be at lower risk of drinking and driving. Thus, these values are likely to be equally motivating for all segments of the target group.

Alcohol was a central feature of the social life of many respondents. While reported typical alcohol consumption levels were relatively modest, the frequency with which many respondents report drinking to intoxication may be a social and public health concern beyond the problem of impaired driving crashes.

Respondents already had quite well-developed negative attitudes towards impaired driving. Thus, it would appear that countermeasures designed to convince this target population that impaired driving is wrong would be misplaced. Rather, countermeasures should strengthen existing attitudes against impaired driving.

Most members of this population have already tried some behaviors to avoid impaired driving (e.g., selecting a designated driver) or to prevent others from driving while impaired. The problem appears to be that they do not engage in these behaviors consistently or with consistent success, resulting in many occasions of high-risk behavior. This finding would imply that countermeasures that help to develop better skills for avoiding or preventing impaired driving or that provide even greater motivations for avoiding impaired driving could be beneficial.

\section{One-on-One Discussions: 13- to 15-Year-Olds}

Demographic Characteristics: All but one of the respondents were white. Over 70 percent of respondents had parents in white-collar occupations. Almost 90 percent of respondents said that they planned to attend college. 
Values: With regard to values, these respondents were similar to the older respondents in that they chose family ( 85 percent) or friends ( 50 percent) as one of the two things most important in life. The value most often rated among the top three from the Rokeach list was "an exciting life" ( 30 percent of respondents).

Drinking and Attitudes Towards Drinking: This group of respondents had little personal experience with alcohol. Over 46 percent of the respondents reported that they had never drunk alcohol. Only one respondent reported drinking regularly. Over 90 percent of respondents said that they did not have close friends who drink.

Respondents had fairly negative attitudes about drinking. With regard to peers who drink, onethird of respondents stated that they did not care and the remainder had negative reactions to peers who drink. Almost three-quarters of the respondents stated that their friends would react negatively if the respondent drank. Over 90 percent of respondents stated that their parents would react very negatively if the respondent drank. On the topic of drinking and driving, 11 percent of respondents reported that they have friends who drink and drive. All of these respondents reacted negatively to this behavior.

When asked whether they drank more than, less than, or the same as their friends and other people their age, 57 percent of respondents said they drank less than their friends and 69 percent said they drank less than most people their age. It is possible that these respondents perceive that there is more drinking among their peers than is actually the case. They may feel, erroneously, that not drinking takes them out of the mainstream of their peers.

\section{Discussion}

Conclusions for this sample must be somewhat tenuous since the sample is rather small and respondents were entirely self-selected from a single geographic area. Clearly, a dramatic transformation takes place between the 15th and 18th year. The 13- to 15-year-olds in this sample have both the attitudes and behaviors with regard to drinking and drinking and driving that would put them at low risk. More study would be needed to understand the social and developmental factors that change these attitudes and behaviors and lead to heavy drinking and impaired driving in the later teens. It would be very useful to explore further how those factors might be addressed preventively among young adolescents and how existing values can be used.

The same values of family and friends are selected by this age group as by the 18- to 29-yearolds, although the influences they exert and the dynamics of the relationships are different. Significantly, most respondents thought that their friends would disapprove if they drank, thus providing social and peer pressure in the desired direction. There is a more overt focus on having a good time for this group (as compared to the 18- to 29-year-old sample), especially among boys, as evidenced by the selection of "an exciting life" as an important value and the emphasis on "fun to be with" as a quality valued in a friend. 


\section{FOCUS GROUPS}

Focus groups were conducted in order to verify and add to the information collected in the indepth one-on-one discussions. Participants were recruited from the same geographic areas as the one-on-one discussion respondents. For the focus groups, the age range was limited to 21- to 29-year-olds. In order to maximize the amount of information about drinking and driving behavior obtained from the focus groups, recruitment was limited to participants who admitted that they had driven within two hours after drinking any amount of alcohol in the past year. Most participants were drawn from among the respondents of the one-on-one discussions. Membership of the groups is not assumed to be representative of the entire population in this age group. Rather, it is meant to capture a range of attitudes, feelings, and behaviors among drinking drivers of this age.

Twelve focus groups of seven to ten participants each were conducted. Two groups made up of male participants and two groups made up of female participants were conducted in each of the three sites. Male groups were led by a male moderator and female groups were led by a female moderator.

\section{Results}

Drinking Patterns and Attitudes: As was found in the one-on-one discussions, alcohol is a central feature of the social life of participants. Most heavy drinking occurs with groups of friends, usually of the same sex, but occasionally mixed. Heavy drinking takes place primarily in bar or club settings. Parties at private homes were also mentioned. These are not, for the most part, dating situations. Most respondents said that they do drink on dates, but that they drink less.

The overall attitudes of participants towards drinking and abstinence seemed quite ambivalent. For example, when asked to describe someone who never drinks, some participants used terms like "pure," "naturally high," and "balanced." Others described non-drinkers as "anal," "boring," or "worried." Virtually every group said drinking relaxes them, releases their inhibitions, helps them to socialize, and tastes good. However, virtually every group listed more problems associated with alcohol than good points, usually beginning with "hangovers" and, in many groups, including addictions, accidents, and deaths.

Pressure from friends to drink seemed to be pervasive. In some instances, this pressure took the form of overt persuading or nagging to drink. In some cases, pressure was the result of social practices, such as buying rounds, or more subtle social cues. Participants described norms that exist in these social settings that require that all of the members of a social group be "on the same level" of intoxication. 
Drinking and Driving: As in the one-on-one discussions, participants agreed that drinking and driving, especially "drunk" driving, is dangerous, stupid and wrong. Even so, almost all focus group participants admitted that they had sometimes driven when they knew they should not have.

Virtually none of the participants believed that driving after one or two drinks is wrong. While the vast majority of respondents believed that driving "drunk" is wrong, their definitions of this behavior varied and were sometimes imprecise. Most respondents admitted to driving while legally intoxicated on occasion, but appeared to feel that this is morally different than driving drunk habitually.

Respondents used a variety of strategies to avoid driving when they were, by their own definition, too drunk. Unfortunately, judgements about when they are "too drunk" are made after the individual is already impaired by alcohol. Many participants who said they have driven drunk said they did not realize how drunk they were until they were on the road or until the next morning. Even if the person recognizes the level of impairment, however, they often believe they have few options. When asked how they can avoid driving while impaired, most participants mentioned taxis and public transportation, however, they rarely actually used these forms of transportation because of cost and inconvenience. In addition, most respondents were very reluctant to leave their cars behind, both because of the inconvenience of coming back to get it and because of concerns about damage to the car.

Most participants had some experience in preventing others from driving after drinking too much. None of the participants ever mentioned intervention by servers of alcohol to deny an intoxicated patron more alcohol or to prevent an intoxicated patron from driving away from the establishment.

As was the case in the one-on-one discussions, virtually all of the focus group participants used designated drivers in their social groups and most had been the designated driver on some occasions. Frequently the role is assigned very casually, and often the designated driver is simply the person deemed to be least drunk at the end of the evening. Participants clearly have ambivalent feelings about designated drivers. When asked directly how they would describe designated drivers, most groups used adjectives such as "caring" and "responsible," however, they also occasionally used words such as "geeky" and "nerdy" to describe a designated driver. Designated drivers were also described as "party-poopers." Designated drivers are sometimes pressured by their companions to drink. At the same time, participants did express disapproval and annoyance when the designated driver drank too much.

Values and their Relationship to Drinking and Driving: While family was established in the one-on-one discussions as the most consistent value for the 18- to 29-year-old target group, family did not seem to be very directly linked to drinking and driving in the minds of most focus group participants. By contrast, friends, the other consistent value, were reported by focus group participants to be very much involved with drinking and with drinking and driving. Participants drink primarily with groups of friends. Friends exert influence on the amount of drinking. They 
intervene if a companion seems to have drunk too much. They participate in reciprocal arrangements in which they take turns acting as the designated driver.

\section{Discussion}

The above findings suggest that countermeasures against drinking and driving might be successfully developed to elevate the image of responsible behavior, of intervention to prevent others from drinking and driving and of the designated driver within the context of the values of safety, responsibility, families and, particularly, friends.

\section{COUNTERMEASURE CONCEPTS FOR 21- TO 29-YEAR OLDS}

The findings of the one-on-one discussions and the focus groups imply a number of concepts for countermeasures that may provide positive motivations to avoid drinking and driving (to balance existing negative, deterrence-based countermeasures). They may also help the target group to develop the necessary skills to act upon their existing wishes to avoid drinking and driving.

In order to reduce ambivalence about drinking and avoiding drinking and driving:

- Provide positive image of responsible behavior (avoiding drinking and driving).

- Provide positive image of person who prevents others from drinking and driving.

- Provide positive image of designated driver.

- Show immediate positive consequences (gratitude, admiration) for preventing and avoiding drinking and driving and for being the designated driver.

In order to overcome the belief that occasional impaired driving is acceptable:

- Emphasize that responsible driving should be a consistent behavior.

In order to overcome the belief that only driving while very intoxicated is dangerous:

- Emphasize that any amount of alcohol is impairing.

In order to tie into the value of family:

- Invoke images of family as part of motivation for avoiding and preventing drinking and driving.

In order to tie into the value of friends:

- Use value of friendship as major motivation for avoiding and preventing drinking and driving. 
- Invoke concept of reciprocity among friends in being a designated driver or helping others to avoid drinking and driving.

- Provide implicit acknowledgement of the ambivalent influence of friends -- towards and away from responsible behavior.

In order to make countermeasures more realistic:

- Use realistic situations commonly reported by the target audience in which impaired driving occurs; usually at parties and at bars and clubs with large groups of same sex friends. Include common behaviors, such as buying rounds.

- Show strategies for avoiding drinking and driving that are deemed practical by the target audience.

- Provide separate countermeasure messages for men and women (since target group members tend to drink in same-sex groups and may view drinking by the opposite sex as different from drinking by their own sex).

In order to overcome apparent skills deficits among the target audience:

- Model appropriate behavior, including responsible hosting refusing drinks when pressured by others planning how to get home before drinking occurs successful intervention to prevent others from drinking and driving

In order to make the vocabulary of countermeasures meaningful to the target audience:

- Use words like "caring," "responsible," and "trustworthy" provided by the target population, to characterize avoiding and preventing drinking and driving.

\section{ADDITIONAL COUNTERMEASURES NEEDED}

Based on the reports from respondents regarding their drinking and driving experience and behaviors, additional countermeasures seem to be called for:

- Interventions to reduce the availability of alcohol to underage drinkers. (Respondents reported great ease in obtaining alcohol before they could legally purchase it.)

- Interventions to reduce service of alcohol to intoxicated patrons and to prevent intoxicated patrons from driving.

- The development of alternative means of transportation that are low-cost and convenient.

The promotion of these countermeasures could utilize the values and motivations discussed above. 


\section{POTENTIAL CHANNELS FOR COUNTERMEASURE MESSAGES}

Media consultants made three points regarding potential channels for messages:

- Public service announcements may be less credible and powerful than other potential channels.

- Appropriate messages can be imbedded in articles in magazines popular with the target population.

- It is important to saturate the target population with messages using a variety of channels.

The countermeasure message can include a brief, easily recognizable "tag-line" that can be repeated in a variety of contexts.

\section{COUNTERMEASURE CONCEPTS FOR 13- TO 15-YEAR-OLDS}

As discussed above, these young people do not yet drive and drink very little, if at all. In the demographic group included in this study, respondents reported very negative attitudes towards drinking and towards drinking and driving. They reported that their parents and peers also have negative attitudes towards drinking for this age group. Thus, the main goal of countermeasures for this group would be to support these existing attitudes and behaviors and to attempt to strengthen them and sustain them into late adolescence. Countermeasure concepts could include:

Family-based Countermeasures:

- Reenforce the youths' perception of their parents' negative attitudes towards drinking.

- Emphasize that not drinking makes them seem responsible and mature to their parents.

- $\quad$ Reenforce parental support for avoiding riding with impaired drivers.

- Emphasize that avoiding riding with impaired drivers makes them seem responsible and mature to their parents.

Friend-based Countermeasures:

- Emphasize mutual support of non-drinking among friends.

- $\quad$ Emphasize negative attitudes towards drinking among friends.

- Emphasize mutual support of avoiding riding with an impaired driver among friends. 
- Emphasize negative attitudes towards riding with an impaired driver among friends.

- Help youth have a more accurate perception of the low level of drinking among peers.

- Emphasize the respect and admiration that can result from avoiding drinking and avoiding driving with an impaired driver.

Possible channels:

Many possible powerful channels are available for communicating to this age group. Because they are in school, messages can be included in a variety of class settings, including alcohol and other drug education programs or driver's education programs. Values-based countermeasures can be added to existing approaches that emphasize potential negative consequences.

Because of the importance placed on family by this age group, programs that encourage discussions of drinking and of drinking and driving with parents can be potentially effective. Materials encouraging these discussions and providing appropriate messages for parents to give their children can be distributed.

\section{REFERENCES}

National Highway Traffic Safety Administration, Traffic Safety Facts 1992. U.S. Department of Transportation, 1993.

Stewart, K. and Voas, R. Decline in drinking and driving crashes, fatalities and injuries in the USA, in: The Nature of and the Reasons for the Worldwide Decline in Drinking and Driving, Transportation Research Board Circular, The National Academy of Sciences. 


\section{II}

\section{BACKGROUND OF THE RESEARCH}

The last ten years have seen significant decreases in the deaths and injuries resulting from impaired driving. For example, the percent of fatalities related to alcohol dropped from 57 percent in 1982 to 45 percent in 1992 (National Highway Traffic Safety Administration, 1993). Many factors undoubtedly have contributed to this decline and we have no way of knowing which factors have resulted in what decreases. We can be confident, however, that a considerable part of the decrease has resulted from more vigorous and effective enforcement, more stringent prosecution of impaired driving offenses and more effective penalties applied to more offenders (Stewart and Voas, 1993). In addition, some decreases in crashes have resulted from changes in alcohol availability, especially the imposition of 21 as the uniform minimum purchase age throughout the country (NHTSA, 1993).

This progress has been very encouraging, but there is still much that can be done to improve current deterrence-based strategies and to control alcohol availability. There are limits, however, on deterrence and on availability control. Communities will devote only so much of their resources to impaired driving enforcement and they will tolerate more severe and more broadly applied penalties only up to a point, thus alcohol is likely to continue to be easily available.

A dramatic change in the nature of public attitudes about impaired driving has occurred along with the related changes in laws, policies, and practices (Evans, 1991). While impaired driving may still be a fairly common behavior, it is less common than in the past and it is definitely less socially acceptable (Zimring, 1988). Due in large part to the victims' movement, impaired driving went from being an issue that attracted little or no societal concern to one that was the focus of considerable citizen activism and media attention (Evans, 1991). Undoubtedly, the resulting attitude changes, along with the related legal changes, have contributed to the decline in impaired driving.

The changes that have occurred in the attitudes of the general public provide a strong foundation for values-based countermeasures. The objectives of the current project were: 1) to identify existing values that are important influencers of behavior; and 2) to identify countermeasures based on the existing values and motivations of drivers at risk of impaired driving. Since these values and motivations are intrinsic to the individual and are enduring, they have the potential to influence behavior even without the threat of apprehension and punishment. The threat of apprehension and punishment depend on the specific situation and are costly to maintain. If the existing negative attitudes towards impaired driving can be linked to strong, stable underlying values and motivations, there is the potential for additional reductions in impaired driving that do not depend on enforcement. 
This project addressed the following major questions:

- What values do people in selected target groups hold most strongly?

- How can values be incorporated into countermeasures so that members of the target groups will avoid impaired driving and prevent others from driving while impaired?

- What are the social and behavioral contexts in which impaired driving occurs among members of the target groups to which values-based countermeasures can apply? 


\section{III}

\section{RESEARCH APPROACH AND METHODOLOGY}

In order to answer the research questions posed above, information was collected through indepth one-on-one discussions and through a series of focus groups. These data collection efforts were designed to provide detailed information concerning:

- The social and physical settings in which most drinking and driving occurs for the target groups;

- The types of strategies for avoiding impaired driving that are most practical given the settings in which drinking and driving most commonly occurs for the target groups;

- The countermeasures that would be most acceptable to the target groups;

- The ways that values can be applied to these countermeasures;

- The appropriate content and vocabulary for countermeasure messages for the target groups;

- Suggested channels for providing countermeasure messages.

Each of the data collection efforts is described in detail below.

\section{TARGET GROUPS}

The primary target group selected for this research was 18- to 29-year-old drivers who drink at least occasionally. This group was selected because young drivers are at high risk of alcoholrelated crashes: Drivers younger than 30 account for more than half of all drinking drivers who are fatally injured in crashes (Williams and Wells, 1993). In addition, young drivers over 21 have shown the least decline in alcohol-related fatal crashes in the last ten years (Williams and Wells, 1993). The target group includes those for whom the purchase of alcohol is illegal (18to 20-year-olds) as well as those who may legally purchase alcohol.

A second target group was also selected: 13- to 15 -year-olds. This group was selected because they do not yet drive legally. In addition, few in this age group drink regularly. This group was included in order to provide preliminary information that might lead to primary prevention, that is, countermeasures to be used before the high-risk behavior begins. One-on-one discussions only were carried out with this group. 


\section{ONE-ON-ONE DISCUSSIONS}

\section{Development of the Discussion Guides}

A semi-structured, in-depth discussion guide was developed for each of the target groups ${ }^{3}$ to capture information and trends related to values, leisure time activities, and experiences and attitudes related to impaired driving. The guides included open-ended questions, for the most part, about the following topics:

- $\quad$ Demographic information
- $\quad$ Drinking patterns
- $\quad$ Leisure activities
- $\quad$ Pecision-making processes regarding drinking and drinking and driving
- $\quad$ Feelings about impaired driving
- $\quad$ Perception of peers' feelings about impaired driving
- $\quad$ Experience with and perceptions of various impaired driving countermeasures
- $\quad$ Strongly held values regarding self
- $\quad$ Strongly held values regarding friends
- $\quad$ Recommentronglations for countermeasures

In order to obtain information about values, the discussion guides included open-ended questions, such as, "What are the three things in life that are most important to you?" "What are the three most important qualities you look for in a friend?" In addition, respondents were asked to rank two lists of specified values in order of importance to them. These lists were developed by Milton Rokeach and colleagues (Rokeach, 1973). The rankings of these values have been found in previous research to differ between drug abusers and non-drug abusers as well as between convicted intoxicated drivers and other drivers (Rokeach, Kearney, and Grube, 1985).

The guide for each target group was pilot-tested with 30 members of the target groups and revised to improve clarity and to fit within reasonable time limits. Ten staff were trained to carry out the discussions.

Copies of the discussion guides for the youth and adult groups are included in Appendix B.

3 The design of data collection instruments and the analysis of data for this project was carried out with the input of a panel of experts in various aspects of drinking and driving, high risk behavior by youth and young adults, and developmental processes of youth. A list of the expert panelists appears in the final section of the report. 


\section{Respondent Recruitment}

Three geographic areas were selected for recruitment: Montgomery County, Maryland; Madison, Wisconsin; and Palo Alto, California. Each of these sites is described below. These areas were not selected to be representative of the population of the United States, but rather to present a range of demographic, geographic, economic and cultural features that would broaden the applicability of the findings of the study.

Montgomery County, Maryland is a suburban area near Washington, D.C. It has a population of 757,027 and a median household income of $\$ 54,089$. It is 89 percent White (six percent of Hispanic origin), three percent Black, seven percent Asian, and one percent other races.

Madison, Wisconsin is the capital of Wisconsin and the site of a large university. It includes some small manufacturing and serves a rural population in the surrounding areas. It has a population of 191,262 and median household income of $\$ 29,420$. The population is 91 percent White (two percent of Hispanic origin), four percent Black, four percent Asian and one percent other races.

Palo Alto, California is part of the San Francisco Bay area and includes a variety of industries as well as a university in its economic base. It has a population of 55,900 and median household income of $\$ 55,333$. It is 88 percent White (19 percent of Hispanic origin), two percent Black, and ten percent Asian.

Recruitment of the 18- to 29-year-old sample was carried out through random digit dialing in each of the three sites. When the telephone screeners reached a household, they asked if anyone residing within the household was within the appropriate age range. When they spoke to the first available person in the age range, they asked if the person was a licensed driver and if he or she drank alcohol at least once per month. Those people who answered yes to these questions were asked to participate in an in-person discussion at a later date. They were told that the discussions were on the topic of their opinions and experiences related to drinking and driving. Seventy percent of potential respondents agreed to participate. They were offered between $\$ 35$ and $\$ 50$ for their participation (the amount depended on the site). The screeners asked for their name and telephone number. Respondents were later contacted and appointments scheduled for the discussions. Of those potential respondents who initially agreed to participate, nine percent were not reachable at the telephone number given, eleven percent later declined to participate, and eight percent did not keep appointments. ${ }^{4}$

Recruitment for the 13- to 15-year-olds was carried out at four middle and high schools in and around Madison, Wisconsin. Information about the study and parental permission forms were distributed in home room classes. Students who returned the permission forms were scheduled for discussions during free time at school. They received $\$ 10$ for their participation.

\footnotetext{
When respondents did not arrive at scheduled appointments, repeated attempts were made to re-contact them and schedule new appointments. Some respondents, however, were not reachable or never kept their appointments.
} 


\section{Carrying out the Discussions}

All of the discussions were carried out face-to-face, one-to-one with project staff. Discussions with the 18- to 29-year olds took place in project offices at the three sites. Discussions with the 13- to 15-year-olds took place in the schools in Madison.

Discussions with the older group lasted approximately one to one-and-one-half hours. For the younger group, the discussions lasted approximately 30 to 45 minutes. Although discussions generally followed the discussion guide, respondents were encouraged to expand on some answers and to provide additional information where appropriate. Staff took notes during the discussions and all discussions were tape-recorded for later use in coding the information provided.

\section{Respondent Characteristics}

Geographic and demographic breakdowns of the sample appear below.

18- to 29-year-olds:

- Montgomery County, Maryland -- 92

Madison, Wisconsin -- 92

Palo Alto, California -- 92

- 136 males

140 females

- $\quad$ 18-20 years old -- 29

21-24 years old -- 106

25-29 years old -- 141

mean age -24.5

13- to 15-year-olds:

- Madison, Wisconsin

- 30 males

24 females

- $\quad 13$ years old -- 26

14 years old -- 16

15 years old -- 12

mean age -- 13.7 
As can be seen above, the samples were roughly evenly divided by gender. The age distribution was not even, however. In particular, few 18- to 20-year-olds were captured by the random digit dialing recruitment methods. In the school sample, more 13-year-olds than 14- or 15-year-olds volunteered for the study.

\section{Coding of Discussion Data}

Some of the answers to discussion questions were brief and fit into pre-coded categories (e.g., age, years of education, number of drinks usually consumed). For other questions, coding categories were constructed based on the actual answers given by respondents. For example, respondents were asked to name the three things most important to them in life. Answers varied widely ( "my family," "getting a good job," "my cat"). Coding categories for these answers were constructed by listing all of the responses given and then dividing them into naturally occurring categories. Other questions elicited long answers including several types of elements (e.g., "Tell me about the last time you prevented someone from driving when you thought they were too drunk to drive."). For such questions, a list of elements and coding categories were constructed. (For the example above, elements included the age, sex, and relationship of the person the respondent prevented from driving and the type of method used to prevent them.)

All answers were coded and entered into an SPSS data file for analysis.

\section{FOCUS GROUPS}

As will be discussed in the Results section below, the one-on-one in-depth discussions yielded a great deal of information about the target groups. Focus groups were then conducted in order to verify and add to that information, to explore more complex attitudes, to use the group dynamics to bring out different types of information, and to explore countermeasure concepts.

\section{Development of the Discussion Guide}

Based on the findings of the one-on-one discussions, a focus group discussion guide was developed. The guide was designed to elicit more detailed information about some of the topics covered in the one-on-one discussions, for example, how designated drivers are used. They were also designed to draw from participants' deeper attitudes and feelings about relevant topics than could be elicited in the more formal one-on-one discussions. For example, participants were shown pictures of animals (see Appendix $C$ for copies of the pictures) and asked to imagine them as different types of people and to describe them in terms of their drinking and driving behavior. They were also asked to draw pictures symbolizing their feelings towards family, friends, responsible driving, and the connection among those concepts. (Family and friends were most frequently listed as being most important to respondents in the one-to-one discussions.) Such exercises helped to elicit some of the complexity of the attitudes and feelings of participants as well as providing the natural vocabulary participants used in discussing such issues. The 
presence of a group was used to elicit realistic reactions of participants in social settings. For example, the participants role-played various drinking-driving situations.

A copy of the focus group guide is included in Appendix $C$.

\section{Recruitment of the Focus Group Participants}

Participants were recruited from the same geographic areas as the one-on-one interview respondents. For the focus groups, the age range was limited to 21- to 29-year-olds. Too few respondents under 21 were included in the one-on-one discussions to allow definitive conclusions to be drawn about this age group. The decision was made, therefore, to include in the focus groups only those participants who could legally drink. In order to maximize the amount of information about drinking and driving behavior obtained from the focus groups, recruitment was also limited to participants who admitted that they had driven within two hours after drinking any amount of alcohol in the past year.

Most participants were drawn from among the respondents of the one-on-one discussions. Additional people were recruited by asking participants to recommend friends for participation in the focus groups. The friends were screened to meet the criteria of having driven within two hours of drinking within the last year. Participants were paid $\$ 40$ to participate in a group, which lasted approximately two hours.

Participants in the group are not assumed to be representative of the entire population in this age range. Rather, they are assumed to capture a range of attitudes, feelings, and behaviors among drinking drivers of this age.

\section{Conducting the Focus Groups}

Twelve focus groups of seven to ten participants each were conducted. Two groups made up of male participants and two groups made up of female participants were conducted in each of the three sites. Consistent with usual focus group protocol, male groups were led by a male moderator and female groups were led by a female moderator. All groups were tape recorded and some were videotaped. Moderators were from RIVA Qualitative Market Research, Inc. 


\section{IV \\ ONE-ON-ONE DISCUSSIONS: 18- TO 29-YEAR-OLDS}

\section{RESULTS}

Two major types of analysis were conducted of the information from the one-on-one discussions with the respondents who were 18 to 29 years old. The first examined the characteristics of the overall sample, their values, their life-styles, and their behavior and attitudes regarding drinking and driving. The second divided the sample into subgroups on the basis of drinking and impaired driving behavior in order to determine whether there were differences between these subgroups. ${ }^{5}$

\section{Overall Sample}

\section{Personal Characteristics}

Respondents were primarily white ( 84 percent) and in white-collar occupations ( 58 percent, with an additional 17 percent who were students, not otherwise employed). The large majority had at least some college education ( 83 percent). As mentioned earlier, only 11 percent of respondents were in the 18- to 20-year age group. (See Appendix A, Tables A-1 and A-2 for detailed demographic data.)

\section{Values}

Family was named most frequently as one of the three things valued most in life (chosen by 72 percent of respondents). Friends were named next most frequently (by 48 percent). An additional 38 percent of respondents named spouse or significant other or children (which can also be viewed as "family"). The next most frequently mentioned item was "health," named by 23 percent of respondents. From a list of 18 values generated by Rokeach, the values most frequently chosen as among the five that were most important to respondents were health (57 percent), true friendship ( 57 percent), a sense of accomplishment (46 percent), family security (46 percent), and self-respect (44 percent.) From a second list of 18 valued characteristics, the values most frequently named as among the five most important to respondents were "honest" (70 percent), "responsible" ( 50 percent), and "broadminded" (43 percent) (Figure 1). (For more detail, see Appendix A, Tables A-3 through A-5.) (See Appendix B for full list of values in Discussion Guide.)

${ }^{3}$ Cluster analysis was also performed with all drinking drivers (defined on page 25) using values and life-style information. The results of the analysis indicated that the respondents could not be meaningfully divided into subgroups that differ in terms of their values and life-style characteristics. 


\section{FIGURE 1}

Summary of Values

18- to 29-year-olds

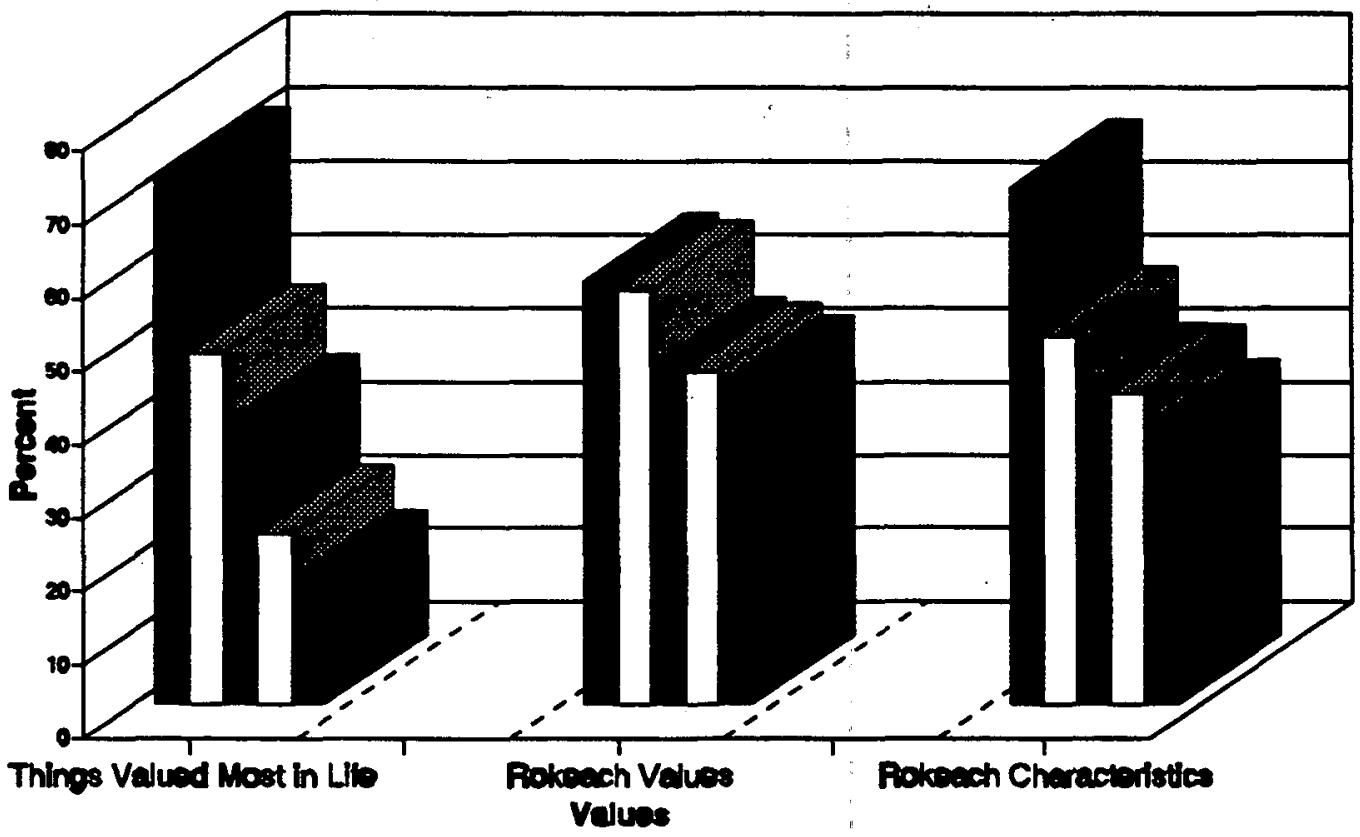

\begin{tabular}{|lll|ll|l|l|l||}
\hline \hline 7 Vamily & $72 \%$ & Health & $58 \%$ & Honest & $70 \%$ \\
\hline Friends & $48 \%$ & Friendship & $57 \%$ & Responsible & $50 \%$ \\
\hline Spouse/Child & $38 \%$ & Accomplishment & $46 \%$ & Broadminded & $43 \%$ \\
\hline Health & $23 \%$ & Family Security & $46 \%$ & Loving & $43 \%$ \\
\hline Accomplishment & $17 \%$ & Self Respect & $44 \%$ & Ambitious & $38 \%$ \\
\hline
\end{tabular}


Honesty was the characteristic most frequently named (by 62 percent of respondents) as among the three most important qualities in a friend (See Appendix A, Table A-6). Loyalty and dependability were named by 36 percent. Trustworthiness, being fun to be around, a sense of humor, and sharing common interests were all named by at least 25 percent of respondents.

\section{Leisure activities}

Sports were named most frequently as among respondents' three favorite leisure activities (63 percent) (See Appendix A, Table A-7). Time with friends was mentioned by 39 percent of respondents and hobbies by 31 percent. Respondents reported that alcohol use commonly went along with sports and time with friends.

\section{Drinking}

Most respondents reported usually drinking on weekends (64 percent). (Note: Only respondents who drink alcohol were eligible for participation in this study.) Over half of the respondents reported normally drinking one to three drinks at a time on weekends (Figure 2). Thirty-nine percent of the respondents reported usually drinking during the week. About half of the respondents reported drinking 12 or fewer drinks per week (Figure 3).

\section{FIGURE 2}

Number of Alcoholic Beverages Respondent Consumes at One Time on Weekends 18- to 29-year-olds

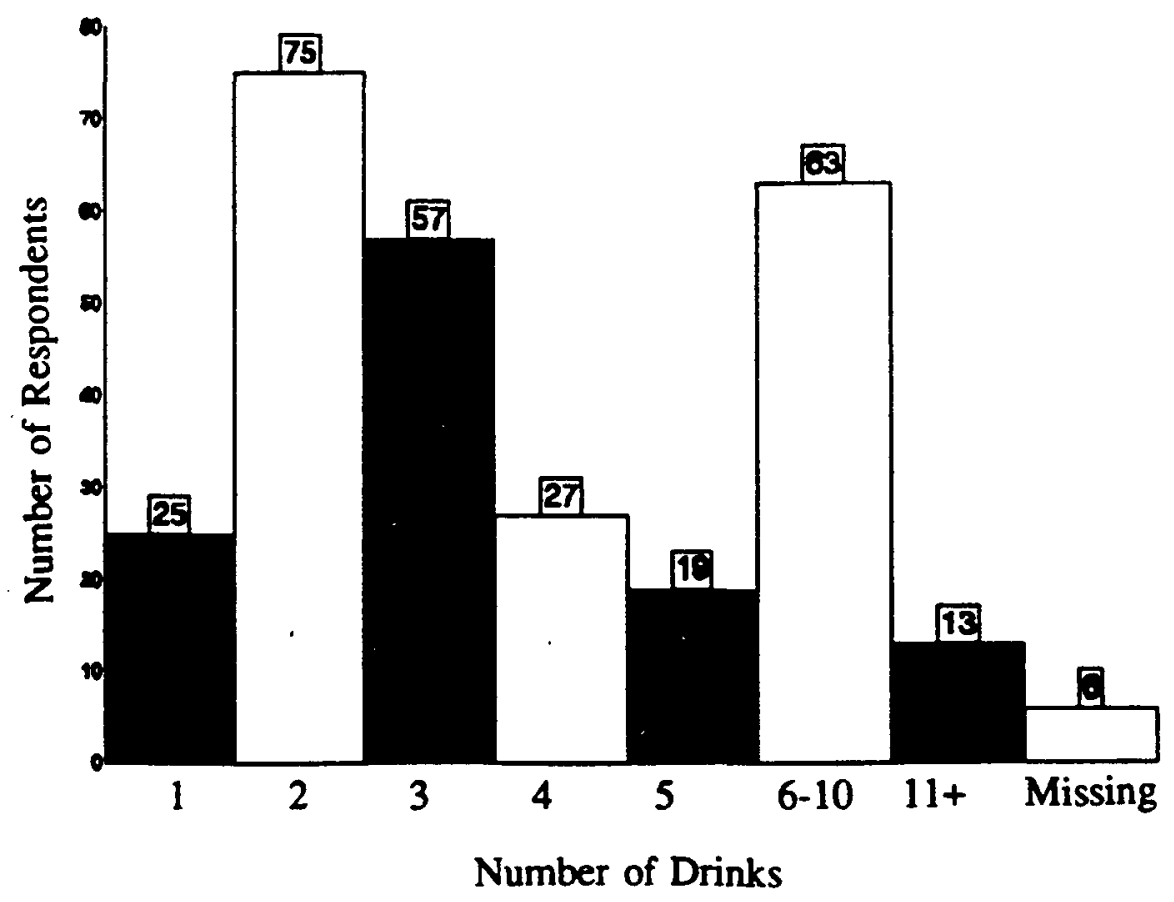


FIGURE 3

Number of Alcoholic Beverages Consumed at One Time During the Week

18- to 29-year-olds

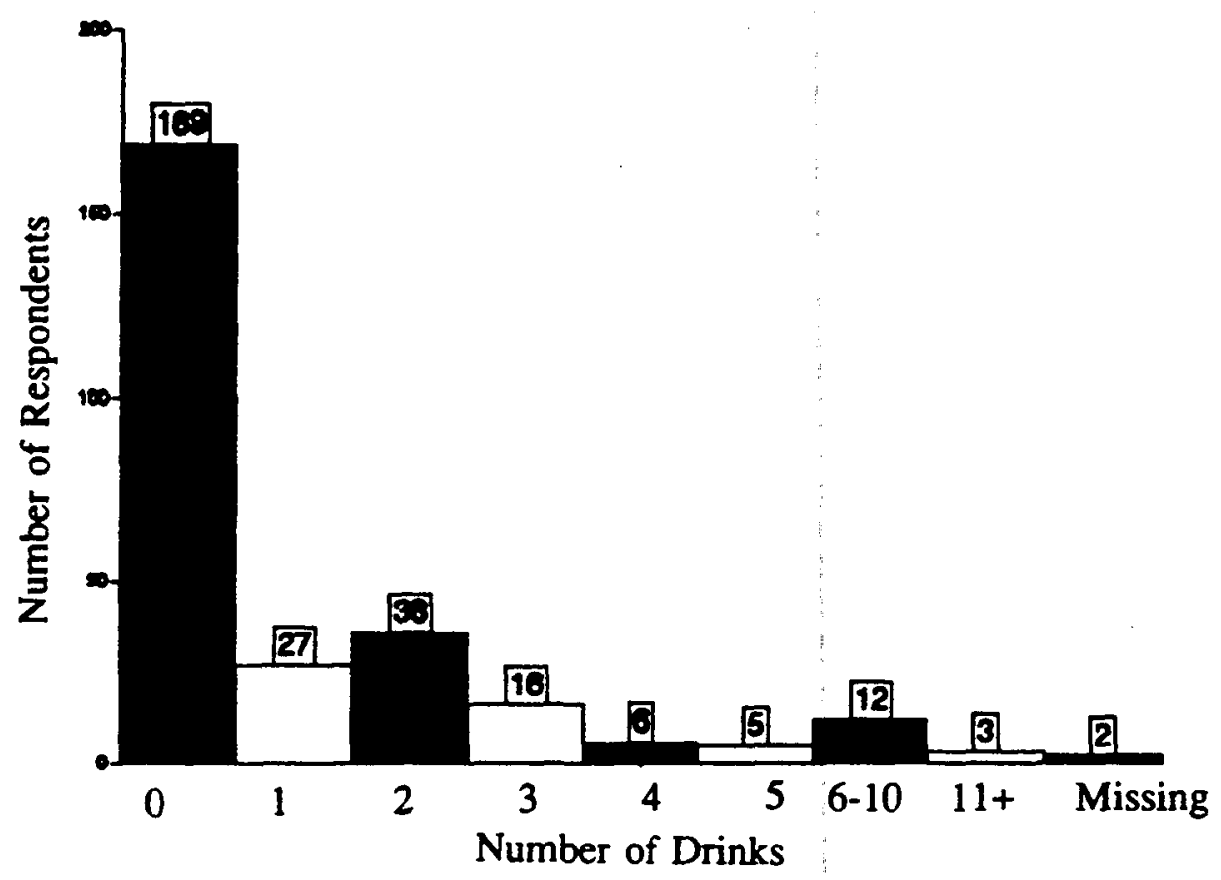

The answers given to direct questions about typical levels of drinking appear to indicate rather modest alcohol consumption. When asked to describe a variety of drinking situations, however, respondents appeared to draw from a rather rich and varied history of heavy drinking, indicating that at least on occasion, much heavier drinking has taken place.

Alcohol is a central feature of the social life of a majority of the target group, as illustrated by the following comments:

"How else are you supposed to meet people (without going to bars?)"

"Watching Monday night football with the guys and beer just go together."

"I knew I shouldn't be spending my parent's money on alcohol, but I didn't have the creativity to find something else to do."

Much of the heavy drinking reported takes place with groups of friends (often of the same sex). Bars appear to be the most common setting for heavy drinking. Celebrations, such as birthday parties and weddings, are occasions of particularly heavy drinking.

A variety of forms of peer or social pressure to drink were reported. These included respondents' companions urging them to drink or teasing them if they declined, not wanting to appear without 
a drink in their hand, or a general sense that the occasion called for drinking. For example, when respondents were asked if anyone ever criticized their drinking, some replied that they were criticized for not drinking enough. In bar situations, respondents who choose not to drink alcohol reported that their friends say things like, "one or two drinks won't hurt (even though you are driving)," or "you have to keep up (drinking) with us." As one respondent put it, "In my old group of friends, if I didn't drink I would have been teased mercilessly." In general, the drinking friends' comments are geared toward making the non-drinker feel abnormal.

\section{Drinking and Driving}

Most respondents admitted to driving while impaired. About two thirds answered yes to the question: "Have you ever driven after drinking so much that you would have been in trouble with the police if you had been stopped?" Nine percent of the respondents reported having been arrested for drunk driving. Eighty-four percent of respondents were defined as current "drinking drivers" because they:

- Admitted to driving while impaired within the last year (thought they would have been in trouble with the police if stopped);

- Had been arrested for DUI in the last year;

- Usually drink on weekends and usually drive themselves; or

- Admitted to having driven within 2 hours of consuming alcohol in the last year.

(See Appendix A, Table A-8.)

The reasons for impaired driving seem to be simple: The respondents have a lifestyle that includes frequent drinking and at least occasional drinking to intoxication. On these occasions most respondents reported that the primary concern is to "get home." One respondent said, "After a night of drinking, we all get a bad case of "get-home-itis." Potential negative consequences seem unlikely or less important. Rationalizations given by respondents include driving by saying that they only had to drive a short distance or that they were the least drunk person in a group. In many cases, respondents said that they only realized how drunk they were after they were already driving or the next day when they were sober. As one respondent put it, "I felt I was sober enough and I wanted to be in my own bed."

Inconvenience seemed to be the most powerful deterrent to using alternatives to drunk driving. Respondents did not report being embarrassed to admit they were too drunk to drive, rather they just did not want the hassle or expense of other ways of getting home or avoiding driving. In most cases, they had driven to the drinking location and would not leave their cars behind to use alternative means of transportation to get home. As one respondent explained, "I think that people drink and drive because they don't like the inconvenience of asking someone to come pick them up, or the inconvenience of waiting for a cab and having to come back to pick up their car." 
Concern about consequences of impaired driving focused for the most part on potential arrest and the resulting embarrassment, inconvenience and expense. In fact, some respondents said that they preferred to have a companion -- even one more intoxicated than themselves -- drive them home so that they themselves would not take the risk of being arrested. One respondent reported driving home with a friend who drove with one eye covered because it "helped her drive better."

Designated drivers were the preferred means of avoiding impaired driving. Over 80 percent of the respondents reported using a "designated driver" on a regular basis. About two thirds of the respondents who reported using a designated driver reported that the designated driver usually drank. In 13 percent of these cases, the designated driver was reported to drink from three to six drinks on a regular basis. Respondents reported many instances in which the designated driver became intoxicated. In fact, this was a common reason respondents gave for occasions when they drove after drinking more than they should have. Frequently, the designated driver was not selected until the end of the evening when the least drunk person drove everyone home. One respondent reported, "At the end of the night we played 'rock, scissors, paper' to see who would drive home."

\section{Attitudes towards drinking and driving}

With very few exceptions, respondents said that they believe that drinking and driving is wrong, bad, and dangerous. Typical comments included:

"I don't want to hurt someone else."

"It's like playing Russian roulette with your life."

Drinking and driving is not positively valued for its own sake (at least respondents did not admit to valuing it). Only two respondents said that they like to drink and drive or that they considered it their right to do so. Most respondents reported that they had, at least on some occasions used some means of avoiding driving while impaired themselves, stopped someone else from drinking and driving, or used some means of avoiding riding with an impaired driver. Almost 55 percent related that they had left their cars behind and used some other means of getting home (See Table 1). Almost 80 percent of respondents reported preventing someone from driving while impaired, using a variety of means (See Table 2). Sometimes, especially for men, intervention to prevent them from driving took a somewhat violent turn: One respondent reported that he had gotten into fights a number of times (when he himself was drunk) in order to keep friends from driving after drinking. Another said, "When I was in the Marines, I had to beat the out of one guy who wouldn't give up his keys." 
TABLE 1

How Did Respondent Get Home to Avoid Driving While Impaired?

\begin{tabular}{|c|c|c|}
\hline $1.2: 18:=1$. & Trevarenter & ier cen \\
\hline Triendas & 80 & 29.0 \\
\hline 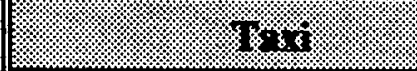 & 32 & 11.6 \\
\hline Wolleded & 24 & 8.7 \\
\hline Oother: & 20 & 7.2 \\
\hline 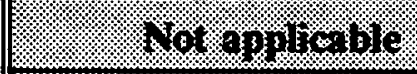 & 114 & 41.3 \\
\hline 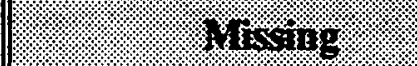 & 6 & 2.2 \\
\hline
\end{tabular}

TABLE 2

How Did Respondent Prevent Someone From Driving While Impaired?

\begin{tabular}{|c|c|c|}
\hline & Traver:est & Tercent \\
\hline Took 1 ress & 88 & 31.9 \\
\hline 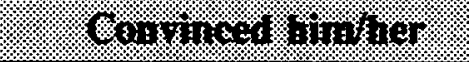 & 74 & 26.8 \\
\hline Orove ningher longe & 24 & 8.7 \\
\hline 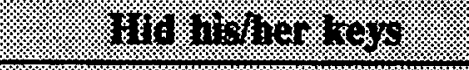 & 6 & 2.2 \\
\hline 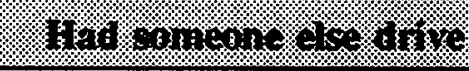 & 5 & 1.8 \\
\hline 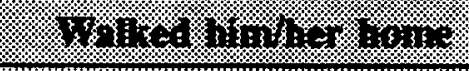 & 2 & .7 \\
\hline (1: & 9 & 3.3 \\
\hline 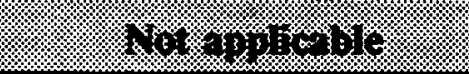 & 58 & 21.0 \\
\hline masing: & 10 & 3.6 \\
\hline
\end{tabular}




\section{Description of Drinking Driver Subgroups}

Discriminant analyses were carried out to examine differences in values and lifestyle between current drinking drivers and non-drinking drivers. (See Appendix A, Table A-9 for detailed results.) $)^{6}$ Current drinking drivers were defined as individuals who: 1 ) admitted to driving while intoxicated in the last year, or 2) had been arrested for driving under the influence (DUI) in the last year, or 3) usually drink on weekends and usually drive themselves, or 4) admitted to having driven within 2 hours of consuming any amount of alcohol in the last year.

Non-drinking drivers $(\mathrm{N}=36)$ were more likely than current drinking drivers to be married and to have more children. More non-drinking drivers say they enjoy driving and they were slightly more likely than current drinking drivers to say that they do things to stay physically fit. They were also more likely to say that the amount they drink is affected by others. In terms of values, the non-drinking drivers were more likely to choose the values of health, inner harmony, being intelligent and being logical. When asked what they would change in their lives, they were likely to say that they would like a better salary or wish they had continued their education. These respondents enjoy hobbies and spending time with their families in their spare time. They were more likely than the current drinking drivers to mention honesty and being outgoing as qualities they value in a friend.

Current drinking drivers $(\mathrm{N}=190)$ were more likely than non-drinking drivers to drink because of anger or frustration or to fit in with friends. They are more likely to value self-respect, being obedient and pleasure. Members of this group were more likely than non-drinking drivers to say that they wish they had attended a different school. In their leisure time, current drinking drivers were more likely than non-drinking drivers to go to parties or bars or to spend time with boyfriends or girlfriends.

Discriminant analyses were also conducted to determine the significant differences between other groups of interest: heavy versus light drinkers'; people who report driving while intoxicated versus those who do not; The analyses demonstrate differences between the groups in a variety of realms:

\footnotetext{
${ }^{6}$ Discriminant Analysis is a statistical procedure that utilizes linear combinations of the independent variables (also called predictor variables) to infer optimal weighting of the variables in order to predict group membership of cases.

${ }^{7}$ Heavy drinkers were defined as those respondents who report usually drinking five or more drinks at a time. Light drinkers were defined as those respondents who report usually drinking fewer than five drinks at a time.

- Respondents who reported that they had "driven after drinking so much that you would have been in trouble with the police if you had been stopped."
} 
- There are demographic differences between the groups. Heavy drinkers and arrested drunk drivers tend to be male; heavy drinkers tend to be younger (with the highest percentage of heavy drinkers being 21 to 23 years old); arrested drunk drivers tend to be older'; heavy drinkers are more likely than light drinkers to be single.

- There are lifestyle differences between the groups. Light drinkers are more likely than heavy drinkers to mention movies and travel as favorite activities.

- Other risky behavior tends to go along with heavy drinking or driving while intoxicated, including not wearing a seat belt, engaging in thrilling and risky activities, riding with an impaired driver, smoking and having friends who use drugs.

- Other indications of drinking problems are associated with heavy drinking and being arrested for drunk driving, including positive answers to questions about symptoms of problem drinking (i.e., drinking first thing in the morning and wanting to cut down on drinking).

- Differences in values (as determined by Rokeach scales) were less striking, although for both heavy drinkers and self-reported intoxicated drivers (but not respondents arrested for drunk driving), "pleasure" was chosen as an important value more frequently than by light drinkers or drivers who do not report ever driving when they thought they were legally intoxicated.

(See Appendix A, Tables A-10, A-11, and A-12 for detailed results.)

\section{DISCUSSION}

The one-on-one discussions provided a great deal of useful information to be confirmed and further developed in the focus groups. The discussions established that family and friends were the values most common to everyone in the sample. In addition, health and a sense of accomplishment were frequently named. Thus, these values are likely to be potential points of motivation for most members of the 18- to 29-year-old target group. Few systematic differences in values were detected between members of the sample most likely to be at high risk of drinking and driving (the heavy drinkers, the self-reported intoxicated drivers, the drivers with previous drunk driving arrests, and the self-reported drinking drivers) as compared to members of the sample who would be at lower risk of drinking and driving. Thus, these values are likely to be equally motivating for all segments of the target group.

Alcohol was a central feature of the social life of many respondents. While reported typical alcohol consumption levels were relatively modest, the frequency with which many respondents

\footnotetext{
9 This finding is probably an artifact, given that the analysis included instances of drinking and driving any time in the past. Older respondents have a longer past in which to have accumulated an instance of impaired driving.
} 
reported drinking to intoxication may be a social and public health concern beyond the problem of impaired driving crashes.

Respondents already had quite well-developed negative attitudes towards impaired driving. Thus, it would appear that countermeasures designed to convince this target population that impaired driving is wrong would be misplaced. Rather, countermeasures should strengthen existing attitudes against impaired driving.

Most members of this population have already tried some behaviors to avoid impaired driving or to prevent others from driving while impaired. The problem appears to be that they do not engage in these behaviors consistently, resulting in many occasions of high-risk behavior. This finding would imply that countermeasures that help to develop better skills for avoiding or preventing impaired driving or that provide even greater motivations for avoiding impaired driving could be beneficial.

An important issue to consider in trying to understand these inconsistencies in attitudes and behaviors is the proximal factors in drinking/driving situations, especially perceived social norms. These norms may be even more important than perceived possible outcomes. Respondents reported various forms of social and peer pressure to drink, even when they were going to have to drive. This type of norm can be more powerful and salient in high risk situations than a more generalized norm against impaired driving or the seemingly remote risk of crashes or arrests. Thus, countermeasures should be explored to counterbalance these norms in the high risk situation. That is, values and motivations that prevent impaired driving should be made more salient in drinking situations. They should focus on counteracting norms that call for drinking or concerns about the inconvenience of avoiding impaired driving or other immediate negative consequences. 


\section{V. \\ ONE-ON-ONE DISCUSSIONS: 13- TO 15-YEAR-OLDS}

\section{RESULTS}

\section{Overall Sample}

\section{Personal Characteristics}

There was a total sample of 54 respondents in Madison, Wisconsin in the 13- to 15-year-old age group. Staff was more successful in recruiting the younger respondents: 26 respondents were 13 years old while only 12 were 15 years old. Thirty respondents were boys and 24 were girls.

The socio-economic and demographic characteristics of respondents were rather homogeneous. All but one of the respondents were white. Over 70 percent of respondents-had parents in whitecollar occupations. Almost 90 percent of respondents said that they planned to attend college. (See Appendix A, Table A-13 for details).

\section{Values}

With regard to values, these respondents were similar to the older respondents in that they chose family ( 85 percent) or friends (50 percent) as one of the two things most important in life ${ }^{10}$. The next most frequently chosen thing was athleticism, chosen by 11 percent of respondents. They differed from older respondents somewhat in the qualities most valued in a friend. Respondents in the 18- to 29-year-old group most often selected honesty (chosen by 62 percent of the sample), loyalty and dependability (chosen by 47 percent) and trustworthiness (chosen by 31 percent). For the 13- to 15 -year-olds, the most frequent quality valued in a friend was that they be fun to be with ( 52 percent), with honesty being the next most frequently named quality (43 percent) and trustworthiness named by 26 percent (Figure 4). (See Appendix A, Tables A14 and $A-15$ for details.)

The value most often rated among the top three from the Rokeach list was "an exciting life" ( 30 percent of respondents). Boys were most likely to rate this value most highly (47 percent, as compared to 13 percent of girls). The next most frequently selected value was "a world at peace" (15 percent of respondents). Girls were more likely than boys to select this value (29 percent of girls as compared to 3 percent of boys). Girls were also more likely to rate "equality" highly (38 percent as compared to 0 percent of boys) (Figure 4). (See Appendix A, Tables A-16 and A-17 for more details.)

\footnotetext{
${ }^{10}$ Because it was necessary to keep the discussions with the 13- to 15-year-olds rather brief, they were asked for only two things they valued in life, two characteristics valued in a friend, etc.
} 


\section{FIGURE 4}

\section{Summary of Values}

13- to 15-year-olds

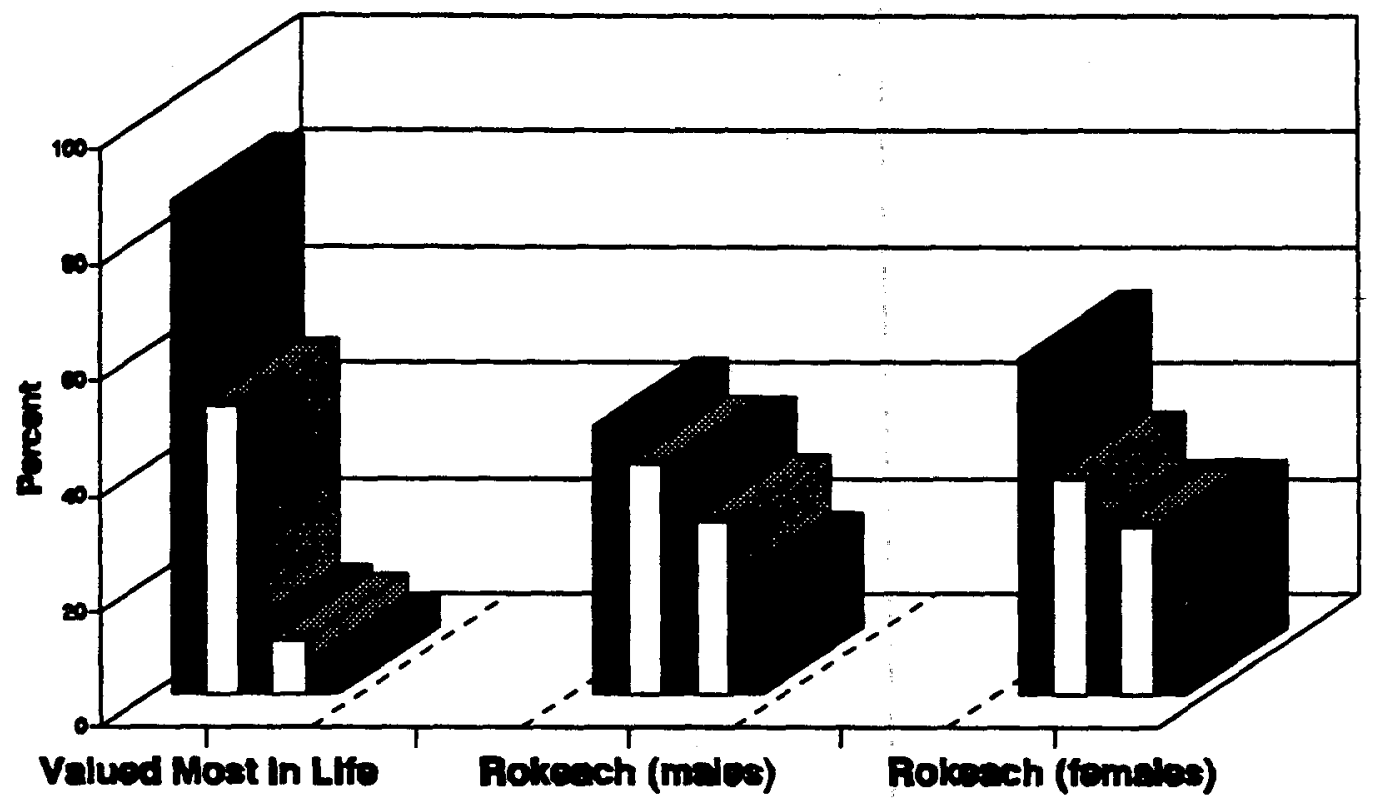

\begin{tabular}{|c|c|c|c|c|c|}
\hline \multicolumn{2}{|c|}{ Vhined Mast nin Whe } & \multicolumn{2}{|c|}{ 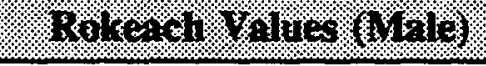 } & \multicolumn{2}{|c|}{ 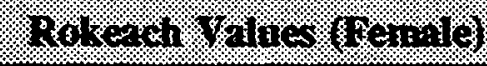 } \\
\hline Family & $85 \%$ & Exciting Life & $47 \%$ & True Friendship & $58 \%$ \\
\hline Friends & $50 \%$ & Freedom & $40 \%$ & Equality & $38 \%$ \\
\hline Athletic Ability & $11 \%$ & Health & $40 \%$ & Health & $29 \%$ \\
\hline Intelligence & $9 \%$ & True Friendship & $30 \%$ & Self Respect & $29 \%$ \\
\hline Girl/Boyfriend & $6 \%$ & Pleasure & $20 \%$ & World at Peace & $29 \%$ \\
\hline
\end{tabular}




\section{Drinking and Driving}

This group of respondents had little personal experience with alcohol. Over 46 percent of the respondents reported that they had never drunk alcohol (See Appendix A, Table A-18). Only one respondent reported drinking regularly. This would compare to national surveys of eighth graders in which almost 30 percent report that they had never used alcohol and 25 percent had used it in the last month (Johnston, O'Malley, Bachman, 1992). It is possible that non-drinking respondents self-selected for the research, since they were volunteers who knew that the general topic of discussion was drinking and driving. It is also possible that the demand characteristics of the face-to-face discussions may lead to different responses than the anonymous questionnaires used in the national surveys. Respondents who participated in this study did not generally include drinkers in their social circle: Over 90 percent of respondents said that they did not have close friends who drink.

Respondents had fairly negative attitudes about drinking. With regard to peers who drink, onethird of respondents stated that they did not care and the remainder had negative reactions to peers who drink ("stay away from them," "think they are stupid," "think they have made a bad decision," etc.) (Table 3). Boys were more likely to say that they did not care if friends drank (50 percent as compared to 13 percent of girls). Almost three-quarters of the respondents stated that their friends would react negatively if the respondent drank (e.g., "try to talk me out of it," "worry about me"). Again, boys were more likely to think that friends would not react negatively (20 percent as compared to 8 percent of girls) (Table 4). Over 90 percent of respondents stated that their parents would react very negatively if the respondent drank (Table 5). 


\section{TABLE 3}

WHAT RESPONDENT THINKS OF PEERS WHO DRINK:

13- to 15-YEAR-OLDS

\begin{tabular}{|c|c|c|}
\hline $18: 8: 8: 8$ & ireanerion: & $2 x^{2} 8=11$ \\
\hline 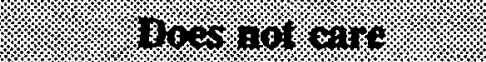 & 18 & $33 \%$ \\
\hline 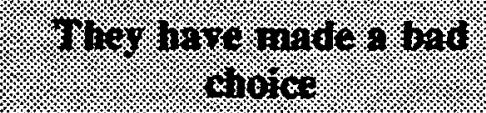 & 13 & $24 \%$ \\
\hline Thinks hey ne stupid & 11 & $20 \%$ \\
\hline 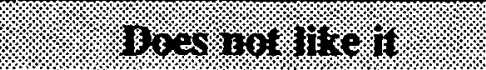 & 4 & $7 \%$ \\
\hline Sters antay hou then & 2 & $4 \%$ \\
\hline Qulier. & 1 & $2 \%$ \\
\hline $1,1,1+18 \mathrm{~g}$ & 5 & $9 \%$ \\
\hline rom & 54 & $100.0 \%$ \\
\hline
\end{tabular}

TABLE 4

WHAT FRIENDS WOULD THINK (OR DO) IF RESPONDENT DRANK (BY GENDER)

13- to 15-YEAR-OLDS

\begin{tabular}{|c|c|c|c|}
\hline & Mare & Ferante & Tous \\
\hline That subiect is stipids & $16(53 \%)$ & $10(42 \%)$ & $26(48 \%)$ \\
\hline youring. & $6(20 \%)$ & $2(8 \%)$ & $8(15 \%)$ \\
\hline 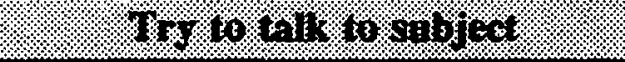 & $3(10 \%)$ & $4(17 \%)$ & $7(13 \%)$ \\
\hline 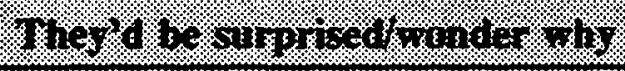 & $1(3 \%)$ & $4(17 \%)$ & $5(9 \%)$ \\
\hline 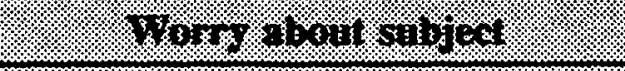 & 0 & $2(8 \%)$ & $2(4 \%)$ \\
\hline 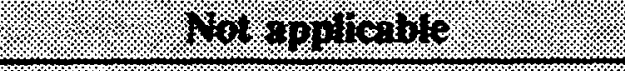 & $2(7 \%)$ & $1(4 \%)$ & $3(6 \%)$ \\
\hline 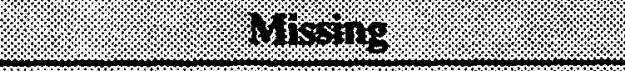 & $2(7 \%)$ & $1(4 \%)$ & $3(6 \%)$ \\
\hline Tom & $30(56 \%)$ & $24(44 \%)$ & $54(100.0 \%)$ \\
\hline
\end{tabular}


TABLE 5

HOW PARENTS WOULD REACT IF RESPONDENT DRANK:

13- to 15-YEAR-OLDS

\begin{tabular}{|c|c|c|}
\hline & Fregingror & $3 e r=2$ \\
\hline $10 \%$ regl angry & 24 & $44 \%$ \\
\hline 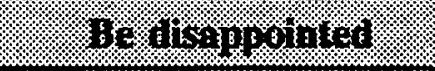 & 10 & $19 \%$ \\
\hline be unse? & 8 & $15 \%$ \\
\hline Prinist stibject: & 4 & $7 \%$ \\
\hline 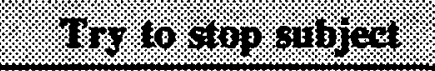 & 3 & $6 \%$ \\
\hline Torild a or crie nueb & 2 & $4 \%$ \\
\hline frot mplicable & 3 & $6 \%$ \\
\hline rofa! & 54 & $100.0 \%$ \\
\hline
\end{tabular}

On the topic of drinking and driving, 11 percent of respondents reported that they have friends who drink and drive. All of these respondents reacted negatively to this behavior.

When asked whether they drank more than, less than, or the same as their friends and other people their age, 57 percent of respondents said they drank less than their friends and 69 percent said they drank less than most people their age. This finding is common among young people. Even given that there may be some self-selection of non-drinkers in this sample, it is likely that these respondents perceive that there is more drinking among their peers than is actually the case. They may feel, erroneously, that not drinking takes them out of the mainstream of their peers.

When asked what the respondent would worry about most if he/she drank a lot, the most frequent response ( 46 percent) was that he/she would drive while intoxicated. The next most frequent response was that he/she would get into trouble with parents (24 percent). (See Appendix A, Table A-19 for more, detail).

Sixty-three percent of respondents said that they discussed drinking and driving with their family and 33 percent said that they had discussed it with their friends. 


\section{DISCUSSION}

Conclusions for this sample must be somewhat tenuous in that the sample is rather small and respondents were entirely self-selected from a single geographic area. Even taking into account some degree of self-selection of non-drinking respondents, however, the contrast between this age group and the 18- to 20-year-old respondents is striking. Clearly, a transformation takes place between the 15th and 18th year. The 13-to 15-year-olds in this sample have both the attitudes and behaviors with regard to drinking and drinking and driving that would put them at low risk. More study would be needed to understand the social and developmental factors that change these attitudes and behaviors and lead to heavy drinking and impaired driving in the later teens. It would be very useful to explore further how those factors might be addressed preventively among young adolescents and how existing values can be used.

The same values of family and friends are selected by this age group, although the influences they exert and the dynamics of the relationships are different. Significantly, most respondents thought that their friends would disapprove if they drank, thus providing social and peer pressure in the desired direction. There is a more overt focus on having a good time for this group (as compared to the 18- to 29-year-old sample), especially among boys, as evidenced by the selection of "an exciting life" as an important value and the emphasis on "fun to be with" as a quality valued in a friend. 


\section{VI \\ FOCUS GROUPS}

\section{RESULTS}

The results of the focus groups validated the findings from the one-on-one discussions conceming drinking and driving attitudes and behavior and the role of values in behavior. The focus groups also provided more detailed and added some complexity to these findings. Again, respondents were selected for participation in the focus group discussions if they were from 21 to 29 years old and if they reported having driven within two hours of drinking an alcoholic beverage during the last year.

\section{Role and Importance of Alcohol in Social Life}

Focus group participants were asked what they do in their leisure time and what role alcohol plays in those activities. The large majority of activities mentioned, especially social activities, were seen as appropriately involving alcohol. Even sports involved alcohol -- if not during play, afterwards. As one participant put it, "We always say, 'If you can't win the game, maybe you can win the party." When asked to suggest ways that they could avoid drinking altogether (as one way of avoiding drinking and driving) respondents rarely generated ideas for other types of social activities that would not include drinking but rather tended to talk about ways of avoiding drinking alcohol in settings that would normally include drinking: "You could drink non-alcoholic beer when you go out."

As was found in the one-on-one discussions, most heavy drinking occurs with groups of friends, usually of the same sex, but occasionally mixed. Heavy drinking takes place primarily in bar or club settings. Parties at private homes were also mentioned. These are not, for the most part, dating situations. Most respondents said that they do drink on dates, but that they drink less. Both sexes said that on dates they liked to drink enough to feel more relaxed but were concerned that they not drink so much that they appeared foolish or did something embarrassing. Women seemed particularly concerned about losing control or "doing something I wouldn't normally do."

The overall attitudes of participants towards drinking and abstinence seemed quite ambivalent. For example, when asked to describe someone who never drinks, some participants used terms like "pure," "naturally high," and "balanced." Others described non-drinkers as "anal," "boring," or "worried."

Many participants seemed to have ambivalent feelings about drinking in general. Participants were screened to make sure that they are at least social drinkers, and it is not surprising that they said that drinking was "fun." In fact, the area of strongest agreement across all the groups was what they found good about drinking: virtually every group said drinking relaxes them, releases their inhibitions, helps them to socialize, and tastes good. However, virtually every group listed 
more problems associated with alcohol than good points, usually beginning with hangovers and, in many groups, including addictions, accidents, and deaths. Women were generally more likely to bring up accidents than men, and only women mentioned problems such as addiction and sexual and physical abuse.

Pressure from friends to drink seemed to be pervasive. In some instances, this pressure took the form of overt persuading or nagging to drink. As one respondent put it, "It's like there's something wrong with you if you don't drink." In some cases, pressure was the result of social practices, such as buying rounds, or more subtle social cues ("People just don't like to see you without a drink in your hand."). Participants described norms that exist in these social settings that require that all of the members of a social group be "on the same level" of intoxication. Everyone should be enjoying him/herself, and drinking along with companions is necessary for enjoyment. This type of attitude is particularly problematic when the group has a designated driver, as will be discussed below.

\section{Attitudes Towards Drinking and Driving}

As in the one-on-one discussions, participants agreed that drinking and driving, especially "drunk" driving, is dangerous, stupid and wrong. Even so, almost all focus group participants admitted that they had sometimes driven when they knew they should not have.

Virtually none of the participants reported believing that driving after one or two drinks is wrong. While the vast majority of respondents believe that driving "drunk" is wrong, their definitions of this behavior vary and are sometimes imprecise. Most respondents do not even have a term to describe driving after three, four or even six drinks. For many of them, four or five drinks is not yet "drunk." They do not use the word "impaired" and reported that they really had no definition of this concept. Many respondents said that they might very well be able to drive competently even when over the legal blood alcohol limit, implying that they felt the legal limit to be rather arbitrary.11

Most respondents admitted to driving while legally intoxicated on occasion, but appeared to feel that this is morally different than driving drunk habitually. This can be seen most clearly in the picture sorts that were used to stimulate discussion of what images participants have of people who drink -- or do not drink -- and drive. When asked for words that describe people who sometimes drive impaired, they virtually always said, "average," or "that describes a lot of us." They described the animal pictures selected as occasional impaired drivers as "a fun guy," "nice," "happy-go-lucky." When asked to describe people who drink and drive all the time, however, they generally used harsh, moralistic terms, such as "uncaring," "foolish," "stupid" and "selfish," although they also used some more positive terms like "crafty," "powerful -- does what he likes." It appears that occasionally driving legally impaired does not violate these participants' sense of values and is, in fact, associated with fun. Some stated that people who drink and sometimes

\footnotetext{
"Respondents seemed to have this belief regardless of the legal blood alcohol content in their state $(.08$ percent in Califomia, .10 in Maryland and Wisconsin).
} 
drive impaired are not irresponsible people, although they may occasionally act irresponsibly.

Fear of being arrested for driving while legally impaired does deter participants from drinking and driving. Particularly men in Montgomery County and men and women in Palo Alto expressed a great deal of concern over the possibility of arrest -- especially those who have been previously arrested. For those who have not been arrested, however, the chance of being arrested is treated almost like a game; they repeatedly used the term "getting away with it."

\section{Strategies Used to Avoid Drinking and Driving}

Respondents reported using a variety of strategies to avoid driving when they are, by their own definition, too drunk. One way is to pace their drinking in such a way that when they must drive home they are not intoxicated. One participant has one drink an hour, in an attempt to keep himself below the legal limit. A few participants place numerical limit on their drinking (generally, the limit seems reasonable, such as one or two drinks, but some were much higher.) Others stop drinking at midnight, giving themselves two hours until bar closing time to sober up.

Most group participants seem to spend most of the evening drinking and then use a variety of methods of determining whether they are too drunk to drive. Most participants say the amount they can drink without becoming intoxicated varies from night to night, according to how much they have eaten, how much stress they have been under, etc. They judge whether or not they are all right to drive by physical sensations (numb lips, room tilting, inability to walk) or mental sensations (Am I carrying the conversation okay? Am I having to concentrate too hard? Are my friends making sense?). One obvious problem with such judgements is that they are only made after the person is already impaired. Previous research has shown that people who have been drinking consistently underestimate their blood alcohol content (Bierness, Foss, Voas 1993). Many participants who said they have driven drunk said they did not realize how drunk they are until they were on the road or until the next morning.

Even if the person recognizes the level of impairment, however, they often believe they have few options. When asked how they can avoid driving while impaired, most participants mentioned taxis; however, they rarely if ever actually use them because of the cost. In addition, most respondents are very reluctant to leave their cars behind, both because of the inconvenience of coming back to get them and because of concerns about damage to the car. One respondent recognized the lack of logic of this behavior,

"I have a really nice car and I would never leave it in the parking lot of a bar all night. I guess that's really stupid. I could wreck it much worse driving when I shouldn't. But you don't think about that when you've been drinking."

Another strategy mentioned by respondents to avoid driving while too impaired (by their own definition) was to stop and get something to eat until they were more sober. 
Participants frequently complained that public transportation was not a practical option for getting home from drinking because most transit systems close at midnight, while bars stay open much later. (Respondents seemed to take it for granted that they would stay at the bar until it closed.) Some participants mentioned walking to bars in order to avoid drinking and driving, but in general, participants appeared to fail to plan ahead to avoid drinking and driving. One participant in Madison seemed to assess the situation accurately:

"People do not intend to drive drunk. Their intention is to get drunk. And their intention is to drive, but . . . it's like they don't put the two together."

Most participants seem to have good intentions, but lack the skills to carry through on attempts to avoid driving after drinking. For example, as will be discussed in more detail below, the use of designated drivers is common, but many respondents say the decision is an informal one, often made after the group has already gotten to the bar (which may mean several cars are already involved), and often made at the end of the evening, when "whoever is least drunk" becomes the designated driver. In fact, one of the reasons participants commonly gave for driving drunk is that the designated driver was even more intoxicated.

Participants frequently complained that non-alcoholic beverages at most bars cost as much as alcoholic beverages. Many believed that non-alcoholic beverages should be free, especially to the designated driver.

\section{Intervening to Prevent Others from Driving While Impaired}

Most participants had some experience in preventing others from driving after drinking too much. A role play exercise was conducted in the groups in which one member of a group of friends was served drink after drink to determine at what point friends would begin to intervene. Most participants said that this was not a realistic way of monitoring the drinking behavior of companions. People do not pay attention to how much a companion is drinking throughout the evening. Rather, they might notice that the companion's behavior indicates intoxication at the end of the evening. Women, in particular, reported that at the end of an evening of drinking they habitually asked each other, "Are you OK to drive?" Most participants stated that if someone said that they were capable of driving, companions would be reluctant to contradict them. Male participants reported being more confrontational and aggressive with friends who they thought were too impaired and described physically taking the car keys or even letting the person drink more to the point of losing consciousness so that they could easily be prevented from driving.

It is important to point out here that these judgments about the level of impairment of companions are being made by people who are themselves likely to be under the influence of alcohol. Decision-making about driving often rests in the hands of those who are least drunk. None of the participants ever mentioned intervention by servers of alcohol to deny an intoxicated patron more alcohol or to prevent an intoxicated patron from driving away from the establishment. 


\section{The Role of the Designated Driver}

As was the case in the one-on-one discussions, virtually all of the focus group participants used designated drivers in their social groups and most had been the designated driver on some occasions. As described above, however, frequently the role is assigned very casually, and often the designated driver is simply the person deemed to be least drunk at the end of the evening. In role playing exercises, the participants indicated that even when the designated driver is chosen ahead of time, he or she is usually expected to have at least a few drinks. One participant reported, "The designated driver usually stops drinking at midnight."

Participants clearly have ambivalent feelings about designated drivers. When asked directly how they would describe designated drivers, most groups used adjectives such as "caring" and "responsible." Participants overwhelmingly agree that having a designated driver is a good idea. They also occasionally used words such as "geeky" and "nerdy," however, to describe a designated driver. This ambiguity was particularly apparent in the picture sort. For example, almost all of the groups said the eagle shown in one picture would never drive and drink, or would be a designated driver because he is "proud," "majestic," and needs to be in control. However, others said that the kitten shown in another picture would be a designated driver because she is "timid." Participants said the rather homely pug dog in one picture would be a designated driver because he has no social skills and would not be allowed to go out with the group if he did not volunteer to be the designated driver. Designated drivers were also described as "party-poopers."

As discussed above, designated drivers are sometimes pressured by their companions to drink. One reason for this pressure seems to be the desire for everyone in the social group to be at least somewhat affected by alcohol. Participants sometimes expressed concern about the designated driver (or any completely sober person) being judgmental about their behavior when they were drinking. At the same time, participants did express disapproval and annoyance when the designated driver drank too much (the definition of "too much" varied widely). In role playing exercises they were sometimes quite hostile towards the now-impaired designated driver. The usual strategy to deal with this situation was to stop drinking themselves when they saw that the designated driver was drinking too much.

Participants reported that being the designated driver is often rotated among members of a group of friends and that the only reason anyone would be the designated driver is because it is his or her turn. Many participants directly said "no one wants to be a designated driver," because it's "no fun." One participant said the wolf in one picture would be a designated driver, because wolves are loners, and "you're a lonely son of a buck when you're the designated driver." Some participants did point out the positive aspects of being a designated driver, including that it provided an excuse not to drink if they did not feel like drinking that night and it gave them more power to decide when to go home. It is interesting to note that respondents felt that they needed to have an excuse if they wished not to drink. 
Responsibilities of the designated driver sometimes extend beyond simply driving companions home. The designated driver is also seen as someone who is generally responsible for the safety and welfare of intoxicated companions. The term "baby-sitter" was used in reference to the designated driver and reasons for not wanting to be the designated driver included that the unpleasantness of being responsible for "a bunch of drunks" as well as the loss of an opportunity to participate fully in the evening's activities.

\section{The Influence of Values of Family and Friends on Drinking and Driving}

Family was established in the one-on-one discussions as the most consistent value for the 18- to 29-year-old target group. Family did not seem to be very directly linked to drinking and driving, however, in the minds of most participants. The only time that the idea of family was raised spontaneously during the focus groups was when participants were shown a picture of a family of penguins during the picture sort. Respondents were fairly consistent in saying that the penguins would never drink and drive or would be the designated driver because they were a family and "they would never do anything to hurt the baby." (Some participants did associate the penguins with heavy drinking, however, because of their "tuxedo" outfits.)

When specifically asked about family in relation to drinking and impaired driving, respondents thought largely in terms of serious harm that can befall families, such as a member being involved in a crash, family breakup, and so forth. (Interestingly, when considering the relationship of friends with drinking and impaired driving, respondents expressed themselves in more positive terms, talking about caring and protecting.)

It is important to note that while family was valued by participants, their feelings towards their families were far from uniformly positive. When participants described the symbol they drew to represent their families, they frequently used words like "violent," "anger," "dysfunctional," and "divided." By contrast, when respondents described their friends, the terms they used were uniformly positive.

Friends were, of course, very much involved with drinking and with drinking and driving. Participants drink primarily with groups of friends. Friends exert influence on the amount of drinking. They intervene if a companion seems to have drunk too much. They participate in reciprocal arrangements in which they take turns acting as the designated driver.

In order to determine if the values of friendship and family could be associated with avoiding drinking and driving, participants were asked to draw symbols representing their family and friends. They were also asked to draw a symbol representing responsible driving and to combine the three symbols in a way that showed their relationship to each other. The exercise indicated that most participants could easily associate the three concepts. The majority saw fairly straightforward relationships: If you value your friends and family, you should drive responsibly. Many used words such as "interconnected" and "inter-related" to describe the connection between the three. Some participants had difficulty seeing how "family" could be associated with "friends" and "driving responsibly," although several of these participants said that they learned their values 
from their families, and they use these values when they drive responsibly. Others seemed confused by the task, pointing out that they did not do most of their drinking with family members, therefore, they were not really connected.

When the idea of a designated driver or driving responsibly was placed in the context of family and friends, participants moved very directly to the values of "life" and "safety:" Several used these words to describe the relationship of the three values. Significantly, in this context, not a single participant raised the issue of being pulled over by the police or getting a ticket. Again, this may indicate that, even though fear of getting a ticket is a practical concern, it may not be the kind of moral concern that has real, deep-seated "value" to the participants. They instead focused on values like safety.

The above findings suggest that countermeasures against drinking and driving might be successfully developed to elevate the image of responsible driving behavior within the context of the values of safety, responsibility, families and, particularly, friends. As one participant put it, "Nobody wants to see his buddies in a ditch."

It must be pointed out, in this context, that many participants think that "scare tactics" are more effective, or, at least, should also be used. Some even suggested using scare tactics exploiting the value of family and friends. Some talked about the need for showing the "grim realities."

\section{The Influence of Other Values on Drinking and Driving}

Other values rated highly by one-on-one discussion participants included health and a sense of accomplishment. A minority of focus group participants mentioned health-related issues in relation to drinking or drinking and driving. The most frequently mentioned health consequence was hangovers. Someone in almost every group mentioned the potentially positive effects of drinking on cholesterol levels. Countermeasures could be developed to help establish a linkage in the minds of the target population between health and avoiding drinking and driving; however, this task would be more challenging than for the values of friends and family where such connections already exist.

No focus group participants made any connection between drinking or drinking and driving and professional or other accomplishments. When asked to name the negative consequences of drinking or what worried them when they drank and drove, no one ever mentioned poor job performance or losing a job or not being able to perform other valued tasks well. Thus, for this value, as with health, designing countermeasures to help establish this linkage might be more difficult than making the linkage to family and friends.

\section{Regional and Gender Differences}

Despite the narrow age and social range of the participants, the findings from the twelve focus groups in three different cities also indicate there are some regional, gender, and individual differences in the way young people think--and act-about drinking and driving. In each city, 
there were differences between the male and female groups, as well as differences among participants in the groups. Clearly, people drink differently, and they deal with the problem of drinking and driving in different ways. This in itself suggests that a wide range of approaches might be necessary for countermeasures.

These regional and gender differences are evident in the detailed summaries found in Appendix $D$, which describe the focus groups by city and gender. Some differences are not directly related to drinking and driving issues, but might be important for promotional campaigns. For example, dancing seems much more important in Montgomery County than in the other cities; nature and environmental concerns are most important in Palo Alto. Other differences are much more directly related to drinking and driving Some of the most important of these are listed below:

Gender differences:

- In general, women seem somewhat more willing to say they would not argue if friends told them they had had too much to drink and should not drive (although women in Madison say they have fooled their friends). Women also tend to plan ways of avoiding drinking and driving somewhat more than do men. Women are more likely than men to plan on having designated drivers and are more likely to suggest spending the night at a friend's home rather than drive home drunk.

- Women viewed heavy drinking among men as an aggressive "male thing." They identified pictures of animals such as the gorilla and the bear as drunken men who get into fights. They said that men were particularly likely to insist on driving even when they were intoxicated. Although women admitted to becoming drunk, they associated this behavior with a loss of inhibition rather than with increased aggressiveness for themselves or their female friends.

- Women were more likely than men to list addiction and accidents as problems associated with alcohol. Men were more likely to talk about hangovers.

\section{Regional Differences:}

- Participants in Palo Alto seemed to be more reluctant than others to risk confrontations with friends who become too drunk to drive.

- Participants in Palo Alto seemed the most concerned about the possibilities of being arrested for impaired driving.

- Participants in Madison reported the most peer pressure to drink.

- Since most participants in Madison say they can walk to bars, most say they do not worry very much about drinking and driving. Even so, most of the participants admitted that they had driven impaired. 
While almost all participants said they drink less with members of the opposite sex, the women in Madison were a notable exception: several said they drink more.

\section{DISCUSSION}

There are a number of important implications of the focus group discussions for the development of values-based countermeasures. First is the degree of ambivalence expressed by participants about key issues related to impaired driving. These feelings of ambivalence contribute to the risky behaviors engaged in by this group, but also provide areas in which group members may be most amenable to values-based influences. Participants are ambivalent about alcohol, seeing it as both an important aspect of social life and a substance that can lead to negative consequences, both socially and physically. Participants sometimes described abstainers and very light drinkers in positive terms, but also used very negative terms for them. Thus, participants try to stay in a poorly defined middle ground that allows them to be in the social mainstream (which abstinence does not) and at the same time not suffer damage from overuse. Participants value staying in control, being responsible, and avoiding embarrassment and harm. These values can be emphasized in countermeasures to help tip the balance of ambivalence towards more responsible behavior with regard to alcohol. Responsible behavior can be modeled and the admirable qualities of those who behave responsibly emphasized.

While persuading or teaching this group to reduce heavy drinking may be possible, alcohol seems highly central to their social life and it may be difficult to change this group's propensity to put themselves into social situations in which heavy drinking is likely, for example, to avoid hanging around in bars.

Another area of ambivalence is in attitudes towards impaired driving. Participants view drunk driving as wrong. Occasional drunk driving, however, is seen as normative. Participants did not seem to have a clear conception of the continuum of impairment that begins with the first drink and therefore viewed driving after drinking -- even a fairly large quantity -- as acceptable, unless the driver is really "drunk." Countermeasures can take advantage of the overall negative attitude towards drunk driving and help members of the target group to understand the continuum of impairment and to recognize that one does not have to drive drunk habitually to cause serious problems.

Perhaps the most important ambivalence surrounds the concept of friends. Friends were one of the two key values identified for this target group, second only to family. Moreover, friends, for this group, are viewed as far more salient to impaired driving than is family. Friends can have a positive effect on behavior. Participants expressed the desire to protect and be responsible for their friends. Loyalty and dependability are highly valued in friends. People are willing to enter into reciprocal relationships with friends to help each other, for example, by volunteering to take turns being the designated driver. On the other hand, it is with groups of friends that most heavy drinking takes place. Friends often exert pressure to drink, either explicitly or implicitly. Thus, the value placed on friends can act as an influence to behave responsibly or to engage in high- 
risk behavior. Countermeasures can be designed to try to emphasize the positive influence of friends. They can model responsible and protective behavior of friends towards one another.

Considerable ambivalence was also expressed towards designated drivers. Having a designated driver was seen as a very practical strategy for avoiding impaired driving. Designated drivers were often described in positive terms. Participants, however, usually very much disliked having to be the designated driver and statements were also made indicating that sometimes designated drivers are socially undesirable people who are included in a group only because of the useful service they are willing to provide. Perhaps it is in part because of this ambivalence that the actual use of the designated driver strategy is so often flawed: The designated driver is not selected until the end of the evening or the designated driver drinks, sometimes to the point of intoxication. Countermeasures can be designed to emphasize the positive and admirable qualities of the designated driver and to model appropriate use of the designated driver.

The value of family was less directly related to drinking and driving than is the value of friends. Moreover, respondents expressed deeply ambivalent attitudes towards their families. Respondents did seem concerned about protecting their families from harm (especially the pain that could occur if the participant were in a crash). Countermeasures could be developed to emphasize the need to protect loved ones from harm.

Another way in which the results of the focus groups can be useful is in providing information about the realistic situations in which impaired driving is likely to occur for this target group. Group participants consistently indicated that the heaviest drinking occurs in groups of friends, usually of the same sex. Thus, a countermeasure designed to deal with this situation is likely to be more useful than one that is designed for dating. The focus groups also indicate some of the thinking that leads to drinking and driving behavior. For example, most participants believe that drunk driving is wrong, though they see occasional impaired driving as part of normal behavior. Countermeasures that focus on the moral aspects of drinking and driving may not be necessary. Similarly, many participants have established some sort of limit for drinking when they must drive and in many cases, these limits may be well beyond the point of serious impairment. Thus a countermeasure that simply enjoins drivers to "know your limits" is likely to be ineffective, and possibly counterproductive. Rather, countermeasures that emphasize the impairing effects of alcohol prior to severe intoxication might be more useful.

The focus groups also provide guidance for the development of countermeasures by indicating an appropriate vocabulary for countermeasure messages. For example, a message that emphasizes avoiding drinking in order to stay "in control" might have negative effects, given that drinkers desire to reduce inhibitions and may view others who are too much in control with suspicion. 


\section{VII}

\section{DEVELOPMENT OF VALUES-BASED COUNTERMEASURE CONCEPTS}

Information gained through the one-on-one discussions and the focus groups was used to develop countermeasure concepts that are linked to the values and motivations of the target group and that fit realistically within the drinking and driving behavior and common drinking and driving situations reported by the respondents. As discussed above, the target group placed the most consistently high value on family and friends. These values are already linked to drinking and driving and these linkages could be reinforced. Most directly, persuasive appeals can be built around these values and delivered through a variety of channels. The nature of the recommended messages and potential channels for communicating these messages will be discussed below.

In addition to simple appeals to existing values, information gathered from respondents indicates the need for and potential effectiveness of several different types of countermeasures to prevent impaired driving, including a reduction in the availability of alcohol to underage drinkers, the use of more responsible service practices, and the provision of alternative means of transportation. It may be possible to link these countermeasures to existing values. A discussion of these countermeasures and how they might be related to values follows the description of the direct appeals.

\section{COUNTERMEASURE CONCEPTS}

The findings of the one-on-one discussions and the focus groups imply a number of concepts for countermeasures that would seem to enhance their likelihood of having a positive impact on the behavior of the target audience.

One conclusion that can be drawn from the discussions and focus groups is that respondents drink primarily because drinking is positively valued. It may be effective, therefore, if countermeasures appeal to countervailing positive motivations. That is, it may be more effective if target groups view avoiding drinking and driving as something positively valued rather than just as a way of avoiding something negative. This approach can add a new dimension to existing countermeasures that are based on fear (of arrest, embarrassment, injury, guilt, etc.). The target group already responds to negative motivations (especially avoidance of arrest). Strong deterrence-based countermeasures already exist. It may be that the addition of positive motivations for avoiding drinking and driving may work well within this environment.

The target group also seems to lack specific skills to avoid drinking and driving. For example, they have not developed good skills for planning ahead to avoid driving after drinking, they do not know how to use a designated driver most effectively, and they do not know how to judge levels of impairment in themselves or their companions. A second element to the values-based countermeasures that is potentially effective is the modelling of appropriate skills. 
With these ideas in mind, the following countermeasure concepts are proposed:

In order to reduce ambivalence about drinking and avoiding drinking and driving:

- $\quad$ Provide positive image of responsible behavior (avoiding drinking and driving).

- Provide positive image of person who prevents others from drinking and driving.

- $\quad$ Provide positive image of designated driver.

- Show immediate positive consequences (gratitude, admiration) for preventing and avoiding drinking and driving and for being the designated driver.

In order to overcome the belief that occasional impaired driving is acceptable:

- Emphasize that responsible driving should be a consistent behavior.

In order to overcome the belief that only driving while truly intoxicated is dangerous:

- Emphasize that any amount of alcohol is impairing.

In order to tie into the value of family:

- Invoke images of family as part of motivation for avoiding and preventing drinking and driving.

In order to tie into the value of friends:

- Use value of friendship as major motivation for avoiding and preventing drinking and driving.

- Invoke concept of reciprocity among friends in being a designated driver or helping others to avoid drinking and driving.

- Provide implicit acknowledgement of the ambivalent influence of friends -- towards and away from responsible behavior.

In order to make countermeasures more realistic:

- Use realistic situations commonly reported by the target audience in which impaired driving occurs; usually at parties and at bars and clubs with large groups of same sex friends. Include common behaviors, such as buying rounds.

- Show strategies for avoiding drinking and driving that are deemed practical by the target audience.

- Provide separate countermeasure messages for men and women (since target group members tend to drink in same-sex groups and may view drinking by the opposite sex as different from drinking by their own sex). 
In order to overcome apparent skills deficits among the target audience:

- Model appropriate behavior, including responsible hosting refusing drinks when pressured by others planning how to get home before drinking occurs successful intervention to prevent others from drinking and driving

In order to make the vocabulary of countermeasures meaningful to the target audience:

- $\quad$ Use words like "caring," "responsible," and "trustworthy" provided by the target population to characterize avoiding and preventing drinking and driving.

\section{ADDITIONAL COUNTERMEASURES NEEDED}

\section{Interventions to reduce the availability of alcohol to underage drinkers}

Respondents reported great ease in obtaining alcohol before they could legally purchase it. In fact, the heaviest drinking by many respondents was reported prior to age 21 . The most commonly reported methods for obtaining alcohol were the use of false or borrowed identification and obtaining alcohol from places that did not ask for identification. It is clear from the current study, as well as other available data, that underage drinking is a frequent occurrence that puts young drivers (and those on the road with them) at great risk.

Because too few of the study respondents (other than the 13- to 15-year-olds) were under 21, this report does not focus on developing countermeasures for this group. It may be possible, however, to develop campaigns to dissuade youth from drinking based on appeals to values related to families and friends. Perhaps, in addition, values-based countermeasures could be used to discourage sales establishments from selling to minors or discourage parents or other adults from providing alcohol to minors. The development of such countermeasure concepts is beyond the scope of this project. It should be noted here, however, that deterrence-based strategies have shown great effectiveness in discouraging drinking by minors (e.g., Blomberg, 1992) and in discouraging sales to minors (e.g., Williams and Wells, 1993 ). Such strategies should be fully exploited, perhaps in concert with values-based countermeasures.

\section{Interventions to reduce service of alcohol to intoxicated patrons}

Most of the heavy drinking reported by respondents took place in commercial establishments (primarily bars and clubs). A great deal of drinking goes on well past the point of obvious intoxication. There were no reports by respondents of attempts by staff at these establishments to cut off drinking or to prevent intoxicated patrons from driving away from the establishment. No mention was ever made of designated driver promotions in any of the establishments. To the contrary, there were reports that establishments encouraged over-consumption of alcohol by 
pricing non-alcoholic beverages at the same or higher cost as alcoholic beverages, by encouraging the buying of rounds, and by other service practices.

Clearly, the adoption of responsible service practices at all licensed establishments could be an effective countermeasure for impaired driving as well as other problems caused by heavy drinking. Establishments that wish to promote more responsible drinking among their patrons can use some of the values-based concepts presented above. It seems unlikely, however, that many establishments will adopt or aggressively promote responsible service practices unless they are prompted to do so by economic self-interest, either by vigorous enforcement of laws against service to intoxicated patrons or by the successful pursuit of dram shop liability claims (see, for example, McKnight, 1991 and Wagenaar, 1991).

\section{The development of alternative transportation}

Respondents almost universally complained of the lack of alternative ways of getting home after drinking. Respondents complained that public transportation stopped running well before the bars closed. Almost all respondents mentioned taxis as a theoretical possibility for alternative transportation but found them impractical because of the expense. Very few appear to have had any experience at all actually using taxis. Frequent mention was made of free or subsidized taxi service as a potential countermeasure. In any case, alternative transportation would most likely have to be available both to and from drinking establishments since respondents almost unanimously stated that they would not leave their cars behind, either because they feared theft or vandalism or because of the inconvenience of coming back to get the car the next day.

Whatever transportation alternatives are available or developed, the countermeasure concepts described above could be used in their promotion.

\section{POTENTIAL CHANNELS FOR COUNTERMEASURE MESSAGES}

Media consultants made three points regarding potential channels for messages:

- Public service announcements may be less credible and powerful than other potential channels. These include segments and scenes in television programs and movies, especially those that are very popular with the target audience and include characters with whom members of the target audience identify.

- Appropriate messages can be imbedded in articles in magazines popular with the target population. These articles may not necessarily deal directly with the countermeasure topic. For example, the article might not be about designated drivers, but rather about party-giving or cars.

- It is important to saturate the target population with messages using a variety of channels. 
The countermeasure message can include a brief, easily recognizable "tag-line" that can be repeated in a variety of contexts. A variety of fairly complex messages conveyed through different channels can be reiterated more simply (especially using the tag-line), for example in posters or table tents in bars, where reiteration of the message is most needed. The poster itself might not include all the needed information, but reminds members of the target audience of the information they have heard in other contexts.

Marketing information about the target audience can be used to identify the television shows, movies, magazines and other channels to which the target audience is most likely to be exposed and to which they are most likely to attend.

\section{POSSIBLE COUNTERMEASURE MESSAGE SCENARIOS}

It is not the purpose of the current project to develop public service announcements or plots for television scripts. If such channels for countermeasures are to be used, they must be developed and tested with the target audience, as described in more detail below. For the purpose of illustrating some of the countermeasure concepts discussed above, the following scenarios are provided:

Suggested tag-line -- "What are friends for?" or "That's what friends are for." to indicate that friends should be responsible for each other's welfare rather than acting as influences for heavy drinking.

INTERVENING TO PREVENT IMPAIRED DRIVING (positive consequences for intervening, reciprocity)

Two friends meet in daytime setting (e.g., at work). One says to the other, somewhat sheepishly, "You were really right last night. I know I gave you a hard time, but I was way too far gone to drive. Thanks a lot." The other replies, "Hey, I know you'd do the same for me. What are friends for?"

INTERVENING TO PREVENT IMPAIRED DRIVING (importance of consistently avoiding impaired driving, the impairing effects of any amount of alcohol)

A group of friends is at a bar. It is closing time. One friend says, "What a great birthday. Thanks a lot, you guys." He/she starts to stand up. "Whoa, that last beer is starting to hit me." Another in the group says, "You only had a few beers, it can't be that bad." The first friend replies, "Right. Anyway, I don't have to go far. I'll just have to be careful." A third friend says, "Wait, this is no way to celebrate a friend's birthday, getting each other into trouble. Let's all take a cab to my place. We can come back early in the morning and get our cars. Anyway, I make a great breakfast." The first friend says, "John/Jane is right. As my birthday present to all of you, I'll pay for the cab. Thanks, John/Jane for looking out for us." They all agree, patting John/Jane on the back. $\mathrm{He} / \mathrm{she}$ replies, "Hey, what are friends for?" 


\section{PLANNING AHEAD TO AVOID DRINKING AND DRIVING (invokes value of friendship)}

Friends are talking on the phone or at work planning how to get to a bar or party (rather than just home from drinking). Suggested strategies include appointing a designated driver (saying whose turn it is, agreeing to pay for the non-alcoholic drinks for the designated driver), agreeing to share cabs ("Sure, it costs a few bucks, but that beats the alternative") or taking public transportation to the bar or party and a cab home. One friend says to the other, "I'm really glad you made me stop and think about getting ourselves home safely." The other replies, "We're best friends. That means we have to look out for each other. That's what friends are for."

BUYING ROUNDS (modelling responsible behavior with friends; immediate positive feedback for responsible behavior, invokes the value of family)

A group of same-sex friends is in a bar. As a waitress approaches, one says, "I guess this is my round." He/she orders soft drinks and snacks for everyone. When members of the group protest, the friend replies, "Hey, we all have to drive home tonight. And anyway, we would never hear the end of it from our wives/husbands/parents if anything happened." Another member of the group says, "John/Jane is right. To John/Jane: "Thanks for looking out for us. Sometimes we need to be reminded." John/Jane replies, "What are friends for?"

RESPONSIBLE HOSTING (modelling responsible behavior, immediate positive feedback for responsible behavior, invoking value of friendship)

Two or more friends are preparing for a party. The one who is the host mentions the need to prepare snack foods and buy non-alcoholic drinks. He/she talks about games and activities for the party. The others marvel at all this preparation, saying, "Wow, this sounds like a great party. The last one I went to, there was nothing but a keg of beer and nothing to do but drink it." The host replies, "Hey, this is my birthday party. I want to make sure that my friends all have a good time and make it home safely." The other comments, "You're not only a great host, your a good friend." The host replies, "What are friends for?"

DESIGNATED DRIVER REFUSES DRINKS (Modelling responsible behavior, immediate positive feedback for responsible behavior, acknowledging that any amount of alcohol impairs performance, invoking values of friendship and family)

Two (or more) same-sex friends are in a bar. One offers to buy the other a beer. The other refuses, saying, "No thanks. Don't forget I'm driving us home tonight." The other says, "Hey, a few beers aren't going to hurt." The designated driver says, "Listen, you're my best friend. Tonight I'm responsible for getting us home safely. I want to be in top form for an important job like that. Anyway (jokingly), we would never hear the end of it from our wives/husbands/parents if anything happened." The other agrees; saying, 
"You're right. Thanks for being a real pal. Now, let me buy you a (soft drink)." The designated driver says, "That's what friends are for."

POSITIVE IMAGE OF DESIGNATED DRIVER (invokes value of friendship, models reciprocity)

Show a group of friends at a table in a bar. A waitress comes to take their order. One orders enough beers for everyone at the table except one. He/she says, "And I want to buy a (soft drink) for our good friend, John/Jane." The waitress asks, "Just a (soft drink)?" "That's right, John/Jane is the most important member of our group -- tonight's his/her turn to be our designated driver." The waitress remarks, "That is being a real buddy." The designated driver replies modestly, "Hey, what are friends for?"

\section{COUNTERMEASURE CONCEPTS FOR 13- TO 15-YEAR-OLDS}

As discussed above, this group of young people do not yet drive and drink very little, if at all. In the demographic group included in this study, respondents reported very negative attitudes towards drinking and towards drinking and driving. They report that their parents and peers also have negative attitudes towards drinking for this age group. Thus, the main goal of countermeasures for this group would be to support these existing attitudes and behaviors and to attempt to strengthen them and sustain them into late adolescence. Given that drinking is not legal for this group for several years, it would seem that the emphasis in the countermeasures should be upon avoiding drinking by these young people (rather than on avoiding impaired driving) and on avoiding riding with an impaired driver.

\section{Family-based Countermeasures:}

- Reenforce the youths' perceptions of their parents' negative attitudes towards drinking.

- Emphasize that not drinking makes them seem responsible and mature to their parents.

- Reenforce parental support for avoiding riding with impaired drivers.

- Emphasize that avoiding riding with impaired drivers makes them seem responsible and mature to their parents.

A particularly useful countermeasure concept might be some type of facilitation of discussions between parents and children regarding drinking and drinking and driving. Sixty-six percent of respondents reported that they discussed drinking and driving with their parents. If these discussions could be guided in the most potentially productive areas (such as those listed above), full advantage could be taken of the existing strong values and motivations of the 13- to 15-yearold age group. Countermeasures could urge parents and children to discuss this issue and provide 
positive messages for communication both from parent to child and from child to parent.

\section{Friend-based Countermeasures:}

- Emphasize mutual support of non-drinking among friends.

- Emphasize negative attitudes towards drinking among friends.

- Emphasize mutual support of avoiding riding with an impaired driver among friends.

- Emphasize negative attitudes towards riding with an impaired driver among friends.

- Help youth have a more accurate perception of the low level of drinking among peers.

- Emphasize the respect and admiration that can result from avoiding drinking and avoiding driving with an impaired driver.

While not as many of the respondents reported discussing drinking and driving with their friends as with their parents ( 33 percent as compared to 66 percent), it appears that discussions do take place. Countermeasures could be designed to encourage these discussions and to provide messages that affirm the existing peer pressure this age group reports feeling against drinking and against drinking and driving. One method that has been used to help young people realize that most peers do not use alcohol is to have students carry out surveys among their classmates regarding their use of alcohol. The students are often surprised at the low levels of use, thus validating their own decisions not to use. No evaluation data are available to indicate the effectiveness of this approach, however, it is supported conceptually by the findings of the current project.

\section{POSSIBLE CHANNELS FOR COUNTERMEASURE MESSAGES}

Many possible powerful channels are available for communicating to this age group. Because they are in school, messages can be included in a variety of class settings, including alcohol and other drug education programs or driver's education programs. Values-based countermeasures can be added to existing approaches that emphasize potential negative consequences.

As discussed above, because of the importance placed on family by this age group, programs that encourage discussions of drinking and of drinking and driving with parents can be potentially effective. Materials encouraging these discussions and providing appropriate messages for parents to give their children can be distributed through schools, parent organizations, insurance companies, and other sources that. 


\section{VIII}

\section{RECOMMENDATIONS FOR FURTHER RESEARCH}

The current project provides a rich source of information concerning the values of the 13-15 year old and 18- to 29-year-old target groups, their attitudes, behaviors, and beliefs regarding drinking and drinking and driving, and their lifestyle in general. If this information is to be put to best use, however, additional research is required. The highest priorities for further research include testing the countermeasure concepts and broadening the target audience.

\section{TESTING COUNTERMEASURE CONCEPTS}

Information was drawn from the one-on-one discussions and the focus groups that suggested the countermeasure concepts described above. There is no way of knowing if these countermeasure concepts can be effective until they are further developed and tested. The development process would include the following steps:

- Selection of the most appropriate, powerful, and accessible channels for communicating the countermeasure messages.

This step would include further marketing research with the target group to determine what communication channels they are most exposed to and which they would find most credible. Practical decisions must be made regarding the degree to which the potentially effective channels are accessible for such messages.

The Harvard Alcohol Project was able to include scenes depicting the use of designated drivers in many different network television programs. It also used a saturation public information campaign in a well-defined geographic area to reenforce the message (DeJong and Winston, 1990). MTV might be a particularly effective channel for reaching the target audience. Local radio stations might be a very accessible channel of communication. Radio stations tend to have highly segmented audiences, so messages could be specifically tailored to the demographic and cultural characteristics of the listeners.

- Development of specific countermeasure messages.

With input from the target audience, specific countermeasure messages can be developed, reflecting the themes described above. Focus groups or individual discussions can indicate the degree to which messages are realistic, acceptable, and appealing and the likelihood that they would bring about the desired behavior.

- Testing of the countermeasure messages. 
Countermeasure messages can be conveyed through the selected channels and their effectiveness measured. Immediate measures of effectiveness could include surveys to determine exposure of members the target audience to the messages, their recall of the messages, and their perception of the effects of the messages on their behavior. Only a very intense campaign applied fairly broadly would be expected to have a measurable effect on impaired driving.

\section{DEVELOPING AND TESTING COUNTERMEASURES FOR OTHER TARGET GROUPS}

As discussed earlier in the report, participants in this study were largely white, urban and suburban, and in white-collar jobs. Recent changes in attitudes and behavior regarding drinking and driving are likely to be adopted by this demographic group before less educated, less mainstream groups. For example, the acceptance that impaired driving is something that ought to be avoided is not as widespread among other demographic groups (Kennedy, 1994). In order to broaden the applicability of the countermeasure concepts (even within the 21- to 29-year-old age group), further research would have to be carried out with a more rural population or less educated groups, for example, or with members of various racial and ethnic groups. It is highly likely that basic values might differ or that drinking settings, beliefs about drinking and driving, and appropriate vocabulary for discussing values and issues would be quite different.

It would seem quite important to broaden the age groups studied. Most crucial would be further work with 18- to 20-year-olds and with 16-to 18-year-olds. As discussed earlier in the report, the 18th through the 20th year seem to be a time of very heavy drinking and remarkably irresponsible behavior. The current project was unable to explore the values, beliefs, and behaviors of this group sufficiently to suggest values-based countermeasure concepts appropriate to this group as distinct from the 21-to 29-year-olds. Such an exploration would seem highly desirable.

As can be seen from the contrast between the 13- to 15-year olds and the 18-year-olds who participated in the one-on-one discussions in this study, a transformation of attitudes, beliefs and behaviors regarding drinking and drinking and driving appears to take place between the fifteenth and the eighteenth year. A better understanding of this developmental process could be very useful in suggesting countermeasures that could prevent the kind of drinking and driving behavior evident in the 18- to 20 -year-old group. 


\section{IX}

\section{REFERENCES}

Beimess, D., Foss, R., and Voas, R. Drinking drivers' estimates of their own blood alcohol concentrations, Journal of Traffic Medicine, 21:73-78, 1993.

Blomberg, R. "Lower BAC Limits For Youth: Evaluation of the Maryland 0.02 Law." National Highway Traffic Safety Administration, U.S. Department of Transportation, HS 807 860, 1992.

DeJong, W. and Winsten, J. The use of mass media in substance abuse prevention, Health Affairs, Summer, 1990.

Evans, L. Traffic Safety and the Driver, Van Nostrand Reinhold, 1991.

Johnston L., O'Malley, P., and Bachman, J. Smoking, Drinking, and Illicit Drug Use Among American Secondary School Students, College Students, and Young Adults, 1975-1991, U.S. Department of Health and Human Services, Rockville, Maryland, 1992.

Kennedy, B. Behavioral Challenge of the High Risk Drinking Driver. Paper presented at the 73rd annual meeting of the Transportation Research Board, Washington, D.C., 1994.

McKnight, J. Enforcement and Server Intervention. Paper presented at the Impaired Driving Initiative Expert Panel Meeting, Office for Substance Abuse Prevention, U.S. Department of Health and Human Services, Arlington, Virginia, 1991

National Highway Traffic Safety Administration, Traffic Safety Facts 1992. U.S. Department of Transportation, 1993.

Rokeach, M., Keamey, K., and Grube, J. Values and Traffic Safety, Social and Economic Sciences Research Center, Washington State University, 1985.

Rokeach, M., The Nature of Human Values, New York, Free Press, 1973.

Stewart, K. and Voas, R. Decline in drinking and driving crashes, fatalities and injuries in the USA, in: The Nature of and the Reasons for the Worldwide Decline in Drinking and Driving, Transportation Research Board Circular, The National Academy of Sciences.

Wagenaar, A. Effects of alcoholic beverage server liability on traffic crash injuries, Alcoholism: Clinical And Experimental Research, Vol. 15, Nol. 6, 1991. 
Williams, A., and Wells, J. Factors associated with high blood alcohol concentrations among fatally injured drivers in the United States, 1991, Insurance Institute for Highway Safety, Arlington, Virginia, 1993.

Zimring, F. Law, society and the drinking driver: Some concluding reflections. In: Social Control of the Drinking Driver, M. Laurence, J. Snortum and F. Zimring (eds.), University of Chicago Press, Chicago, 1988. 


\section{APPENDIX A TABLES}

TABLE A-1

Race

18- to 29-year-olds

\begin{tabular}{|c|c|c|}
\hline & 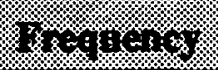 & regran \\
\hline 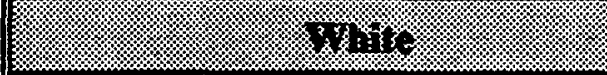 & 232 & $84.1 \%$ \\
\hline 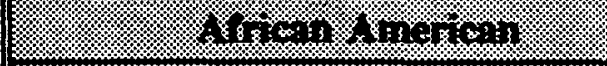 & 14 & $5.1 \%$ \\
\hline 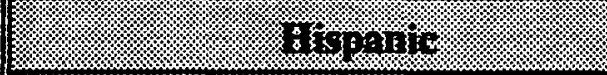 & 12 & $4.3 \%$ \\
\hline 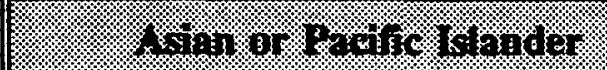 & 14 & $5.1 \%$ \\
\hline (3) & 4 & $1.4 \%$ \\
\hline
\end{tabular}

Occupation

18- to 29-year-olds

\begin{tabular}{|c|c|c|}
\hline & 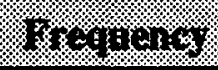 & rerozil \\
\hline 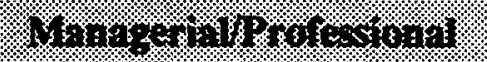 & 98 & 35.5 \\
\hline 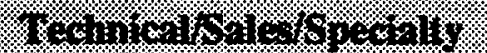 & 54 & 19.6 \\
\hline Serviree & 42 & 15.2 \\
\hline 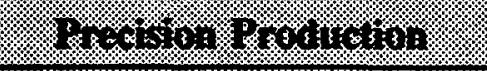 & 4 & 1.4 \\
\hline 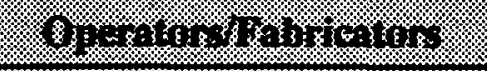 & 9 & 3.3 \\
\hline 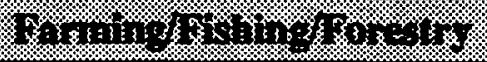 & 1 & 0.4 \\
\hline monemants & 5 & 1.8 \\
\hline 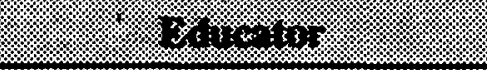 & 8 & 2.9 \\
\hline 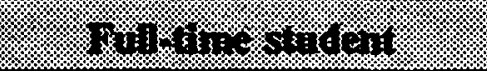 & 79 & 28.6 \\
\hline 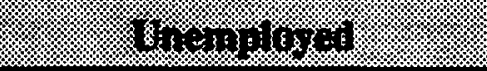 & 7 & 2.5 \\
\hline 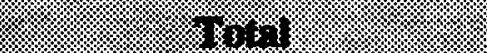 & $307 *$ & \\
\hline
\end{tabular}

Total equals 307 because some respondents were both full-time students and employed. 


\section{TABLE A-2}

\section{Employment Status}

18- to 29-year-olds

\begin{tabular}{|c|c|c|}
\hline 2 & $08090=0$ & 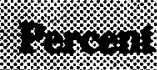 \\
\hline 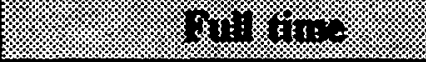 & 155 & 56.2 \\
\hline 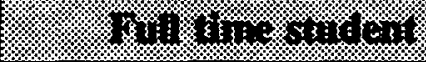 & 79 & 28.6 \\
\hline 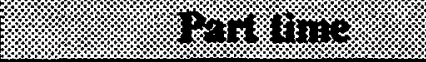 & 27 & 9.8 \\
\hline Qnemingor & 9 & 3.2 \\
\hline Gonentiver & 6 & 2.2 \\
\hline rosin: & 276 & 100.0 \\
\hline
\end{tabular}

Level of Education

18- to 29-year-olds

\begin{tabular}{|c|c|c|}
\hline $4: 180$ & 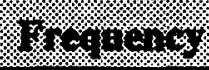 & 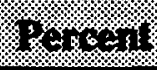 \\
\hline 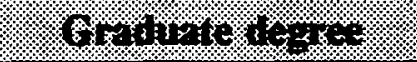 & 21 & 7.6 \\
\hline 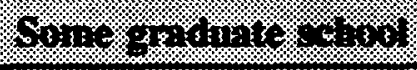 & 38 & 13.8 \\
\hline Conter gratiges & 74 & 26.8 \\
\hline 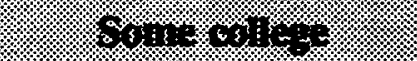 & 95 & 34.4 \\
\hline 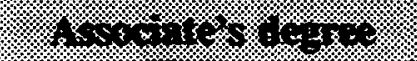 & 17 & 6.2 \\
\hline 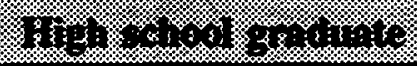 & 22 & 7.6 \\
\hline 12.8338 & 3 & 1.1 \\
\hline 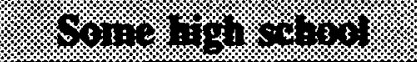 & 5 & 1.8 \\
\hline 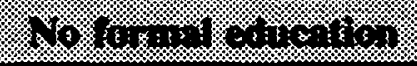 & 1 & 0.4 \\
\hline mo. & 276 & 100.0 \\
\hline
\end{tabular}


TABLE A-3

Things Valued Most in Life

18- to 29-year-olds

\begin{tabular}{|c|c|c|c|c|}
\hline & Thine? & Tanze 4 & Tran 3 & T:2:? \\
\hline rarais & $111(40.2 \%)$ & $52(18.8 \%)$ & $36(13.0 \%)$ & $199(72 \%)$ \\
\hline ritanns: & $31(11.2 \%)$ & $53(19.2 \%)$ & $48(17.4 \%)$ & $132(47.8 \%)$ \\
\hline 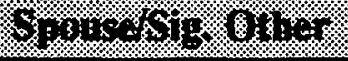 & $34(12.3 \%)$ & $38(13.8 \%)$ & $14(5.1 \%)$ & $86(31.2 \%)$ \\
\hline 18.913 & $21(7.6 \%)$ & $26(9.4 \%)$ & $17(6.2 \%)$ & $64(23.2 \%)$ \\
\hline 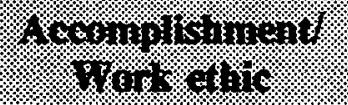 & $5(1.8 \%)$ & $15(5.4 \%)$ & $28(10.1 \%)$ & $48(17.3 \%)$ \\
\hline Trangin: crircess & $7(2.5 \%)$ & $14(5.1 \%)$ & $22(8.0 \%)$ & $43(15.6 \%)$ \\
\hline Oraterifinn & $9(3.3 \%)$ & $18(6.5 \%)$ & $14(5.1 \%)$ & $41(14.9 \%)$ \\
\hline Int: 3 eritionce & $16(5.8 \%)$ & $7(2.5 \%)$ & $10(3.6 \%)$ & $33(11.9 \%)$ \\
\hline 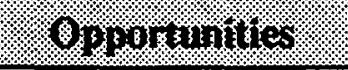 & $1(0.4 \%)$ & $8(2.9 \%)$ & $19(6.9 \%)$ & $28(10.2 \%)$ \\
\hline Yomoren & $15(5.4 \%)$ & $5(1.8 \%)$ & 0 & $20(7.2 \%)$ \\
\hline Fain & $7(2.5 \%)$ & $8(2.9 \%)$ & $5(1.8 \%)$ & $20(7.2 \%)$ \\
\hline Pess. & $1(0.4 \%)$ & $3(1.1 \%)$ & $13(4.7 \%)$ & $17(6.2 \%)$ \\
\hline Ooliner. & $17(6.2 \%)$ & $28(10.1 \%)$ & $37(13.4 \%)$ & $82(29.7 \%)$ \\
\hline mirsing & $1(0.4 \%)$ & $1(0.4 \%)$ & $12(4.3 \%)$ & $14(5.1 \%)$ \\
\hline Trota & $276(100.0 \%)$ & $276(100.0 \%)$ & $276(100.0 \%)$ & \\
\hline
\end{tabular}


TABLE A-4

\section{Rating of Rokeach Values}

18- to 29-year-olds

\begin{tabular}{|c|c|c|c|c|c|c|}
\hline & 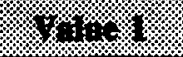 & 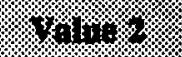 & 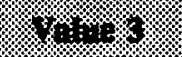 & 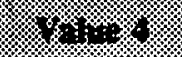 & \% & $4=$ \\
\hline 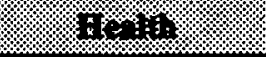 & $45(16.3 \%)$ & 44 (15.9\%) & $29(10.5 \%)$ & $11(4.0 \%)$ & 30 (10.9\%) & 159 (57.6\%) \\
\hline 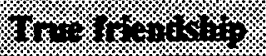 & $17(6.2 \%)$ & $39(14.1 \%)$ & $40(14.5 \%)$ & $35(12.7 \%)$ & $25(9.1 \%)$ & $156(56.6 \%)$ \\
\hline 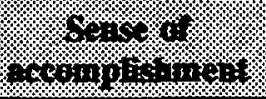 & $22(8.0 \%)$ & $19(6.9 \%)$ & $25(9.1 \%)$ & $31(11.2 \%)$ & $31(11.2 \%)$ & $128(46.4 \%)$ \\
\hline 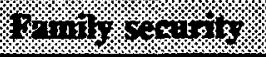 & $35(12.7 \%)$ & $36(13.0 \%)$ & $28(10.1 \%)$ & $12(4.3 \%)$ & $15(5.4 \%)$ & $126(45.5 \%)$ \\
\hline 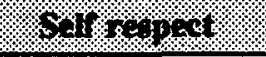 & $36(13.0 \%)$ & $28(10.1 \%)$ & $24(8.7 \%)$ & $24(8.7 \%)$ & $9(3.3 \%)$ & $121(43.8 \%)$ \\
\hline $4 H_{10}+10 \%$ & $12(4.3 \%)$ & $16(5.8 \%)$ & $25(9.1 \%)$ & $23(8.3 \%)$ & $25(9.1 \%)$ & $101(36.6 \%)$ \\
\hline $300=0 \%$ & $20(7.2 \%)$ & $14(5.1 \%)$ & $14(5.1 \%)$ & $22(8.0 \%)$ & $22(8.0 \%)$ & $92(33.4 \%)$ \\
\hline 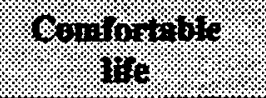 & $12(4.3 \%)$ & $4(1.4 \%)$ & $12(4.3 \%)$ & $31(11.2 \%)$ & $21(7.6 \%)$ & $80(28.8 \%)$ \\
\hline 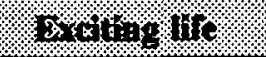 & $8(2.9 \%)$ & $11(4.0 \%)$ & $18(6.5 \%)$ & $16(5.8 \%)$ & $19(6.9 \%)$ & $72(26.1 \%)$ \\
\hline $6 \%$ & $9(3.3 \%)$ & $12(4.3 \%)$ & $11(4.0 \%)$ & $18(6.5 \%)$ & $17(6.2 \%)$ & $67(24.3 \%)$ \\
\hline 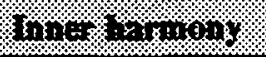 & $20(7.2 \%)$ & $13(4.7 \%)$ & $11(4.0 \%)$ & $8(2.9 \%)$ & $8(2.9 \%)$ & $60(21.7 \%)$ \\
\hline 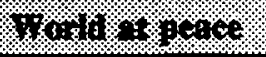 & $11(4.0 \%)$ & $14(5.1 \%)$ & $9(3.3 \%)$ & $10(3.6 \%)$ & $12(4.3 \%)$ & $56(20.3 \%)$ \\
\hline S.runitis & $5(1.8 \%)$ & $13(4.7 \%)$ & $8(2.9 \%)$ & $12(4.3 \%)$ & $14(5.1 \%)$ & $52(18.8 \%)$ \\
\hline 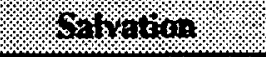 & $19(6.9 \%)$ & $3(1.1 \%)$ & $4(1.4 \%)$ & $6(2.2 \%)$ & $2(0.7 \%)$ & $31(12.3 \%)$ \\
\hline$\%=1 \%$ & $2(0.7 \%)$ & $7(2.5 \%)$ & $8(2.9 \%)$ & $7(2.5 \%)$ & $9(3.3 \%)$ & $30(11.9 \%)$ \\
\hline (1) & 0 & $1(0.4 \%)$ & $3(1.1 \%)$ & $5(1.8 \%)$ & $7(2.5 \%)$ & $16(5.8 \%)$ \\
\hline 400949 & 0 & $2(0.7 \%)$ & $7(2.5 \%)$ & $4(1.4 \%)$ & $10(3.6 \%)$ & $23(8.2 \%)$ \\
\hline 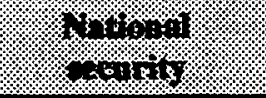 & $1(0.4 \%)$ & 0 & 0 & $1(0.4 \%)$ & 0 & $2(0.8 \%)$ \\
\hline 148, & $2(0.7 \%)$ & 0 & 0 & 0 & 0 & $2(0.7 \%)$ \\
\hline Missons & 0 & 0 & 0 & 0 & $\mathbf{0}$ & 0 \\
\hline
\end{tabular}


TABLE A-5

Rating of Rokeach Characteristics 18- to 29-year-olds

\begin{tabular}{|c|c|c|c|c|c|c|}
\hline & $4 \%$ & 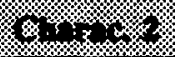 & $x$ & 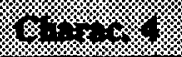 & 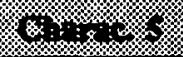 & 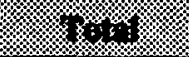 \\
\hline 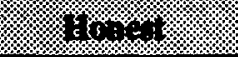 & $86(31.2 \%)$ & 51 (18.5\%) & $26(9.4 \%)$ & $17(6.2 \%)$ & $14(5.1 \%)$ & $194(70.4 \%)$ \\
\hline 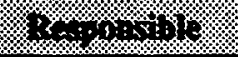 & $19(6.9 \%)$ & 33 (12.0\%) & 29 (10.5\%) & $36(13.0 \%)$ & $22(8.0 \%)$ & $139(50.4 \%)$ \\
\hline 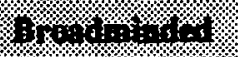 & $23(8.3 \%)$ & $21(7.6 \%)$ & $23(8.3 \%)$ & $32(11.6 \%)$ & $19(6.9 \%)$ & $118(42.7 \%)$ \\
\hline 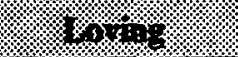 & $38(13.8 \%)$ & $19(6.9 \%)$ & $25(9.1 \%)$ & $11(4.0 \%)$ & $24(8.7 \%)$ & $117(42.5 \%)$ \\
\hline 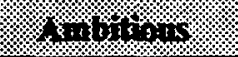 & $17(6.2 \%)$ & $17(6.2 \%)$ & $18(6.5 \%)$ & $23(8.3 \%)$ & 29 (10.5\%) & 104 (37.7\%) \\
\hline $1+14+2=1,4)$ & $20(7.2 \%)$ & $22(8.0 \%)$ & $24(8.7 \%)$ & $15(5.4 \%)$ & $19(6.9 \%)$ & $100(36.2 \%)$ \\
\hline $3_{93,5}$ & $17(6.2 \%)$ & $22(8.0 \%)$ & $30(10.9 \%)$ & $18(6.5 \%)$ & $11(4.0 \%)$ & $95(35.6 \%)$ \\
\hline 30243408 & $4(1.4 \%)$ & $15(5.4 \%)$ & $23(8.3 \%)$ & $12(4.3 \%)$ & $26(9.4 \%)$ & 80 (28.8\%) \\
\hline monoginition & $6(2.2 \%)$ & $15(5.4 \%)$ & $16(5.8 \%)$ & $21(7.6 \%)$ & $20(7.2 \%)$ & $78(22.8 \%)$ \\
\hline 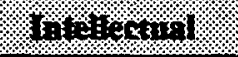 & $14(5.1 \%)$ & $15(5.4 \%)$ & $14(5.1 \%)$ & $16(5.8 \%)$ & $18(6.5 \%)$ & 77 (27.9\%) \\
\hline 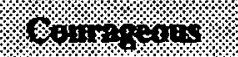 & $8(2.9 \%)$ & $11(4.0 \%)$ & $13(4.7 \%)$ & $21(7.6 \%)$ & $19(3.6 \%)$ & $72(22.8 \%)$ \\
\hline Heintin & $8(2.9 \%)$ & $8(2.9 \%)$ & $13(4.7 \%)$ & $19(6.9 \%)$ & $7(2.5 \%)$ & 55 (19.9\%) \\
\hline 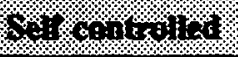 & $7(2.5 \%)$ & $11(4.0 \%)$ & $5(1.8 \%)$ & $13(4.7 \%)$ & $9(3.3 \%)$ & $42(16.3 \%)$ \\
\hline $2 \%, 4 \%$ & $4(1.4 \%)$ & $6(2.2 \%)$ & $6(2.2 \%)$ & $7(2.5 \%)$ & $8(2.9 \%)$ & $31(11.2 \%)$ \\
\hline 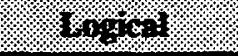 & $1(0.4 \%)$ & $6(2.2 \%)$ & $4(1.4 \%)$ & $9(3.3 \%)$ & $6(2.2 \%)$ & $26(9.2 \%)$ \\
\hline 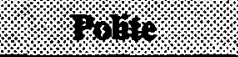 & $1(0.4 \%)$ & $2(0.7 \%)$ & $1(0.4 \%)$ & $4(1.4 \%)$ & $10(3.6 \%)$ & $18(6.5 \%)$ \\
\hline $8 \%$ & $2(0.7 \%)$ & $1(0.4 \%)$ & $3(1.1 \%)$ & 0 & $10(3.6 \%)$ & $16(5.8 \%)$ \\
\hline 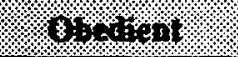 & $1(0.4 \%)$ & 0 & $2(0.7 \%)$ & $2(0.7 \%)$ & $1(0.4 \%)$ & $6(2.2 \%)$ \\
\hline $0 \%+1+3$ & 0 & $1(0.4 \%)$ & 0 & 0 & $3(1.1 \% 0$ & $4(1.5 \%)$ \\
\hline H & 0 & 0 & 0 & $\mathbf{0}$ & $1(0.4 \%)$ & $1(0.4 \%)$ \\
\hline
\end{tabular}


TABLE A-6

Qualities Looked for in a Friend

18- to 29-year-olds

\begin{tabular}{|c|c|c|c|c|}
\hline & Binimy r & 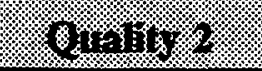 & (2) & ron: \\
\hline mibrest & $124(44.9 \%)$ & $35(12.7 \%)$ & $12(4.3 \%)$ & $171(61.9 \%)$ \\
\hline 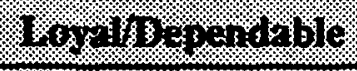 & $32(11.6 \%)$ & $63(22.8 \%)$ & $36(13.0 \%)$ & $131(47.4 \%)$ \\
\hline 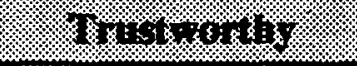 & $47(17.0 \%)$ & $25(9.1 \%)$ & $14(5.1 \%)$ & $86(31.2 \%)$ \\
\hline 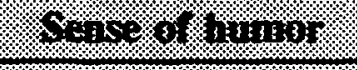 & $14(5.1 \%)$ & $47(17.0 \%)$ & $23(8.3 \%)$ & $84(30.4 \%)$ \\
\hline 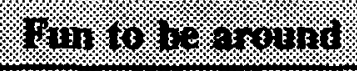 & $10(3.6 \%)$ & $31(11.2 \%)$ & $42(15.2 \%)$ & $83(30.0 \%)$ \\
\hline Squres comanon & $13(4.7 \%)$ & $21(7.6 \%)$ & $36(13.0 \%)$ & 70 (25.3\%) \\
\hline singis: & $7(2.5 \%)$ & $18(6.5 \%)$ & $19(6.9 \%)$ & 44 (15.9\%) \\
\hline Biglo 178 & $6(2.2 \%)$ & $12(4.3 \%)$ & $14(5.1 \%)$ & $32(11.6 \%)$ \\
\hline roos intener & $6(2.2 \%)$ & $3(1.1 \%)$ & $10(3.6 \%)$ & $19(6.9 \%)$ \\
\hline 3in & $1(0.4 \%)$ & 0 & $2(0.7 \%)$ & $3(1.1 \%)$ \\
\hline olyest & $16(5.8 \%)$ & $21(7.6 \%)$ & $53(19.2 \%)$ & $90(32.6 \%)$ \\
\hline 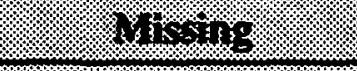 & 0 & 0 & $15(5.5 \%)$ & $15(5.5 \%)$ \\
\hline Tow: & $276(100.0 \%)$ & $276(100.0 \%)$ & $\begin{array}{c}276 \\
(100.0 \%)\end{array}$ & \\
\hline
\end{tabular}


TABLE A-7

Favorite Leisure Time Activities

18- to 29-year-olds

\begin{tabular}{|c|c|c|c|c|}
\hline & 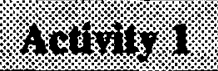 & 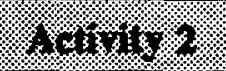 & 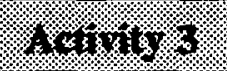 & 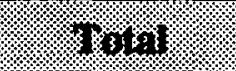 \\
\hline signons: & $67(24.3 \%)$ & $60(21.7 \%)$ & $46(16.7 \%)$ & $173(62.7 \%)$ \\
\hline 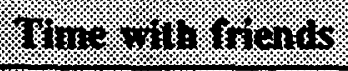 & $31(11.2 \%)$ & $41(14.9 \%)$ & $35(12.7 \%)$ & $107(38.8 \%)$ \\
\hline$i$ & $40(14.5 \%)$ & $30(10.9 \%)$ & $16(5.8 \%)$ & $86(31.2 \%)$ \\
\hline (2) 3-ings & $18(6.5 \%)$ & $30(10.9 \%)$ & $20(7.2 \%)$ & $68(24.6 \%)$ \\
\hline 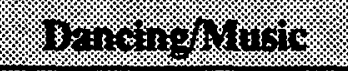 & $12(4.3 \%)$ & $19(6.9 \%)$ & $16(5.8 \%)$ & $47(17.0 \%)$ \\
\hline 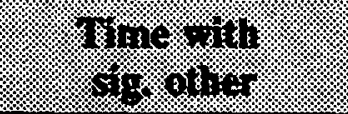 & $18(6.5 \%)$ & $11(4.0 \%)$ & $12(4.3 \%)$ & $41(14.8 \%)$ \\
\hline 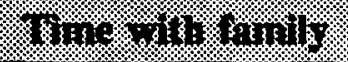 & $16(5.8 \%)$ & $11(4.0 \%)$ & $12(4.3 \%)$ & $39(14.1 \%)$ \\
\hline Yisoniss & $15(5.4 \%)$ & $11(4.0 \%)$ & $11(4.0 \%)$ & $37(13.4 \%)$ \\
\hline 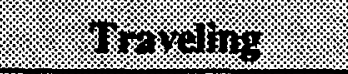 & $12(4.3 \%)$ & $6(2.2 \%)$ & $19(6.9 \%)$ & $37(13.4 \%)$ \\
\hline Sil.ping Retiving: & $5(1.8 \%)$ & $5(1.8 \%)$ & $14(5.1 \%)$ & $24(8.7 \%)$ \\
\hline 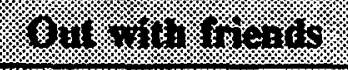 & $3(1.1 \%)$ & $11(4.0 \%)$ & $5(1.8 \%)$ & $19(6.9 \%)$ \\
\hline 831.0 .390 & $5(1.8 \%)$ & $2(0.7 \%)$ & $4(1.4 \%)$ & $11(3.9 \%)$ \\
\hline 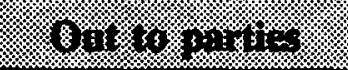 & $1(0.4 \%)$ & $5(1.8 \%)$ & $4(1.4 \%)$ & $10(3.6 \%)$ \\
\hline 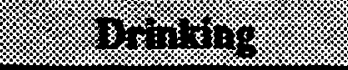 & 0 & 0 & $3(1.1 \%)$ & $3(1.1 \%)$ \\
\hline 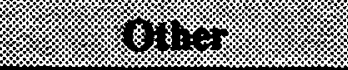 & $31(11.2 \%)$ & $32(11.6 \%)$ & $50(18.1 \%)$ & $113(40.9 \%)$ \\
\hline linsing: & $2(0.7 \%)$ & $2(0.7 \%)$ & $9(3.3 \%)$ & $13(4.7 \%)$ \\
\hline
\end{tabular}


TABLE A-8

\section{Current Drinking Drivers*}

18- to 29-year-olds

\begin{tabular}{|c|c|c|}
\hline & 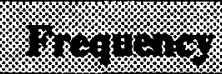 & replen \\
\hline 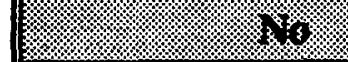 & 36 & 15.9 \\
\hline (2es) & 190 & 84.1 \\
\hline 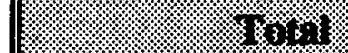 & 276 & 100.0 \\
\hline
\end{tabular}

* Respondents who: •Admit to driving while impaired within the last year;

-Had been arrested for DUI in the last year;

- Usually drink on weekends and usually drive; or

-Admit to having driven within 2 hours of drinking alcohol in the last year.

Has Respondent Ever Been Arrested for DUI/DWI?

18- to 29-year-olds

\begin{tabular}{|c|c|c|}
\hline & Tirecinerios & Rercenin \\
\hline 4 & 251 & 90.9 \\
\hline 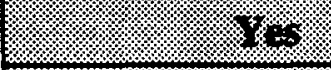 & 25 & 9.1 \\
\hline R०: & 276 & 100.0 \\
\hline
\end{tabular}

Has Respondent Ever Had So Much to Drink That They Thought They Would be in Trouble With the Police if Stopped?

18- to 29-year-olds

\begin{tabular}{|c|c|c|}
\hline 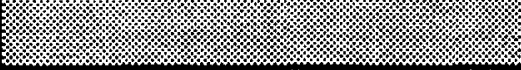 & 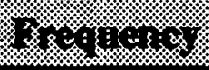 & 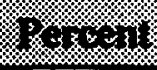 \\
\hline $2 \%$ & 81 & 29.3 \\
\hline (19-1 & 166 & 60.1 \\
\hline 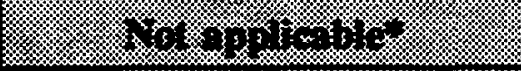 & 25 & 9.1 \\
\hline minsing & 4 & 1.5 \\
\hline$-10,3,1$ & 276 & 100.0 \\
\hline
\end{tabular}

"Respondents were not asked this question if they said "yes" to the DUIDWI question. 
TABLE A-9

\section{DISCRIMINANT ANALYSES}

\section{Non-Drinking Drivers vs. Current Drinking Drivers 18- to 29-year-olds}

\begin{tabular}{|c|c|c|c|c|}
\hline 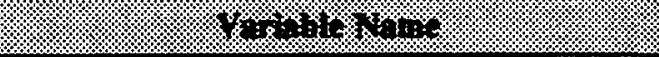 & 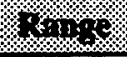 & 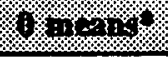 & 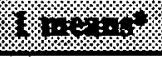 & 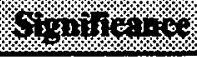 \\
\hline 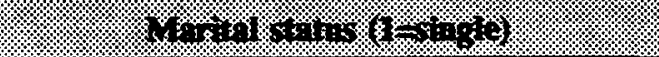 & $0-2$ & 1.806 & 1.495 & .0331 \\
\hline 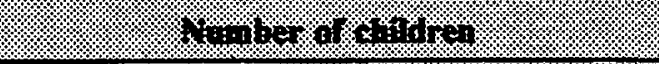 & none & .278 & .176 & .0336 \\
\hline 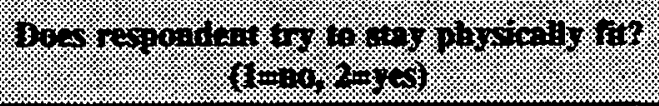 & $0-2$ & 1.889 & 1.805 & .0814 \\
\hline 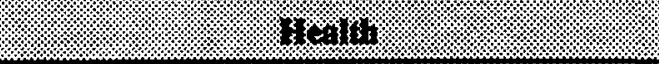 & $1-18$ & 13.500 & 12.195 & .0400 \\
\hline 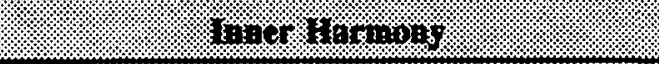 & $1-18$ & 10.083 & 8.963 & .0469 \\
\hline 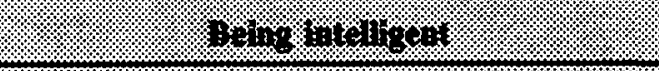 & $1-18$ & 11.111 & 9.226 & .0012 \\
\hline 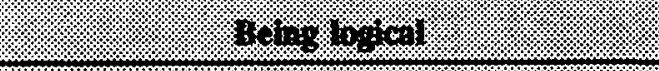 & $1-18$ & 8.444 & 7.658 & .0383 \\
\hline 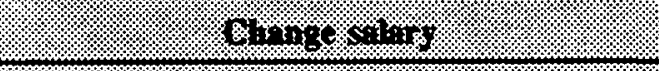 & $1-12$ & 6.222 & 5.053 & .0372 \\
\hline 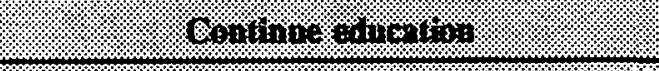 & $1-12$ & 5.333 & 4.847 & .0798 \\
\hline 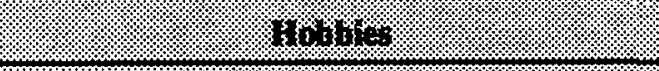 & $1-15$ & 8.556 & 7.763 & .0727 \\
\hline 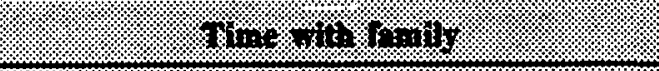 & $1-15$ & 7.833 & 6.884 & .0119 \\
\hline $\left.\log _{2}+x_{3}\right)$ & $1-10$ & 7.833 & 7.184 & .0814 \\
\hline 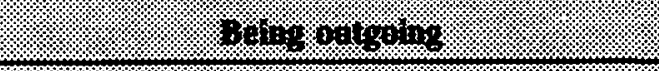 & $1-10$ & 4.972 & 4.484 & .0380 \\
\hline 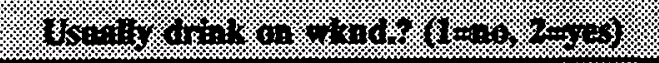 & $0-2$ & 1.472 & 1.674 & .0021 \\
\hline 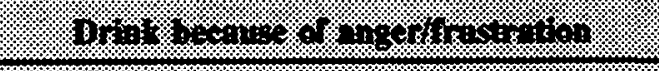 & $1-8$ & 3.000 & 3.084 & .0857 \\
\hline 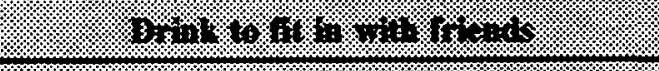 & $1-8$ & 3.000 & 3.200 & .0146 \\
\hline 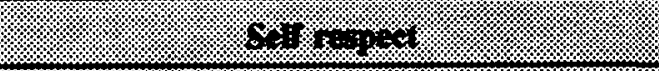 & $1-18$ & 10.083 & 11.295 & .0508 \\
\hline 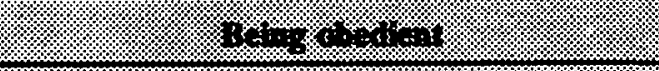 & $1-18$ & 7.000 & 7.274 & .0599 \\
\hline$(x+4=18$ & $1-18$ & 7.000 & 8.211 & .0000 \\
\hline 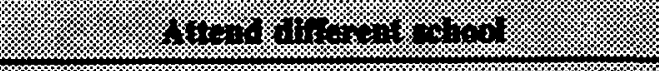 & $1-12$ & 4.000 & 4.147 & .0845 \\
\hline 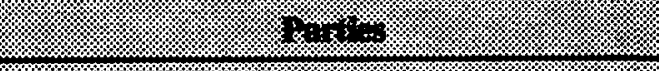 & $1-15$ & 6.000 & 6.316 & .0198 \\
\hline$\sqrt{1.1010}$ & $1-15$ & 6.000 & 6.326 & .0202 \\
\hline ; & $1-15$ & 6.611 & 7.189 & .0729 \\
\hline
\end{tabular}

* $0=$ Non-drinking drivers, $1=$ Current drinking drivers 
TABLE A-10

\section{DISCRIMINANT ANALYSES}

Comparison of Heavy Drinkers vs. Light Drinkers*

18- to 29-year-olds

\begin{tabular}{|c|c|c|c|c|}
\hline Yuraner The & 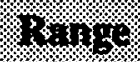 & 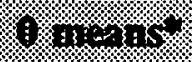 & 4 nenns? & 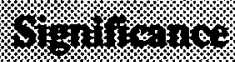 \\
\hline 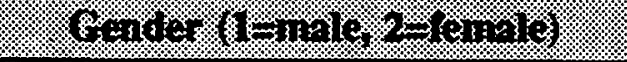 & $0-2$ & 1.556 & 1.368 & .0080 \\
\hline : & $18-29$ & 24.824 & 23.316 & .0004 \\
\hline 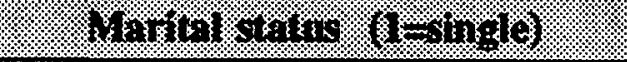 & $0-2$ & 1.324 & 1.171 & .0154 \\
\hline 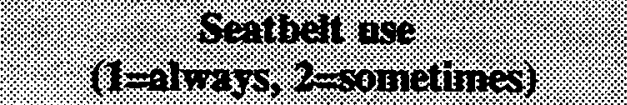 & $1-3$ & 1.232 & 1.474 & .0032 \\
\hline 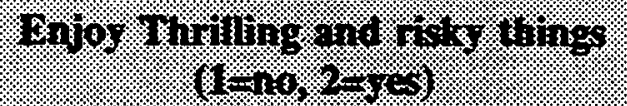 & $0-2$ & 1.634 & 1.750 & .0817 \\
\hline 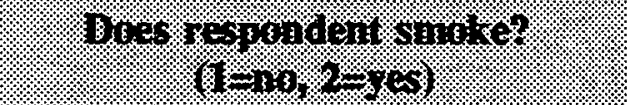 & $0-2$ & 1.183 & 1.303 & .0442 \\
\hline Bor ments ise & $0-2$ & 1.275 & 1.474 & .0031 \\
\hline 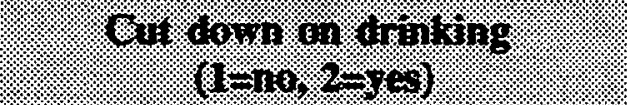 & $0-2$ & 1.472 & 1.737 & .0001 \\
\hline 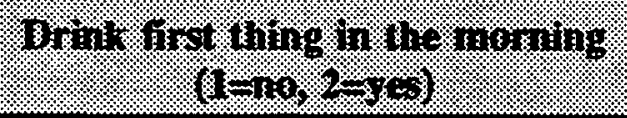 & $0-2$ & 1.120 & 1.263 & .0070 \\
\hline Pleasirse & $1-18$ & 7.634 & 8.342 & .0618 \\
\hline
\end{tabular}

* $0=$ light drinkers, $1=$ heavy drinkers 
TABLE A-11

\section{DISCRIMINANT ANALYSES}

\section{Self Reports of Intoxicated Driving*}

18- to 29-year-olds

\begin{tabular}{|c|c|c|c|c|}
\hline roringering & 3.8ng8 & 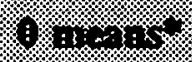 & 4 : & Gyeringenese \\
\hline 8.82 & $18-29$ & 23.203 & 24.597 & .0024 \\
\hline Pinor mint & $0-2$ & 1.559 & 1.712 & .0105 \\
\hline 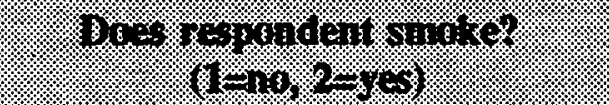 & $0-2$ & 1.102 & 1.245 & .0219 \\
\hline Ples:sirite & $1-18$ & 7.305 & 8.137 & .0467 \\
\hline
\end{tabular}

* $\quad 0=$ respondents who have never drunk enough alcohol then driven to be in trouble with the police if pulled over

$1=$ respondents who have drunk enough alcohol then driven to be in trouble with the police if pulled over 
TABLE A-12

\section{DISCRIMINANT ANALYSIS}

\section{Respondents Who Have Never Been Arrested for DUI/DWI}

vS.

Respondents Who Have Been Arrested for DUI/DWI

18- to 29-year-olds

\begin{tabular}{|c|c|c|c|c|}
\hline rorntue rone & $3 \%$ & 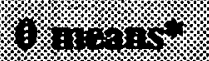 & $121.90 .0 .5^{2}$ & 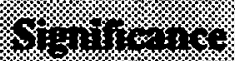 \\
\hline 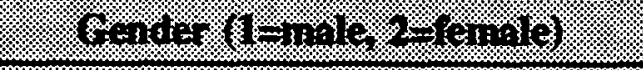 & $0-2$ & 1.525 & 1.208 & .0032 \\
\hline 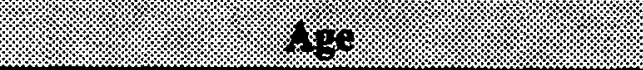 & $18-29$ & 24.167 & 25.625 & .0261 \\
\hline 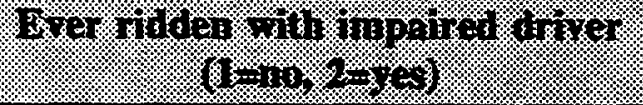 & $0-2$ & 1.616 & 1.917 & .0035 \\
\hline 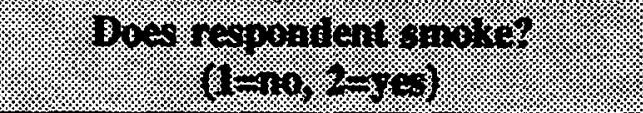 & $0-2$ & 1.207 & 1.375 & .0634 \\
\hline 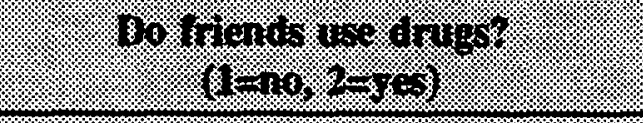 & $0-2$ & 1.318 & 1.583 & .0098 \\
\hline 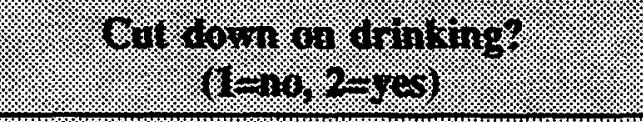 & $0-2$ & 1.530 & 1.833 & .0046 \\
\hline 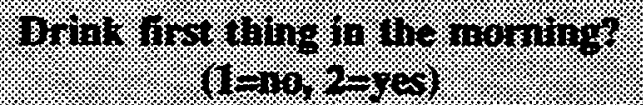 & $0-2$ & 1.131 & 1.458 & .0000 \\
\hline
\end{tabular}

* $\quad 0=$ respondents who have never been arrested for DUI/DWI

$1=$ respondents who have been arrested for DUI/DWI 
TABLE A-13

Parents' Occupations:

13- to 15-year-olds

\begin{tabular}{|c|c|c|c|}
\hline $2:=$ & vornes: & ranter & Trom \\
\hline 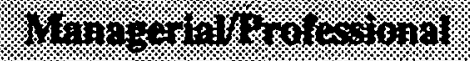 & $32(59.3 \%)$ & $29(53.7 \%)$ & $61(56.5 \%)$ \\
\hline 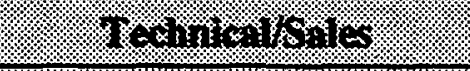 & $9(16.7 \%)$ & $7(13.0 \%)$ & $16(14.8 \%)$ \\
\hline 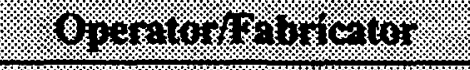 & $2(3.7 \%)$ & $9(16.7 \%)$ & $11(10.2 \%)$ \\
\hline 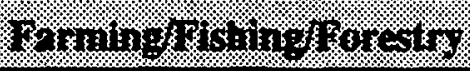 & $2(3.7 \%)$ & $4(7.4 \%)$ & $6(5.6 \%)$ \\
\hline Serpica & $3(5.6 \%)$ & $2(3.7 \%)$ & $5(4.6 \%)$ \\
\hline Tionenniver. & $4(7.4 \%)$ & 0 & $4(3.7 \%)$ \\
\hline 1010 . & $1(1.9 \%)$ & $2(3.7 \%)$ & $3(2.8 \%)$ \\
\hline 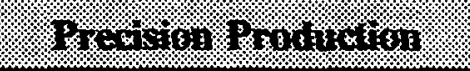 & 0 & $1(1.9 \%)$ & $1(.9 \%)$ \\
\hline Sunbert Unsure: & $1(1.9 \%)$ & 0 & $1(.9 \%)$ \\
\hline Total & $54(100.0 \%)$ & $54(100.0 \%)$ & $108(100.0 \%)$ \\
\hline
\end{tabular}

PLANS FOR THE FUTURE:

13- to 15-year-olds

\begin{tabular}{|c|c|c|}
\hline & Hogroging & Terberit \\
\hline Gizirio & 2 & $3.7 \%$ \\
\hline$[2618$ : & 48 & $88.9 \%$ \\
\hline erivin & 3 & $5.6 \%$ \\
\hline (II & 1 & $1.9 \%$ \\
\hline
\end{tabular}


TABLE A-14

First and Second Thing Respondent Values Most in Life:

13- to 15-year-olds

\begin{tabular}{|c|c|c|c|}
\hline & Trater & 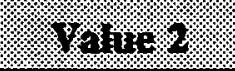 & Trowi \\
\hline Farnily & $33(61.1 \%)$ & $13(24.1 \%)$ & $46(85.2 \%)$ \\
\hline Triemas & $8(14.8 \%)$ & $19(35.2 \%)$ & $27(50.0 \%)$ \\
\hline inticic intints. & $2(3.7 \%)$ & $4(7.4 \%)$ & $6(11.1 \%)$ \\
\hline Irteningencerschool & $3(5.6 \%)$ & $2(3.7 \%)$ & $5(9.3 \%)$ \\
\hline (Ëminoytriens: & $1(1.9 \%)$ & $2(3.7 \%)$ & $3(5.6 \%)$ \\
\hline Masie: & $1(1.9 \%)$ & $2(3.7 \%)$ & $3(5.6 \%)$ \\
\hline Ure & $1(1.9 \%)$ & $2(3.7 \%)$ & $3(5.6 \%)$ \\
\hline Pets: & $1(1.9 \%)$ & $1(1.9 \%)$ & $2(3.8 \%)$ \\
\hline Tutures: & 0 & $2(3.7 \%)$ & $2(3.7 \%)$ \\
\hline Faith & $1(1.9 \%)$ & $1(1.9 \%)$ & $2(3.8 \%)$ \\
\hline Griag in a house & $1(1.9 \%)$ & $1(1.9 \%)$ & $2(3.8 \%)$ \\
\hline Irentin & $1(1.9 \%)$ & 0 & $1(1.9 \%)$ \\
\hline ear & $1(1.9 \%)$ & 0 & $1(1.9 \%)$ \\
\hline Fin & 0 & $1(1.9 \%)$ & $1(1.9 \%)$ \\
\hline oringr. & 0 & $1(1.9 \%)$ & $1(1.9 \%)$ \\
\hline Minsting & 0 & $3(5.6 \%)$ & $3(5.6 \%)$ \\
\hline To: & $54(100.0 \%)$ & $54(100.0 \%)$ & \\
\hline
\end{tabular}


TABLE A-15

Respondent by Qualities Looked for in a Friend:

13- to 15-year-olds

\begin{tabular}{|c|c|c|c|}
\hline & Fru Giantin & 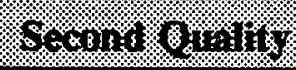 & inow \\
\hline 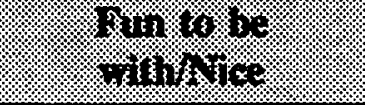 & $10(18.5 \%)$ & $18(33.3 \%)$ & $28(51.8 \%)$ \\
\hline thanest & $19(35.2 \%)$ & $4(6.4 \%)$ & $23(42.6 \%)$ \\
\hline 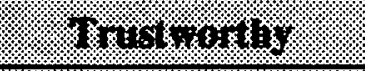 & $8(14.8 \%)$ & $6(11.1 \%)$ & $14(25.9 \%)$ \\
\hline $\begin{array}{l}\text { Carngluderstand } \\
\text { Ing }\end{array}$ & $6(11.1 \%)$ & $2(3.7 \%)$ & $8(14.8 \%)$ \\
\hline sense of him & $3(5.6 \%)$ & $4(7.4 \%)$ & $7(13.0 \%)$ \\
\hline Iroglyelingle. & 0 & $6(11.1 \%)$ & $6(11.1 \%)$ \\
\hline 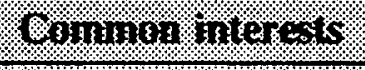 & $4(7.4 \%)$ & $2(3.7 \%)$ & $6(11.1 \%)$ \\
\hline Inteligent & $3(5.6 \%)$ & $1(1.9 \%)$ & $4(7.5 \%)$ \\
\hline 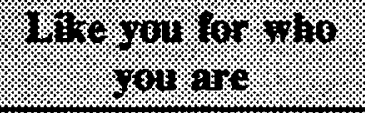 & 0 & $3(5.6 \%)$ & $3(5.6 \%)$ \\
\hline Goudiniterter. & 0 & $2(3.7 \%)$ & $2(3.7 \%)$ \\
\hline Gisiguming & 0 & $1(1.9 \%)$ & $1(1.9 \%)$ \\
\hline jogitin. & 0 & $1(1.9 \%)$ & $1(1.9 \%)$ \\
\hline 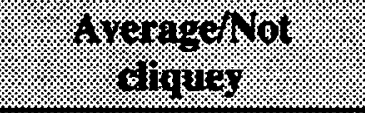 & 0 & $1(1.9 \%)$ & $1(1.9 \%)$ \\
\hline oniner. & $1(1.9 \%)$ & $2(3.7 \%)$ & $3(5.6 \%)$ \\
\hline 4hesing & 0 & $1(1.9 \%)$ & $1(1.9 \%)$ \\
\hline 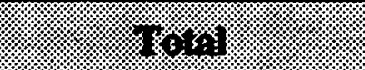 & $54(100.0 \%)$ & $54(100.0 \%)$ & \\
\hline
\end{tabular}


TABLE A-16

Male Respondents Rating of Rokeach Values:

13- to 15-year-olds

\begin{tabular}{|c|c|c|c|c|}
\hline & Yaros & Tature 2 & 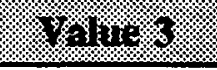 & Tom: \\
\hline Twiting his & $13(43.3 \%)$ & $1(3.3 \%)$ & 0 & $\begin{array}{c}14 \\
(46.6 \%)\end{array}$ \\
\hline 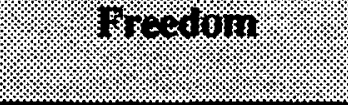 & $5(16.7 \%)$ & $7(23.3 \%)$ & 0 & $\begin{array}{c}12 \\
(40.0 \%)\end{array}$ \\
\hline greanu & 0 & $8(26.7 \%)$ & $4(13.3 \%)$ & $\begin{array}{c}12 \\
(40.0 \%)\end{array}$ \\
\hline True meroling & 0 & 0 & $9(30.0 \%)$ & $9(30.0 \%)$ \\
\hline Pleassire & 0 & $1(3.3 \%)$ & $5(16.7 \%)$ & $6(20.0 \%)$ \\
\hline Trivolon & 0 & 0 & $6(20.0 \%)$ & $6(20.0 \%)$ \\
\hline Cornfortante Lire & $5(16.7 \%)$ & 0 & 0 & $5(16.7 \%)$ \\
\hline 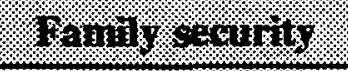 & $3(10.0 \%)$ & $1(3.3 \%)$ & $1(3.3 \%)$ & $5(16.6 \%)$ \\
\hline 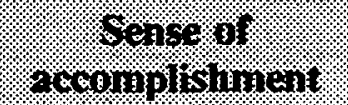 & $2(6.7 \%)$ & $2(6.7 \%)$ & 0 & $4(14.4 \%)$ \\
\hline 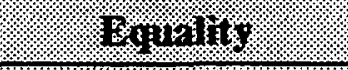 & 0 & $3(10.0 \%)$ & $1(3.3 \%)$ & $4(14.3 \%)$ \\
\hline 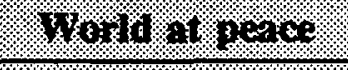 & $1(3.3 \%)$ & $2(6.7 \%)$ & 0 & $3(10.0 \%)$ \\
\hline Gefr respeat & 0 & $2(6.7 \%)$ & $1(3.3 \%)$ & $3(10.0 \%)$ \\
\hline inotid of bentiry & $1(3.3 \%)$ & $1(3.3 \%)$ & 0 & $2(6.6 \%)$ \\
\hline 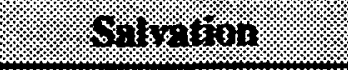 & 0 & $1(3.3 \%)$ & $1(3.3 \%)$ & $2(6.6 \%)$ \\
\hline 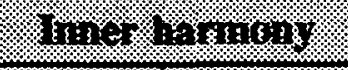 & 0 & 0 & $1(3.3 \%)$ & $1(3.3 \%)$ \\
\hline 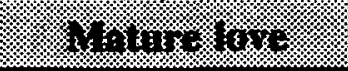 & 0 & $1(3.3 \%)$ & 0 & $1(3.3 \%)$ \\
\hline 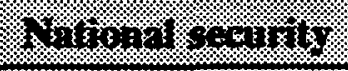 & 0 & 0 & $1(3.3 \%)$ & $1(3.3 \%)$ \\
\hline Social recrizinion & 0 & 0 & 0 & 0 \\
\hline 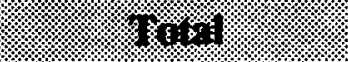 & $30(55.6 \%)$ & $30(55.6 \%)$ & $30(55.6 \%)$ & \\
\hline
\end{tabular}


TABLE A-17

Female Respondents Rating of Rokeach Values:

13- to 15-year-olds

\begin{tabular}{|c|c|c|c|c|}
\hline & Valiar 1 & Yinino 2 & 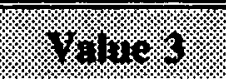 & Tom \\
\hline mir mandGip & 0 & $2(8.3 \%)$ & $12(50.0 \%)$ & $\begin{array}{c}14 \\
(58.3 \%)\end{array}$ \\
\hline Fining: & $5(20.8 \%)$ & $4(16.7 \%)$ & 0 & $9(37.5 \%)$ \\
\hline Jorid ar perce & $7(29.2 \%)$ & 0 & 0 & $7(29.2 \%)$ \\
\hline irentur. & $2(8.3 \%)$ & $3(12.5 \%)$ & $2(8.3 \%)$ & 7 (29.1\%) \\
\hline sertirespect & $1(4.2 \%)$ & $3(12.5 \%)$ & $3(12.5 \%)$ & $7(29.2 \%)$ \\
\hline $170.201 \%$ & $1(4.2 \%)$ & $4(16.7 \%)$ & $1(4.2 \%)$ & $6(25.1 \%)$ \\
\hline ofengire & 0 & $3(12.5 \%)$ & $2(8.3 \%)$ & $5(20.8 \%)$ \\
\hline Januily secrinits & $1(4.2 \%)$ & $2(8.3 \%)$ & $1(4.2 \%)$ & $4(16.7 \%)$ \\
\hline Dreiting life & $3(12.5 \%)$ & 0 & 0 & $3(12.5 \%)$ \\
\hline 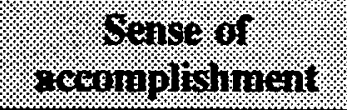 & $3(12.5 \%)$ & 0 & 0 & $3(12.5 \%)$ \\
\hline WE & 0 & 0 & $3(12.5 \%)$ & $3(12.5 \%)$ \\
\hline ULinge lore & 0 & $1(4.2 \%)$ & 0 & $1(4.2 \%)$ \\
\hline Social resognition & 0 & $1(4.2 \%)$ & 0 & $1(4.2 \%)$ \\
\hline 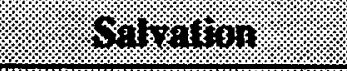 & 0 & $1(4.2 \%)$ & 0 & $1(4.2 \%)$ \\
\hline Wortis or beants & $1(4.2 \%)$ & 0 & 0 & $1(4.2 \%)$ \\
\hline 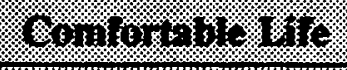 & 0 & 0 & 0 & 0 \\
\hline 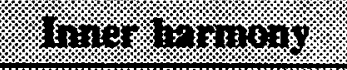 & 0 & 0 & 0 & 0 \\
\hline 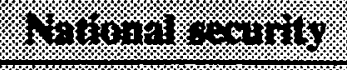 & 0 & 0 & 0 & 0 \\
\hline 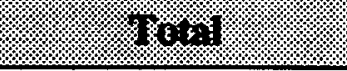 & $24(44.4 \%)$ & $24(44.4 \%)$ & $24(44.4 \%)$ & \\
\hline
\end{tabular}


TABLE A-18

\section{How Often Does Subject Drink?}

13- to 15-year-olds

\begin{tabular}{|c|c|c|}
\hline 2 & Tryageris: & 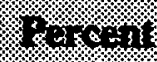 \\
\hline $28=6 \ln 3 x$ & 25 & 46.3 \\
\hline (6) & 5 & 9.3 \\
\hline 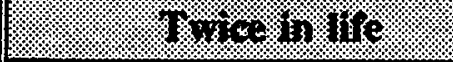 & 5 & 9.3 \\
\hline Three times in life & 3 & 5.5 \\
\hline Tour tines ln lie & 2 & 3.7 \\
\hline 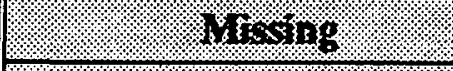 & 14 & 25.9 \\
\hline & 54 & 100 \\
\hline
\end{tabular}


TABLE A-19

What Respondent Would Worry About if He/She Drank A Lot:

13- to 15-year-olds

\begin{tabular}{|c|c|c|}
\hline & Trequenty & Percent \\
\hline 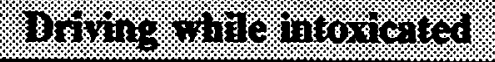 & 25 & $46.3 \%$ \\
\hline Geting n trombe niti & 13 & $24.1 \%$ \\
\hline 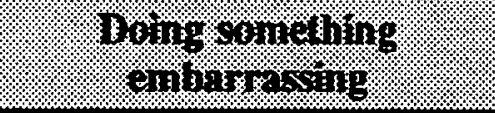 & 2 & $3.7 \%$ \\
\hline 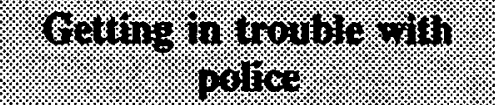 & 2 & $3.7 \%$ \\
\hline ITriting sorneorne else & 2 & $3.7 \%$ \\
\hline 3entwin & 2 & $3.7 \%$ \\
\hline Getting sick & 1 & $1.9 \%$ \\
\hline Gaving a hangorer & 1 & $1.9 \%$ \\
\hline "Hoing somelling & 1 & $1.9 \%$ \\
\hline Boing onneringe on of & 1 & $1.9 \%$ \\
\hline 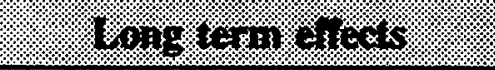 & 1 & $1.9 \%$ \\
\hline 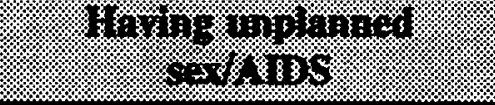 & 1 & $1.9 \%$ \\
\hline 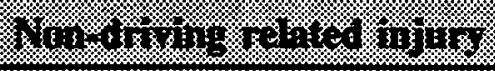 & 1 & $1.9 \%$ \\
\hline 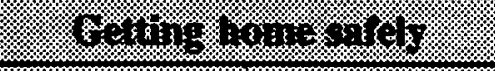 & 1 & $1.9 \%$ \\
\hline ;: & 54 & $100.0 \%$ \\
\hline
\end{tabular}




\section{APPENDIX B \\ DISCUSSION GUIDES}

Location:

D.C. Area

Site 1

Site 2

Discussion Guide

for

One-on-One Discussions

18-29 year olds

\section{BACKGROUND/DEMOGRAPHICS}

1. Gender:

$\mathrm{M}$

F

2. Age

First, I'd like you to tell me a little bit about yourself:

3. Occupation

$$
\text { (Job you do) }
$$

Blue collar

White collar

4. Are you currently employed full time, part time, unemployed and looking for work, retired, going to school, homemaker or something else?

Check all that apply:

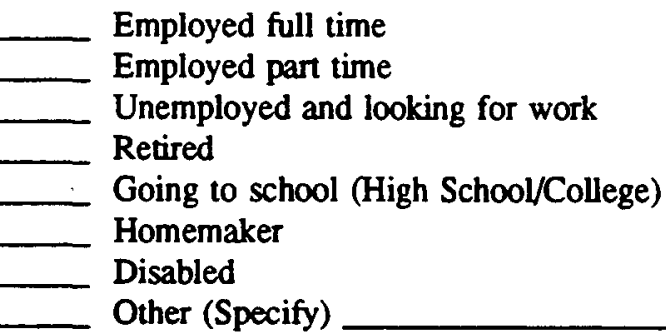

5. Are you currently married, living with someone, divorced, separated, widowed, or single?

$\begin{array}{ll} & \text { Single } \\ & \text { Married } \\ & \text { Living with girlfriend/boyfriend } \\ & \text { Divorced } \\ & \text { Separated } \\ \text { Widowed }\end{array}$

6. Do you have any children?

No

Yes

How many? 
7. Who do you live with? (Record Number)

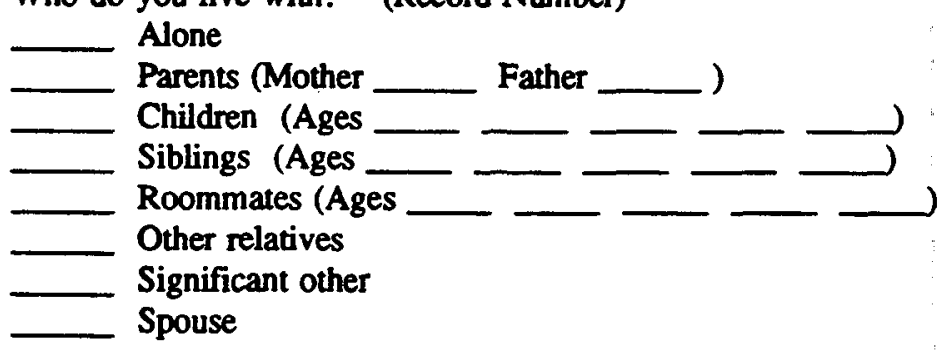

8. Household Income: (Include individual income and that of spouse, only.)

(If student under 21 years old is living at home, include parents income, if known.)

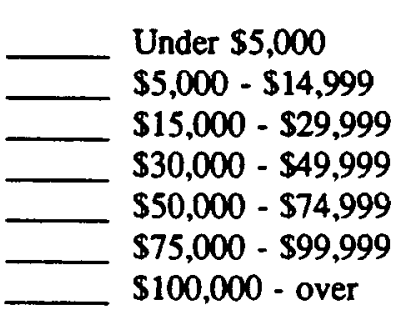

9. What sort of place do you live in?

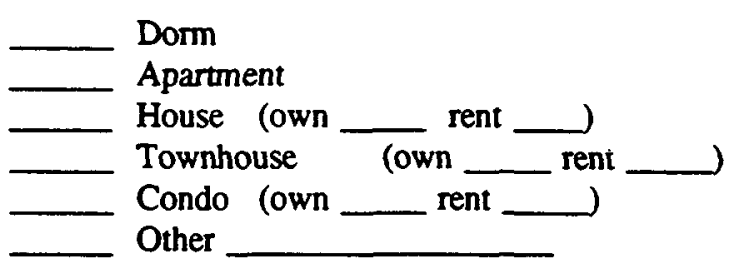

10. What is the highest grade or year of regular school you have completed?
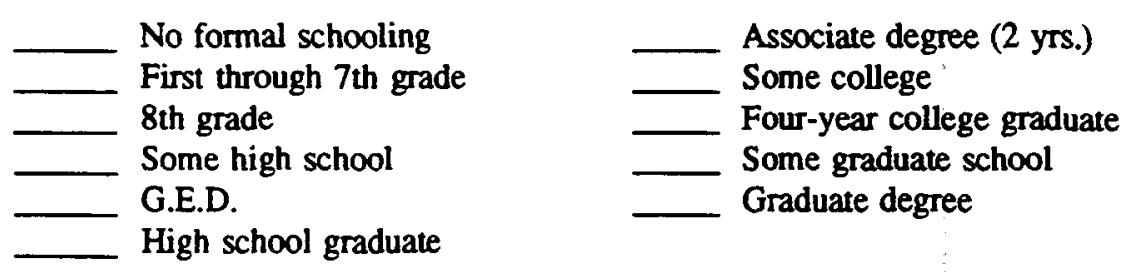

11. What is your racial background?

Caucasian

Black

- Hispanic

Asian or Pacific Islander

Other

12. What is your ethnic background? (i.e., Irish, Polish, etc.)

13. Parent's Occupation: (Even if deceased or retired)

Mother

Father 


\section{VALUES}

Now I am going you ask you some questions about what parts of life sre most important to you.

1) What are the three qualities or characteristics that you look for most in a friend?
1)
2)
3)

2) If you could change three things about your life or yourself, (life circumstances or personal attributes) what would they be?

1)

4) Not change anything
2)

3)

3) What are three things about yourself that you think are most admirable?

1)

3)

4) Has there been any one particular person in your life that you admire and what do you or did you admire about that person?

5) Is there anyone else you particularly admire, and why?

6) What three things do you value the most in your life? (What or who is most important to you?)
1)
2)
3)

7) What would you like to be doing in ten years?

(personally and professionally/with regard to work)

Ten Years

Personally:

Professionally:

8) In general, do you think that people have control over what happens in their lives or do you think it is a marter of luck?

Luck

Control

Both

8a) What makes you feel that way?

9) Do you feel your life is too structured by rules and expectations of others?

No _ Y Yes

(If yes:)

9a) When you feel this way, is there anything in particular you do?

9b) Do you ever drink alcohol when you feel confined by rules and expectations?

No 
Code \#

Now I'd like you to take a few minutes to select five items from this list of values. Rank them in order of importance to YOU, as guiding principals in YOUR life. Study the list carefully and pick out the one value which is the most important to you. Mark a "1" to the left of this value. Then pick out the value that is second most important to you. Mark a "2" to the left. Do this for a total of 5 values. If you change your mind, feel free to change your answers. The end result should show how you really feel.

A COMFORTABLE LIFE (a prosperous life)

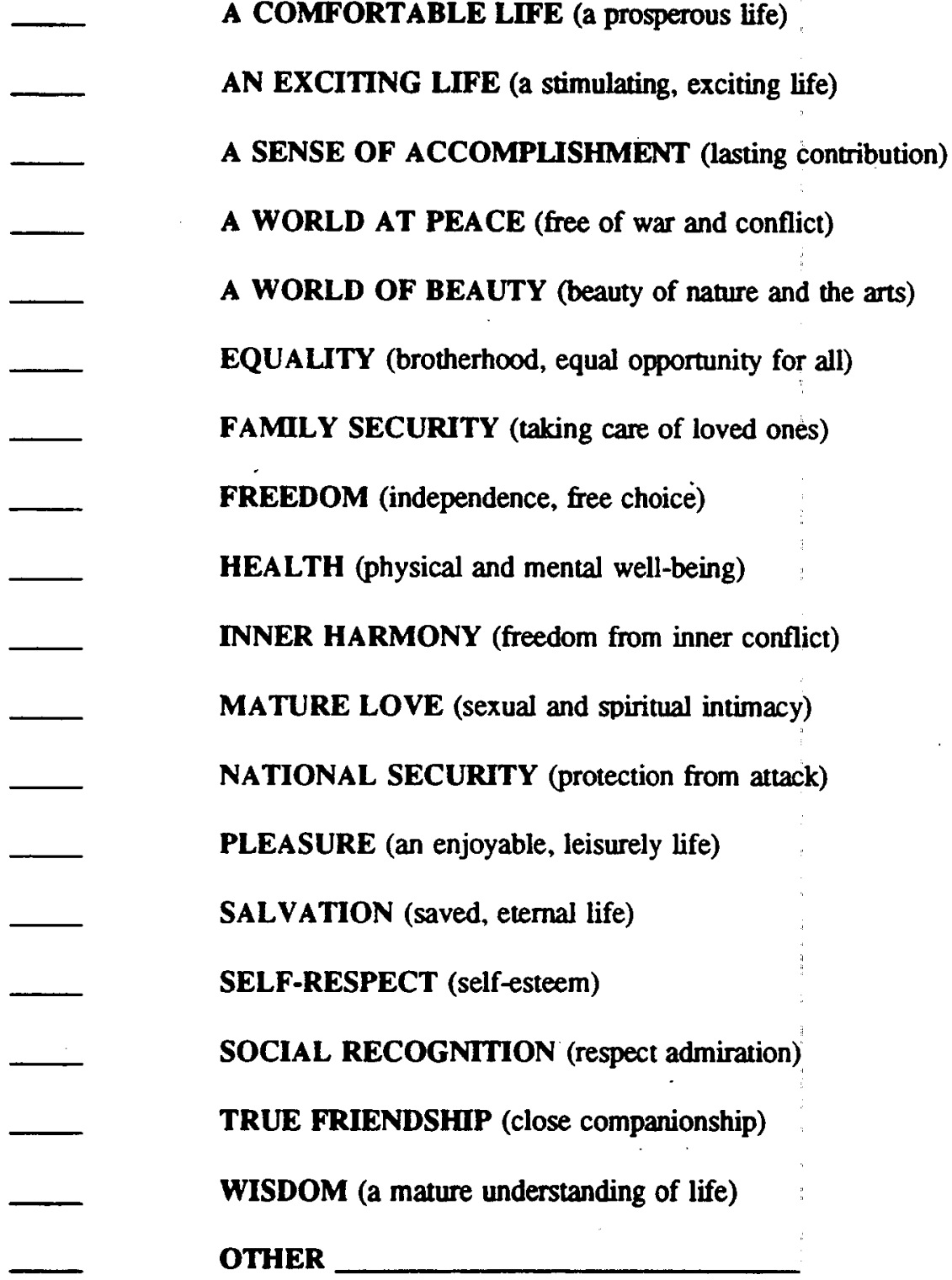

Take each of the five values in order and ask:

What does mean to you. (Why is it important to you?)

1.

2.

3.

4.

5. 
Code \#

Now here is another list of characteristics you might value. Again, select 5 and number them in order of importance, the same as before.

\begin{tabular}{|c|}
\hline AMBITIOUS (hand-working, aspiring) \\
\hline BROADMINDED (open-minded) \\
\hline CAPABLE (competent, effective) \\
\hline CLEAN (neat, tidy) \\
\hline COURAGEOUS (standing up for your beliefs) \\
\hline FORGIVING (willing to pardon others) \\
\hline HELPFUL (working for the welfare of others) \\
\hline HONEST (sincere, truthful) \\
\hline IMAGINATIVE (daring, creative) \\
\hline INDEPENDENT (self-reliant, self-sufficient) \\
\hline INTELLECTUAL (intelligent, reflective) \\
\hline LOGICAL (consistent, rational) \\
\hline LOVING (affectionate, tender) \\
\hline LOYAL (faithful to one's friend, group) \\
\hline OBEDIENT (dutiful, respectful) \\
\hline POLITE (courteous, well-mannered) \\
\hline RESPONSIBLE (dependable, reliable) \\
\hline SELF-CONTROLLED (restrained, self-disciplined) \\
\hline OTHER \\
\hline
\end{tabular}

Take each of the five characteristics in order and ask:

What does mean to you. (Why is it important to you?)

1.

2.

3.

4.

5. 


\section{LEISURE ACTIVITIES}

Now I have some questions about how you spend your spare time.

10) Of the various things you do, what would you say are the three you enjoy the most?
1.
2)
3)

11) What about these things do you really enjoy?

1.

2)

3)

12) Is there any activitiy that you do because you are good at it and because it makes you feel good about yourself?

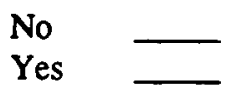

12a) If yes, what?

13) Do you enjoy driving because you think you're good at it?

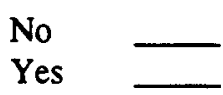

14) Do you ever drive just for fun?

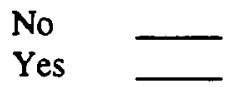

15) What kinds of things do you think are fun to do when you are driving?

(i.e., going fast)

(Ask \#16, if appropriate given answer to \#15)

16) Do you do these/this thing(s) after you have been drinking?

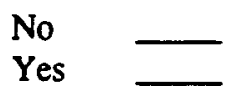

16a) How about your friends, do they ever do that?

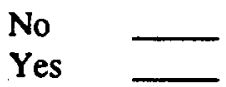

17) Do you like to do (other) things that are thrilling and risky?

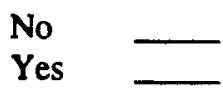

17a) Like what? 
18) Do you wear a seatbelt when in a car?

All the time

Sometimes

No

When?

19) Do you smoke on a regular basis?

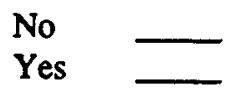

(If yes:)

19a) How old were you when you first started smoking?

19b) Any particular reason why you started smoking?

20) Do you make any special efforts to stay physically fit?

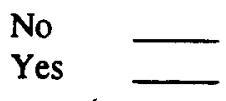

20a) What?

20b) Why? (Probe for: looking good vs. health, longevity)

21) Describe the last party you went to:

22) Describe your idea of an "ideal" party:

23) Now, can you tell me about a typical Friday or Saturday night?

23a) Probe: Do you usually drink alcohol on a typical Friday or Saturday night? If NO, how often do you drink on weekends? (i.e., four times per year)

YES

23b) What do you usually drink?

23c) How much?

23d) Where do.you drink?

23e) Who do you drink with?

23f) How do you get there?

23g) How do you get home?

23h) Who usually drives? 
24) FOR 18-20 YEAR OLDS: How do you get access to alcohol? (For 21 years and older, skip to Q25.)

24a) Do your parents know you drink?

If NO, what would they think if they knew?

If YES, how do they feel about it?

24b) Do your parents know how much you drink?

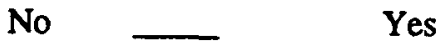

(FOR EVERYONE)

25) Do you usually drink alcohol at other times (besides Friday or Saturday nights)?

No _ Yes

(If yes:)

25a) When?

25b) How much?

25c) Where do you drink?

25d) Who do you drink with?

25e) How do you get there?

25f) How do you get home?

25g) Who usually drives?

26) Is there drug use among your group of friends?

No $\quad$ Yes

26a) What drugs do they usually use?

26b) How often is it used?

26c) Do your friends drive after using ?

No $\longrightarrow$ Yes

26d) Do they drink alcohol along with ?

No - Yes 


\section{DRINKING PATTERNS}

Now I have some more questions about how alcohol fits into your life.

27) (Based on previous answers, select relevant time frame for this individual:)

How many drinks or beers would you have in an avg. week, including the weekend?

How many drinks or beers would you have in an average month?

How many drinks or beers would you have in an average year?

28) How many drinks would you usually have at one time?

29) Have your drinking habits changed over the last few years?

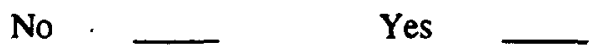

29a) (If yes) In what ways?

29b) What do you think are the reasons for the change?

30) Do you enjoy the feeling you get when drunk or high on alcohol?
No
Yes
Sometimes

30a) What about it do you enjoy/dislike (circle one)?

31) What is your main reason for drinking?

32) Rank in order of importance your reasons for drinking. Pick three. (Show list.)

The options are:

To experiment -- to see what it's like

To relax or relieve tension

To feel good or get high

To seek deeper insights and understanding

To have a good time with my friends

To fit in with a group I like

To get away from my problems or troubles

Because of boredom, nothing else to do

Because of anger or frustration

To get through the day

To increase the effects of some other drug(s)

To decrease (offset) the effects of some other drug(s)

To get to sleep

Because it tastes good

Because I am "hooked" - I feel I have to drink 
33) Do others affect the amount of alcohol you consume (i.e., friends, parents, members of the opposite sex, other people in the setting)?

33a) Who?

33b) In what way?

34) Are there ever times, on evenings or weekends, when you decide not to drink?

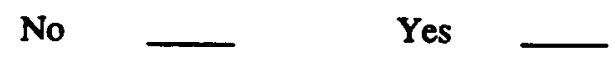

34a) What are your reasons for not drinking?

35) Is it important for you to drink in order to fit in with your friends?

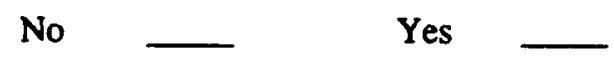

35a) If you didn't drink, what would happen to your social life?

36) Have you ever felt the need to cut down on your drinking?

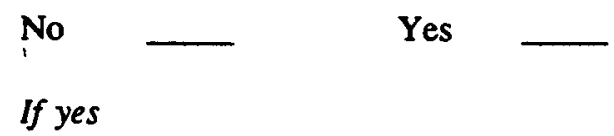

Tell me about that.

37) Have people annoyed you by criticizing your drinking?

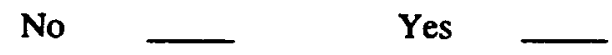

(If yes) Tell me about that.

38) Have you ever felt bad or guilty about your drinking?

No _ Yes

(If yes) Tell me about that.

39) Have you ever had a drink first thing after waking up?

No Yes

(If yes) Tell me about that. 
40) Are there people in your circle of friends who you think have a drinking problem?

No $\longrightarrow$ Yes

(If yes) How do you feel about that?

41) Are there members of your immediate family who you think have a drinking problem?

No Y Yes

(If yes) How do you feel about that?

42) If you were to have a lot to drink (at one sitting), would you have any particular worry or concem about something that could happen as a result? (Let respondent provide their own answer. If they cannot think of any, read the list and ask them which one would be of most concern. If they provide one, probe for a couple of other priority concerns listed below.)

Do something embarrassing

Get sick

Have a hangover

Do something dangerous

Let someone else get you to do something you wouldn't ordinarily do?

Become addicted

Drive while intoxicated

42a) Do you do anything to keep something like that from happening?

43) What is the worst thing that ever happened to you or someone you know when they had been drinking? Tell me about that situation.

43a) (If a drunk driving situation, check here and see probe list.)

43b) Respondent Someone Else 


\section{DRINKING AND DRIVING}

44) Have you ever been arrested for DUI, DWI OR been involved in any alcohol related crash as the driver (whether or not ticketed or arrested?)(May have already answered.)

No $\quad$ Yes

If no, go to $Q 45$.

If yes, probe:

44a) When was that? (How long ago?)

44b) Where were you drinking?

44c) With whom?

44d) Had they been drinking, too?

No $\quad$ Yes

44e) Do you think they were any more sober than you?

No $\quad$ Yes

44f) Do you remember what went through your mind when you made the decision to

drive?

$44 \mathrm{~g}$ ) Did you consider any altematives to driving yourself?

44h) Yes $\quad$ No What?

44i) Why didn't you do that?

44j) Were you worried about anything that might happen while you were driving?

44k) Yes $\quad$ No What?

441) Did you do anything to make it safer for you to be driving?

N4m) Yes _ What?

44n) How did you feel about yourself after incident?

IF RESPONDENT ANSWERED "YES" TO Q44, SKIP Q45-46, AND GO TO Q47

45) Have you ever driven after drinking so much that you thought you might be in trouble with the police if you were stopped?

No _ Y Yes 
If yes, probe:

45a) Tell me about the last time you drove after drinking that much.

45b) When was that? (How long ago?)

45c) Where were you drinking?

45d) With whom?

45e) Had they been drinking, too?

45f) Do you think they were any more sober than you?

No

Yes

45g) Did you consider any altematives to driving yourself?

45h) Yes What?

45i) Why didn't you do that?

45j) Did you do anything to make it safer for you to be driving?

45k) Yes $\quad$ What?

451) Do you remember what went through your mind when you made the decision to

45m) Were you worried about anything that might happen while you were driving?

45n) $\quad \begin{aligned} & \text { Yo } \\ & \text { Yes What? }\end{aligned}$

If yes to $Q 45$, skip to $Q 47$

46) In general, if you drove after drinking, would you worry that something might happen as result?

46a) Yes What?

(Let them answer, then probe for two additional items of most concern.)

Personal injury to self?

Personal injury to others?

Damage to your car from a collision?

Financial repercussions of collision (repairs \& insurance increase?)

Embarrassment over arrest?

Financial repercussions of arrest? (lawyer, fines)

Loss of license?

Trouble with parents or significant others?

Death? 
47) Have you ever ridden with someone who you thought was too drunk to drive?

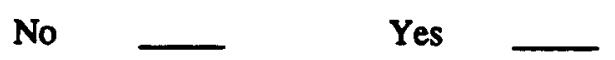

47a) If yes, pick one situation that stands out in your mind and describe it.

47b) Did you consider any alternatives for getting to your destination another way?

No
Yes What?

47c) Why didn't you do that?

48) Have you ever avoided riding with someone who you thought was too drunk to drive?
No
Yes

48a) If yes, pick one situation that stands out in your mind and describe it.

49) (If applicable) N/A

On a night when you know you are going to be drinking, do you ever make plans ahead of time (before you go out or before you start drinking) to try to prevent a situation where you have had too much to drink and have to drive home?

49a) Yes — (If yes) What and why? (May have already answered)

50) In your social group, do you ever use a designated driver?

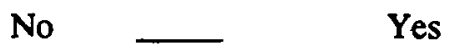

(If yes:)

50a) Do you take turns being the designated driver or is it usually the same person?

Take turns __ Same person

50b) Does the person who drives drink at all?

No

Yes If "yes", how much?

51) (If applicable) N/A

Have you ever left your car somewhere because you thought you had had too much to drink and gotten home some other way?

51a) No _ (If no) What kept you from doing that?

51b) Yes — (If yes) How did you get home? 
(If applicable) NIA

Have you ever spent the night somewhere, at a friend's house, for example, when you had had too much to drink and didn't want to drive home?

52a) No What kept you from doing that?

52b) Yes — (If yes, describe the situation.)

53) Have you ever prevented someone else from driving after drinking? (May have answered)

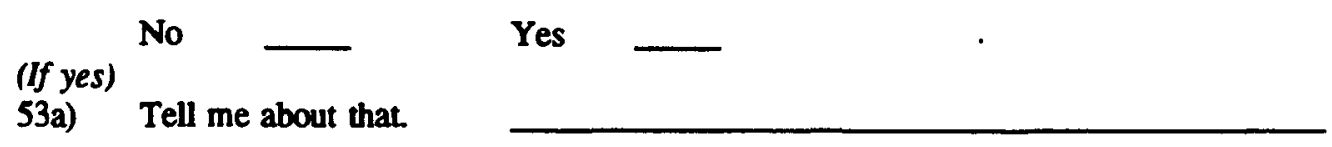

(If necessary probe for the following)

53b) Age of person?

53c) Gender of person:

53d) Was the person: A close friend

53e) How did you do that?

53f) What happened?

53g) How did you feel about doing it?

55) What do you think about alcohol-free activities like "sober prom or graduation" celebrations? What makes events like this attractive/unattractive?

56) Do you and your friends ever discuss drinking and driving?

No

(If yes)

56a) What is generally discussed?

56b) Do you and your family ever discuss drinking and driving?

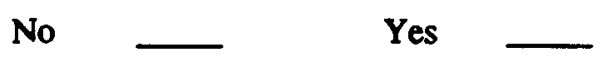

(lf yes)

56c) What is generally discussed?

57) Sometimes when faced with a difficult situation, people don't do what they actually believe is the right thing to do. This happens a lot when people drive after drinking. They believe that driving while impaired is wrong, but they do it anyway. Why do you think that is?

58) If there were no laws against drunk driving, what do you think you would do?

Would your habits change?

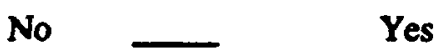

58a) Why? 


\section{COUNTERMEASURE IDEAS}

Say: This is the last question.

59) Can you think of any good ways to keep people from drinking and driving - Like, what kinds of things would you think would be effective with you and your friends?

(If interviewee can't think of any ideas, probe: Think of your best friend, what would work with him/her?)

\section{DEBRIEFING/GENERAL IMPRESSIONS}

1) I'd like to know your impression of this discussion. Did we successfully find out what things are really important to you in your life? (What drives this person?)

Yes

No

If no,

What else should we know about how you feel?

2) May we contact you for other studies?

Yes

No

Note to researcher:

After completing the discussion, briefly describe your general impressions of the person and how the discussion went. Summarize your impressions and especially note impressions not captured by the questions. 
Discussion Guide

for

One-on-One Discussions

13- to 15-year-olds

Madison, WI

Code Number

Researcher

Date

\section{BACKGROUND/DEMOGRAPHICS}

1. Gender:

M

First, I'd like you to tell me a little bit about yourself:

2. Age

3. Grade in School

4. Average Grades or GPA

5. Part-time job, if any

6. Who do you live with?

(Record Number)

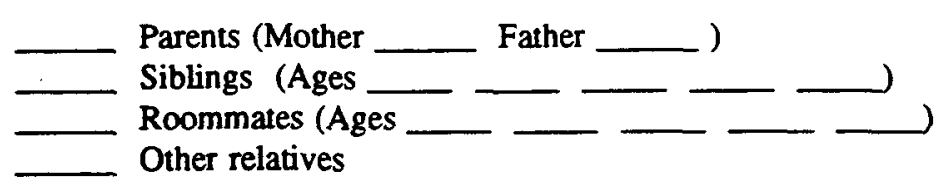

10. What is your racial background?

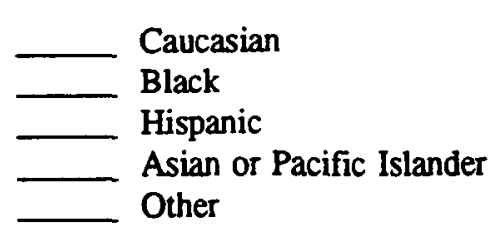

11. What is your ethnic background? (i.e., Irish, Polish, etc.)

12. Parent's Occupation: (Even if deceased or retired)

(Try to get enough info. to determine if BC or WC)

Mother

Father

\section{VALUES}

Now I am going you ask you some questions about what parts of life are most important to you.

1) What are two qualities or characteristics that you look for most in a friend? (May need to provide an example)

1) 
2) If you could change one thing about your life $O R$ yourself, what would it be?

3) Has there been any one particular person in your life that you admire and what do you or did you admire about that person?

4) What two things do you value the most in your life? (What or who is most important to you?)

1)

5) What do you plan on doing after high school?

(Let respondent answer on own. Fill in codes below)

\section{Don't know}

College

Get a job (type of job if noted)

Get married

Other

Now I'd like you to take a few minutes to check three items from this list of values that are most important to you.

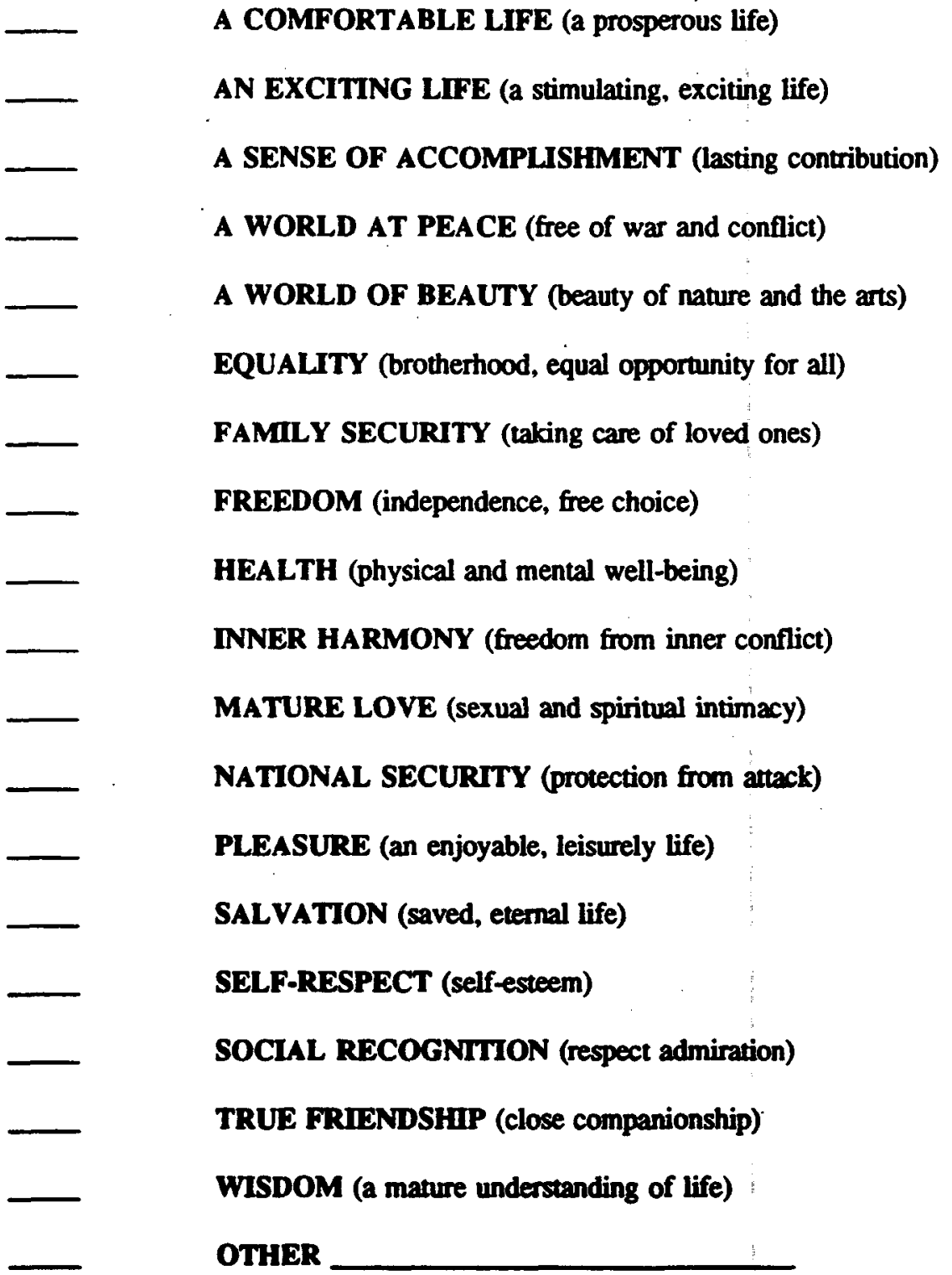


Now here is another list of characteristics you might value. Again, check three that are most important to you.

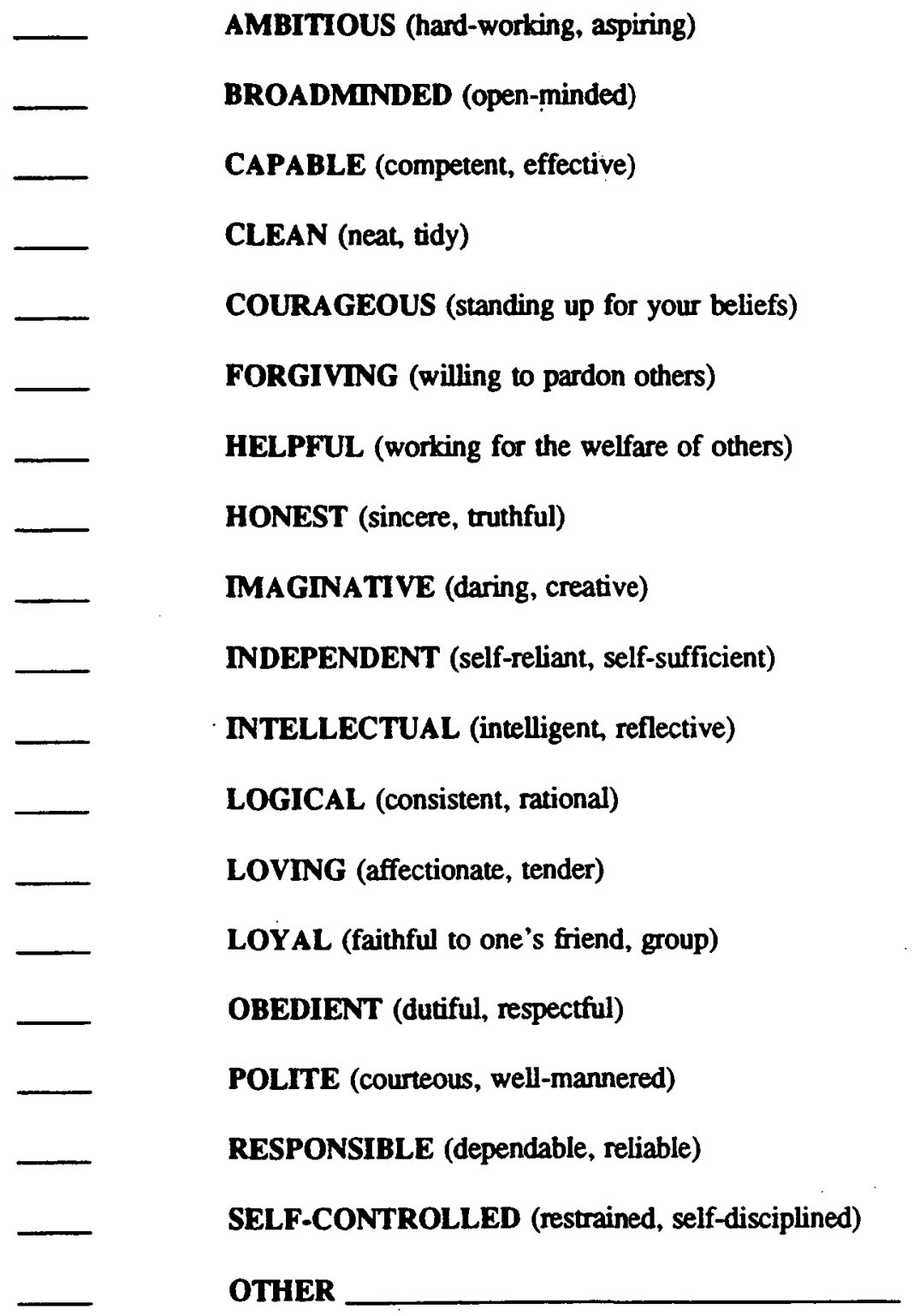




\section{LEISURE ACTIVITIES}

Now I have some questions about how you spend your spare time.

6) Do you like to do things that are thrilling and risky?

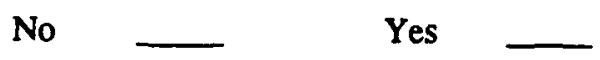

6a) Like what?

7) Do you wear a seatbelt when in a car?

All the time

Sometimes

No

When?

8) Do you smoke on a regular basis?

No Y Yes

(If yes:)

8a) How old were you when you first started smoking?

8b) Any particular reason why you started smoking?

9) Now, can you tell me what you usually do on Friday or Saturday night?

9a) Probe: Do you usually drink alcohol on weekends? How about other times? If NO, how often do you drink? (e.g., four times per year)

9b) _ YES, how often do you drink? (e.g., every weekend, twice per month?)

(FOR NON-DRINKERS AND EXPERIMENTERS - those who have tried drinking four times or less, SKIP TO PAGE 11)

9c) What do you usually drink?

9d) How much at one time? (usually)

9e) Where do you drink?

9f) Who do you drink with?

$9 \mathrm{~g}$ ) How do you get there?

9h) How do you get home?

9i) Who usually drives?

10) How do you get access to alcohol? 
11) Do your parents know you drink? If NO, what would they think if they knew? If YES, how do they feel about it?

\section{DRINKING PATTERNS (Drinkers)}

Now I have some more questions about how alcohol fits into your life.

12) What is the most you have ever had to drink at one time?

12a) How old were you at that time?

12b) Describe that situation. (Include transportation arrangements)

13) What is your main reason for drinking?

14) If you didn't drink, what would happen to your social life? What would your friends think?

\section{DRINKING PATTERNS (NON-DRINKERS AND EXPERIMENTERS)}

15) Do any of your (close) friends drink on a regular basis?

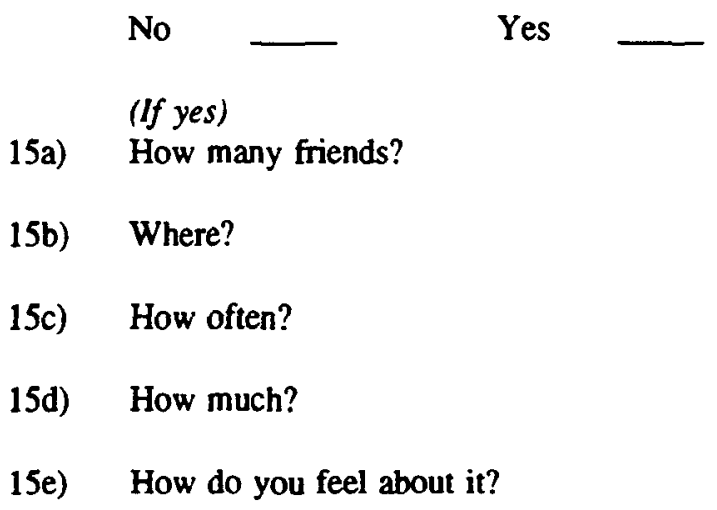

15e) How do you feel about it?

15a) How many friends?

15b) Where?

15c) How often?

15d) How much?

16) How do you feel about other kids at your school who drink?

17) What would your friends think if you drank? What would happen to your social life?

18) How would your parents feel if you drank alcohol? 


\section{DRINKING ATTITUDES AND EXPERIENCES (For Everyone)}

19) Have you had any type of class in school or elsewhere about drugs or alcohol or about impaired driving?

No

$$
\text { Yes }
$$

Describe: (type, topics covered, who taught it, when, length)

20) (For 15 year olds)

Have you had or are you in Driver's Education?

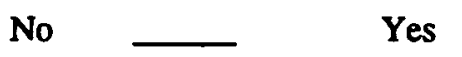

21) Do you have friends who drive?

No

$$
\text { Yes }
$$

(If yes to $Q 21$ )

22) Of your friends who drive, do any of them drive after drinking?

No

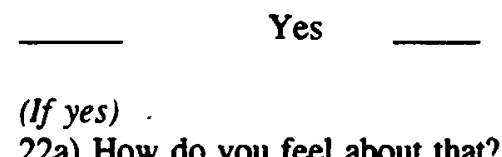

22a) How do you feel about that?

23) Compared to your friends, would you say you drink more, less or about the same?
More
Less
About the same

24) Compared to most other people your age (in general), would you say you drink more, less or about the same?
More
Less
About the same

25) Do your parents drink alcohol?

No Y Yes

(If yes)

25a) How often?

25b) How much?

26) Do your brothers or sisters drink alcohol?
No ' Yes
(Note ages of siblings
(If yes)
26a) How often?
26b) How much? 
27) If you were to have a lot to drink at one time, what would be the number one thing you would worry about happening as a result? (Let respondent provide their own answer. If they cannot think of any, give an example e.g., "making a fool of yourself" or "getting sick." Code appropriately below)

Do something embarrassing

Get sick

Have a hangover

Do something dangerous

Let someone else get you to do something you wouldn't ordinarily do?

Become addicted

Drive while intoxicated

a) personal injury to self

b) personal injury to others

c) damage to car

d) being arrested

e) financial repercussions

f) death

Get into trouble with parents

Get into trouble with police

Get into trouble with coach

Other

\section{(Drinkers only)}

28a) Do you do anything to keep something like that from happening? (Drinkers only)

29) What is the worst thing that ever happened to you or someone you know when they had been drinking? Tell me about that situation.

29a) (If a drunk driving situation, check here and see Probe List.)

29b) Respondent

Someone Else

Probe List (Modify questions if someone else was in the drunk driving situation. Respondent may not know much about the details.)

When was that? (How long ago?)

Where were you drinking?

With whom?

Had they been drinking, too?

Do you think they were any more sober than you?

Do you remember what went through your mind when you made the decision to drive?

Did you consider any alternatives to driving yourself?

Why didn't you do that?

Were you worried about anything that might happen while you were driving?

Did you do anything to make it safer for you to be driving?

How did you feel about yourself after incident? 


\section{DRINKING AND DRIVING (for everyone)}

30) How many people do you know have ever been arrested for DUI or DWI OR been involved in an alcohol related crash (whether or not ticketed or arrested?)

(\#)

31) Have you ever ridden with someone who you thought was too drunk to drive?

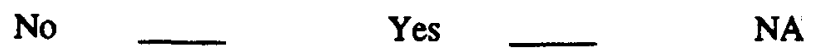

31a) If yes, pick one situation that stands out in your mind and describe it.

31b) Did you consider any alternatives?

31c) Yes What?

31d) Why didn't you do that?

31e) Were you worried about anything that might happen?

No
Yes What?

32) Have you ever avoided riding with someone who you thought was too drunk to drive?

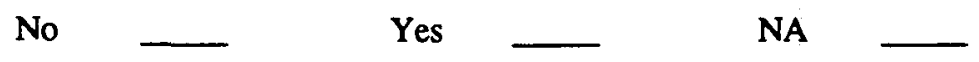

(If yes)

32a) Pick one situation that stands out in your mind and describe it.

33) What do you think is the best way to prevent someone else from driving after they have had too much to drink? (May have already answered)

34) In your group of friends, do you ever use a designated driver? (may have already answered)

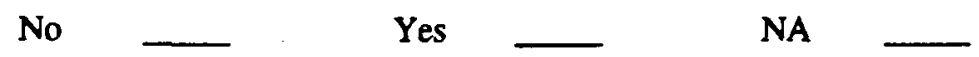

(If yes:)

34a) Tell me how your group does that.

35) Do you and your friends ever discuss drinking and driving?

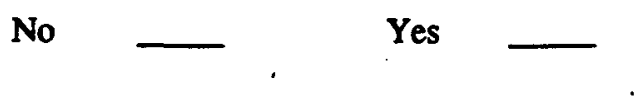

(If yes)

35a) What is generally discussed?

35b) Do you and your family ever discuss drinking and driving?

No

(If yes)

35c) What is generally discussed? 


\section{COUNTERMEASURE IDEAS}

Say: This is the last question.

36) Can you think of any good ways to keep people from drinking and driving -- Like, what kinds of things would you think would be effective with you and your friends?

(If interviewee can't think of any ideas, probe: Think of your best friend, what would work with him/her?)

\section{DEBRIEFING/GENERAL IMPRESSIONS}

1) Do you have any questions about this discussion?

2) Is there anything you would like to add?

Note to Researcher:

After completing the discussion, briefly describe your general impressions of the person and how the discussion went. Summarize your impressions and especially note impressions not captured by the questions. 


\title{
APPENDIX C FOCUS GROUP DISCUSSION GUIDE AND PICTURES
}

\author{
MODERATOR'S GUIDE
}

Date: December 1, 1993

Topic: Drinking \& Driving

Schedule of groups:

$\begin{array}{ll}\text { Group A - Bethesda, MD } & 6 \mathrm{pm} \text { December } 1 \text { (Women) } \\ \text { Group B - Bethesda, MD } & 8 \mathrm{pm} \text { December 1 (Men) } \\ \text { Group C - Bethesda, MD } & 6 \mathrm{pm} \text { December 2 (Women) } \\ \text { Group D - Bethesda, MD } & 8 \mathrm{pm} \text { December 2 (Men) } \\ \text { Group E - Palo Alto, CA } & 6 \mathrm{pm} \text { December 10 (Men) } \\ \text { Group F - Palo Alto, CA } & 11 \text { am December 11 (Women) } \\ \text { Group G - Palo Alto, CA } & 2 \mathrm{pm} \text { December 11 (Men) } \\ \text { Group H - Palo Alto, CA } & 4 \mathrm{pm} \text { December 11 (Women) } \\ \text { Group I - Madison, WI } & 6 \mathrm{pm} \text { December 14 (Women) } \\ \text { Group J - Madison, WI } & 8 \mathrm{pm} \text { December 14 (Men) } \\ \text { Group K - Madison, WI } & 6 \mathrm{pm} \text { December 15 (Women) } \\ \text { Group L - Madison, WI } & 8 \mathrm{pm} \text { December 15 (Men) }\end{array}$

I. INTRODUCTION: Hello, my name is Reyn Kinzey/Becky Day and I'm the Moderator for today's 2 hour group discussion.

Our purpose here today is to:

Get your opinions and attitudes about drinking and driving. Personal disclosure, purpose of research, and need for honesty.

We'll be doing several things tonight:

1. Participating in a group discussion

2. Looking at some pictures

3. Some group exercises (role playing) 
INTROS: First, I'd like for you to introduce each other:

o First name

o What kind of work you do

o How long you have been living in the area

o Favorite hobby, sport, or leisure time activity

MODERATOR INTRO: Appropriate to the setting

We are going to be talking about a number of subjects today that involve your personal views and opinions. I'm not trying to pry in your lives. I'm trying to gain an understanding about some important issues.

I'd like you to feel free to express whatever

you believe.

I also have nothing to sell. This is an opinion research project being conducted with several groups of people like you. I'm an independent opinion researcher hired to help collect opinions.

Feel free to make any negative or positive comments about any of the things we will be discussing today. This is a free flowing discussion and there are no wrong answers.

So we can all be operating on the same channel, here are some ground rules and general information:

DISCLOSURES: $\quad$ 1. The session is being taped so I can write an accurate report - not of who said what, but what was said. Your name will not be used in the report.

2. WHEN APPLICABLE: There is a one way mirror so that people who are working on the project with me can take their own notes and help me modify the project as we go from group to group.

3. Thank you for arranging your schedule today to be here for this session. You are being paid for three things: (1) Your time (2) Your opinions (3) Your honesty. 
GROUND RULES: 1. Please talk one at a time and in a voice at least as loud as mine.

neighbors.

2. Avoid side conversations with your

3. I need to hear from everyone in the course of the conversation, but you don't have to answer every question.

4. Talk to each other. Respond directly to someone who has made a point. Let's keep it conversational rather than just answering my questions.

5. We will observe a no smoking rule in here. If you want to smoke or want a restroom break, please leave the room one at a time and come back as quickly as possible.

6. Say what is true for you and have the courage to stand up for your beliefs, even if you are the only one who feels that way. Don't let the group sway you and don't sell out to the group opinion or a strong talker.

\section{Social Activities/ Drinking}

1. Each of you mentioned at least one or two things you do in your spare time. Let's get some of those up on this flip chart. What do you do for a good time? Where do you go? (LIST ON FLIP CHART)

Probe for:
A) What do you do when you're with friends
B) What do you do when you're alone
C) What do you do when you're with a member of the opposite sex
D) What do you do when you are with your family

2. Tell me what you enjoy most about these activities? (GO THROUGH LISTS)

3. We're going to switch gears a little now. Going back to the activities we listed before, how does drinking play a part in those activities?

4. Are there some activities you generally associate with drinking? Seldom (never) associate with drinking? What about an activity makes it something you might associate with 
drinking or not drinking? Are there some circumstances that lead you to drink more than others? Are there some circumstances where you drink less or not at all? Do you drink the same amount if you are with a member of the opposite sex? (Probe for reasons).

5. What's good/ not so good about drinking?

6. What's the worst problem associated with drinking?

7. What about drinking and driving? How do you deal with that?

8. Is there a difference between drinking-and-driving and driving drunk?

a) How do you "define" the difference?

b) How do you determine your own limit?

c) How and when do you make the decision to drive or not when you are drinking?

9. Have any of you ever driven when you knew you probably had too much to drink? What went through your mind when you did it? What went through your mind the next day?

10. If you knew you had probably had too much to drink, what were the reasons that you drove? (What were the reasons that you had to get home?) If there had been a convenient way to get home, would you have used it? What would make it seem "convenient?"

11. DIVIDE INTO GROUPS OF THREE OR FOUR. I'm going to give you about three minutes to list some solutions that you would feel comfortable using to avoid driving after you've had too much to drink or avoid drinking altogether because you know you have to drive. What are "preventive measures" that are good solutions to this problem?

\section{Attitudes towards Drinking, Not drinking, and Staving in Control}

1. How many of you have ever been a designated driver? What would make someone want to be a designated driver? What would make someone not want to be a designated driver?

2. I want to show you some pictures, and I want you to tell me is this the picture of a:

1. Person who never drinks

2. Person who drinks but never drives impaired

3. Person who drinks and every once in a while drives when impaired

4. Person who drinks and drives all the time

5. Person who a designated driver

The trick here is that they aren't pictures of people at all, so you'll have to use your imagination. (Show pictures of animals and probe for reasons). 
3. To summarize, what do you think about:

1. Person who never drinks

2. Person who drinks but never drives impaired

3. Person who drinks and every once in a while drives when impaired

4. Person who drinks and drives all the time

5. Person who is a designated driver

\section{Role Playing} scenarios:

Have them divide themselves into groups of three or four and prepare to role play three

1. In a bar with good friends. Driver becomes a little too drunk to drive. What do others say/do?

2. In a bar with good friends. You have a Designated driver but he or she decides that "one or two can't hurt." What do others say/do?

3. In a bar with good friends. Designated driver becomes a little too drunk to drive. What do others say/do?

4. You are the designated driver and people are telling you that "one or two won't hurt you." What do others say/do?

After each, ask group of observers:

A) How did you feel about what you saw? Thoughts? Observations (NOTHING MORE NEGATIVE THAN "THAT MIGHT WORK.")

Last question for each scenario is for the driver:

B) How did you feel when the others were talking to you. What had the most impact?

C) IF NOT EXPLORED - What about the need to plan ahead for a designated driver? Are there any problems with planning ahead? How could those problems be avoided?

\section{Friends and Family}

1. I want to switch gears a little for a minute. In all of the scenarios above, I asked you to assume you were with good friends. I want us to talk a little about friends. To get us started, I want you to take one of the crayons in the box, and choose a color--any color-- that you would somehow associate with "friends" or "friendship." And draw some shape--any shape you want-that you would somehow associate with friendship. 
2. Let's talk about what some of you did. (GO THROUGH COLORS AND SHAPES).

3. Let's do the same thing for family. Choose a color you would associate with "family," or choose another color, and draw a shape you'd associate with "family."

4. Let's talk about what some of you did. (GO THROUGH COLORS AND SHAPES).

5. Okay, now let's go back to what we've been talking about--driving responsibly. Pick a color and draw a shape that you'd associate with "driving responsibly."

6. Let's talk about what some of you did. (GO THROUGH COLORS AND SHAPES).

7. Finally, I'd like for you to take all three shapes and colors that you've already used, and put them together into one design. Then, write a word to "sum up" what you did.

8. Let's talk about what some of you did.

9. Do any of your designs say anything to you about the relationships between friends, family, and driving responsibly?

\section{Conclusion (FALSE CLOSE, WHEN APPLICABLE)}

A. I'm going to leave the room for just a moment. While I'm gone, I'd like for you to get in groups of three or four and talk about any other ways people could be encouraged to drink-or not drink--and drive responsibly.

B. FINAL QUESTION: Many of the approaches to reduce drunk driving seem based on negatives--fear and guilt. Can we suggest POSITIVE approaches based on positive values that might be more effective? 


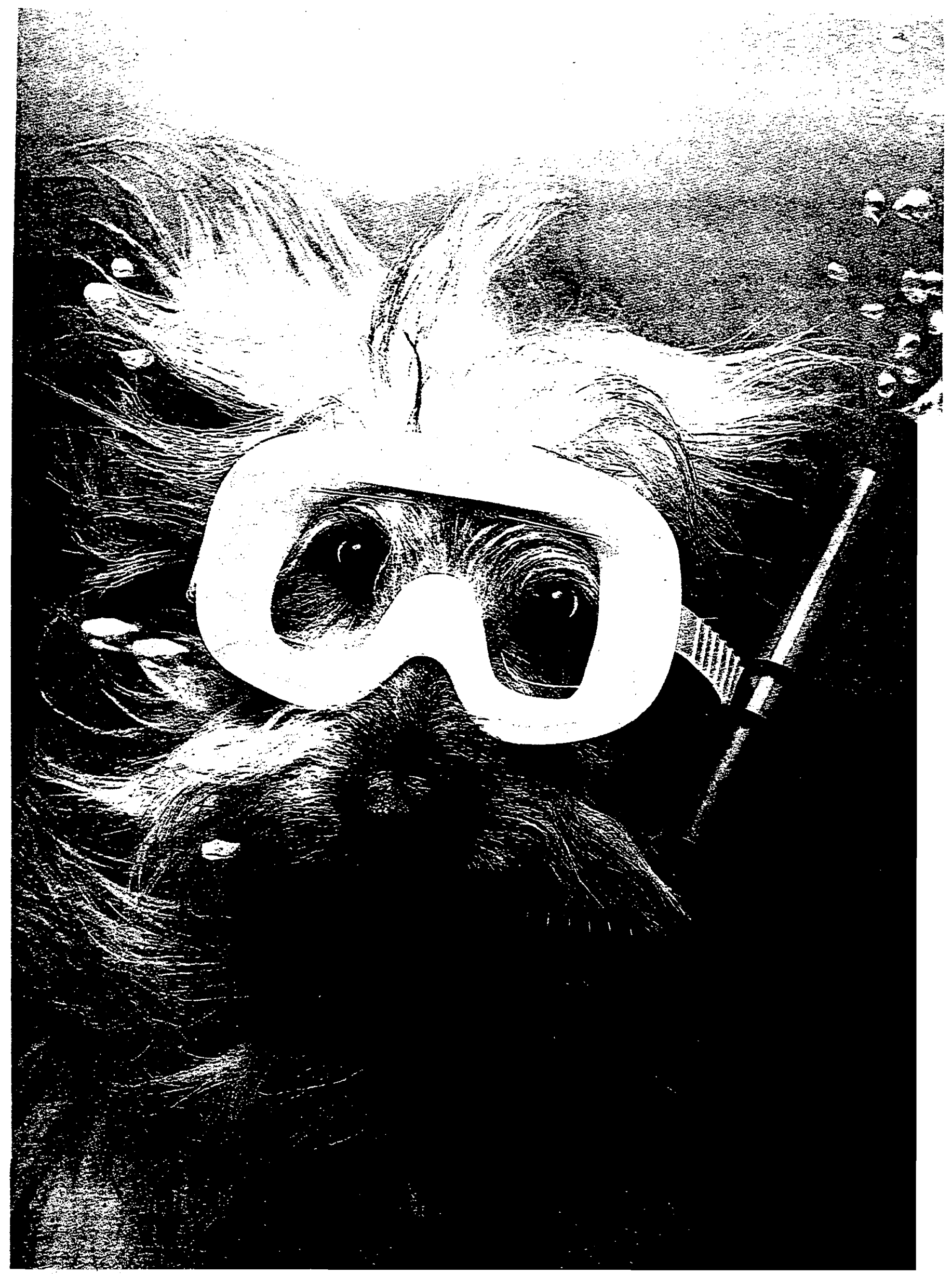




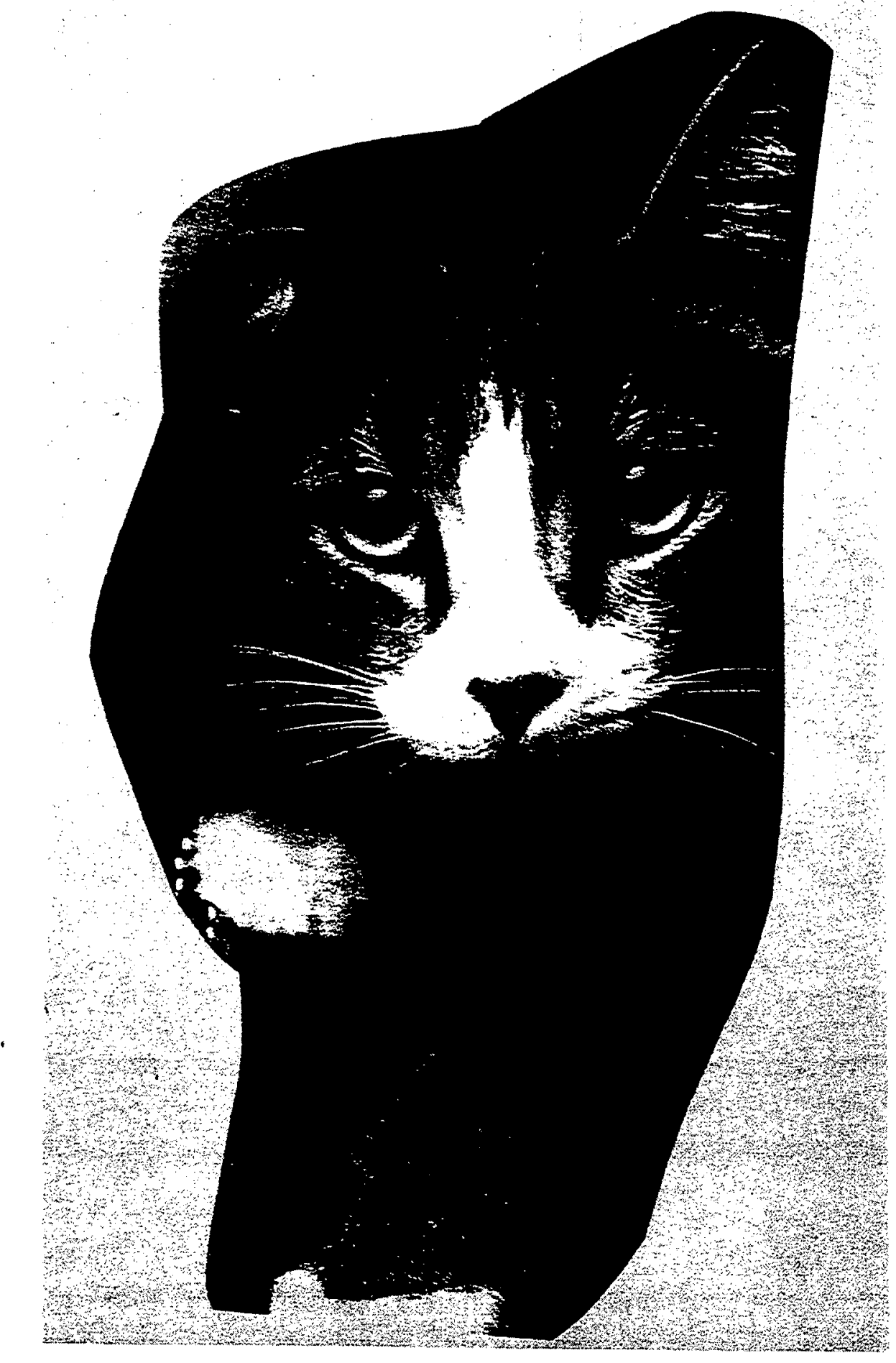




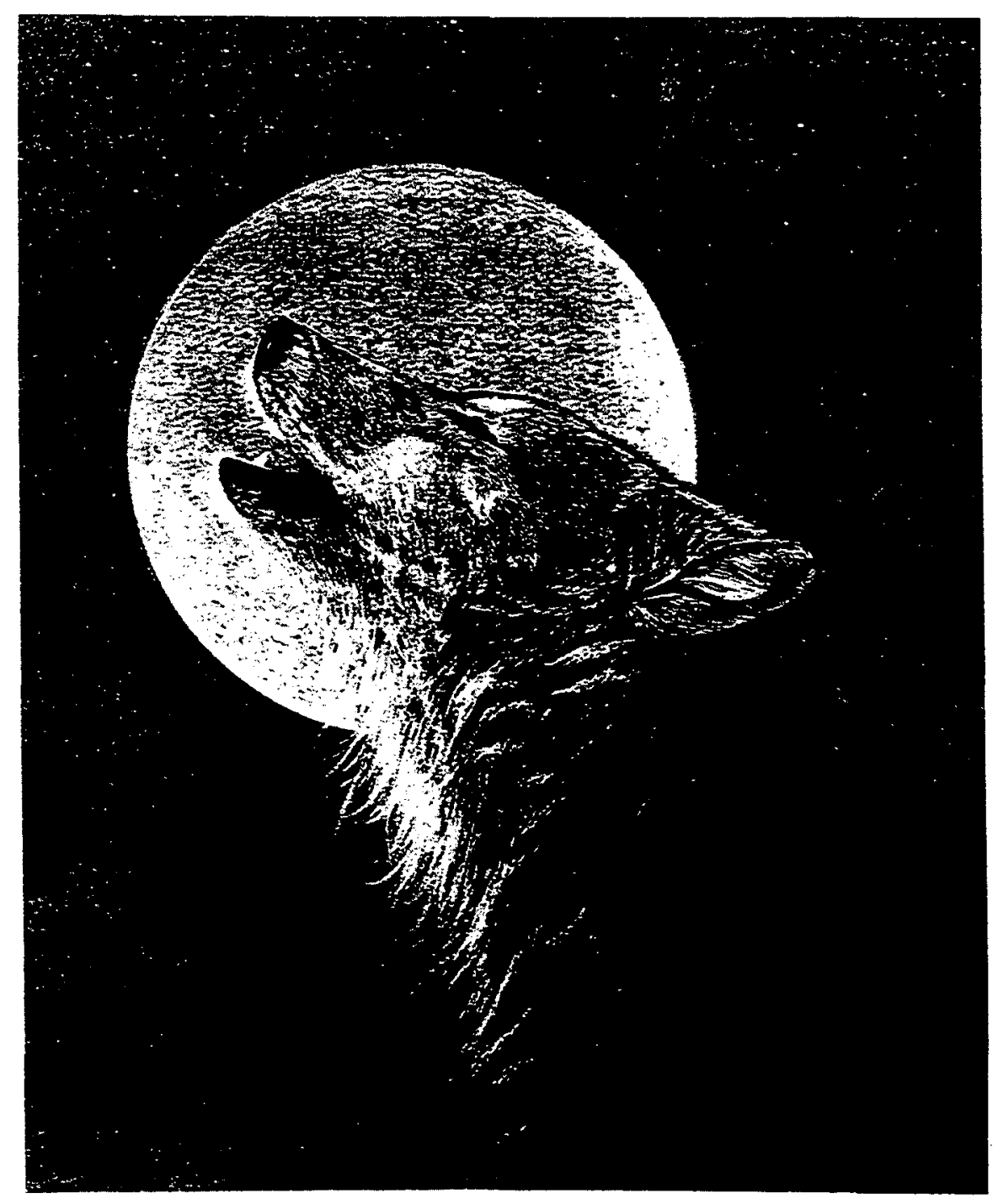




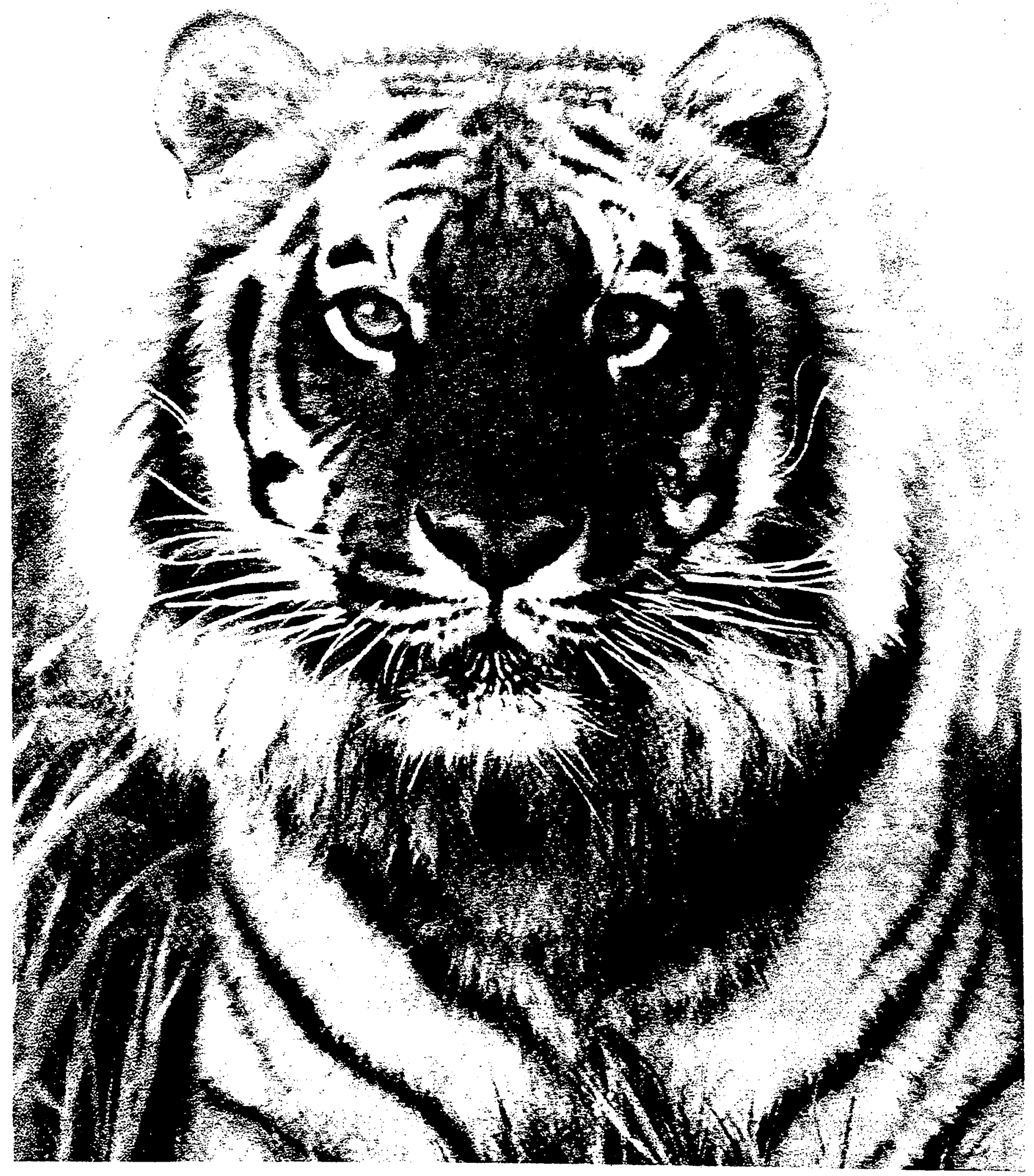




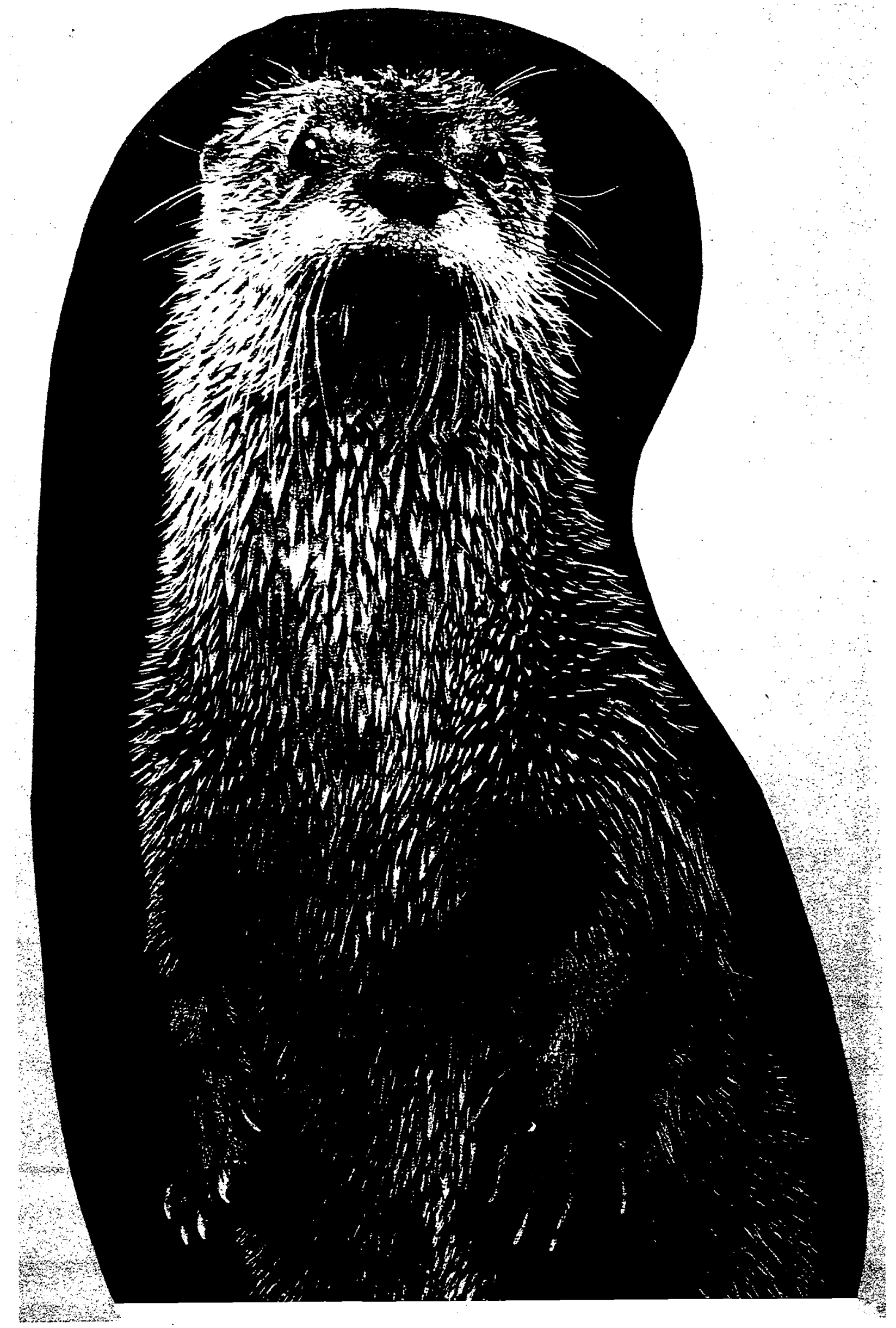




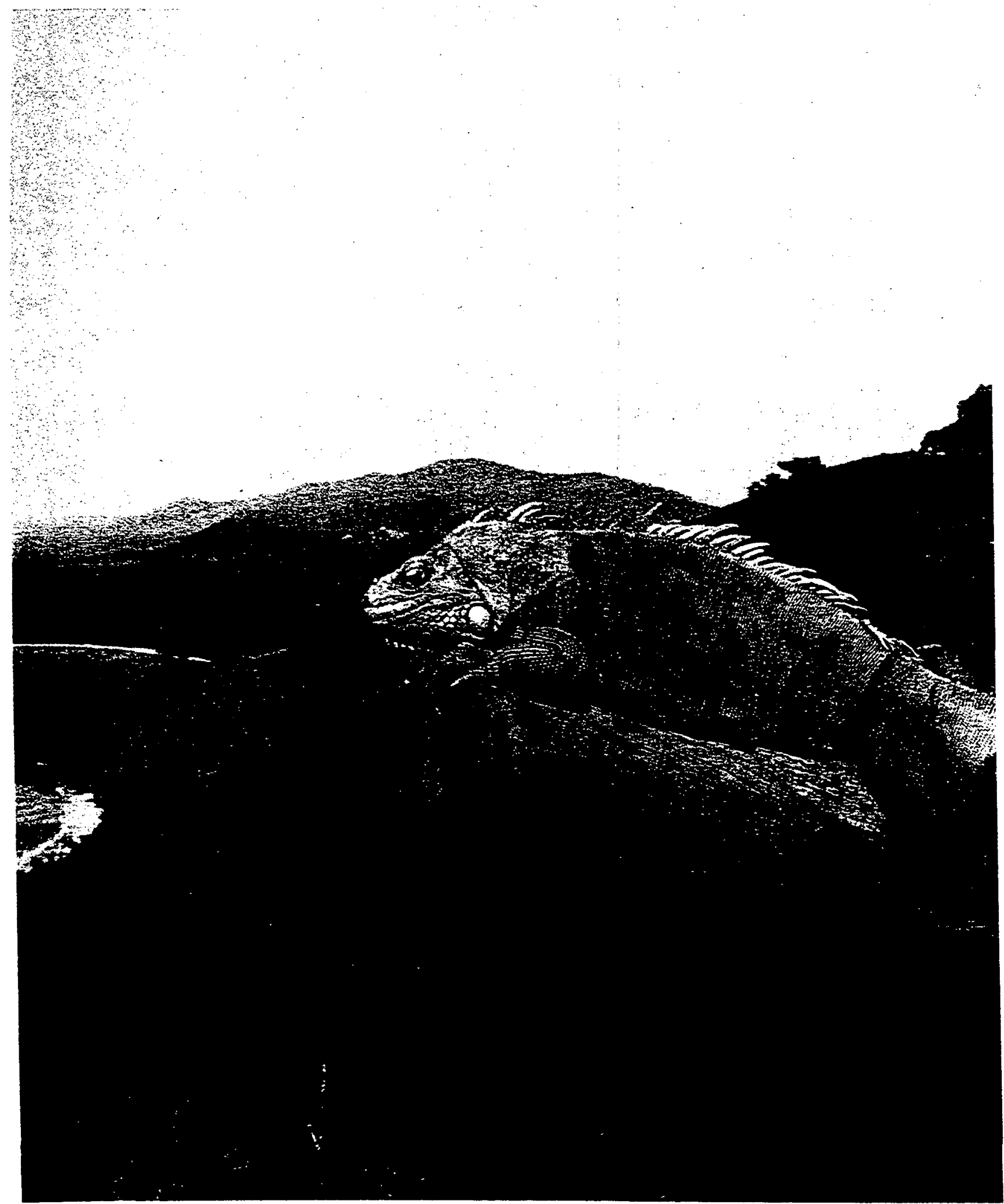




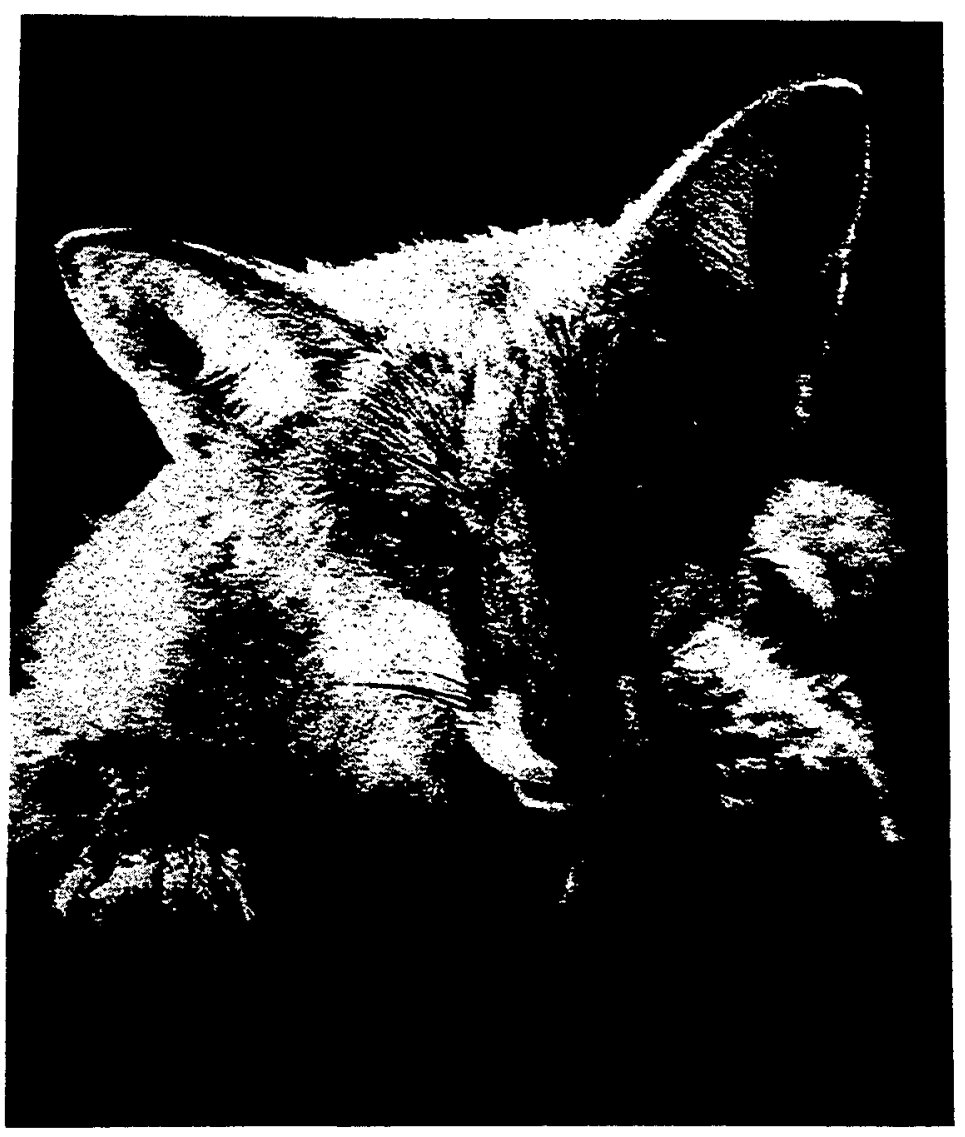




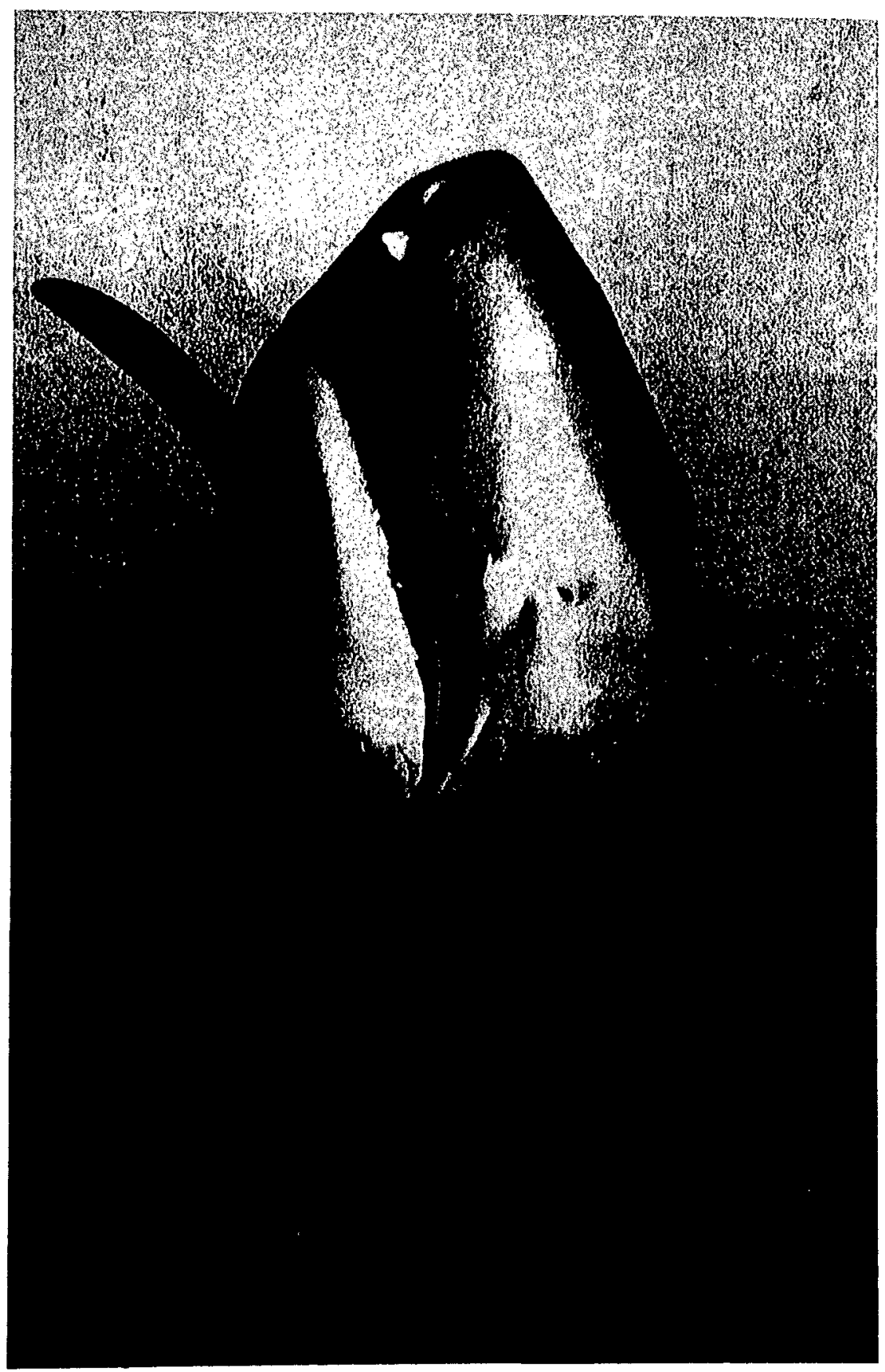




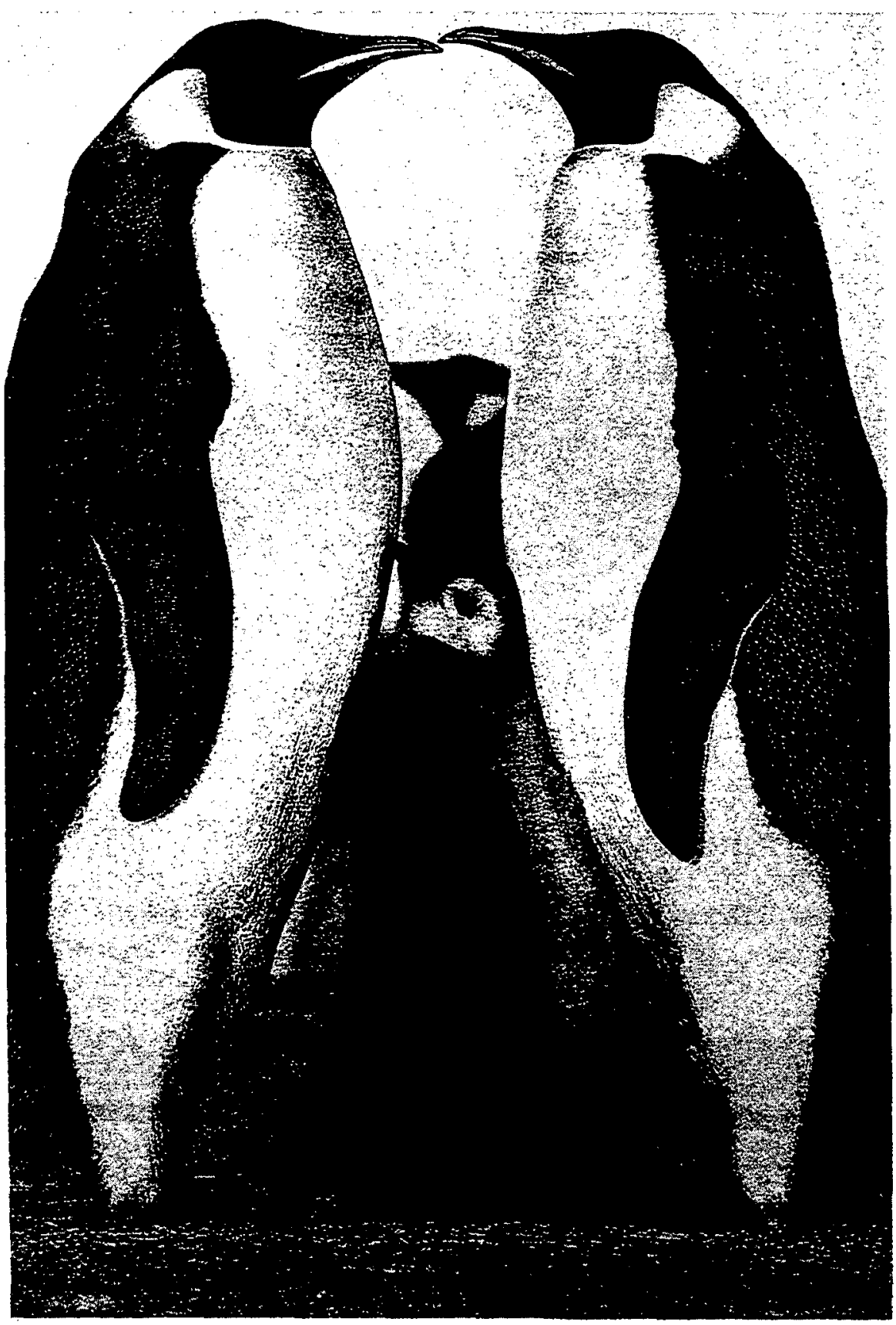




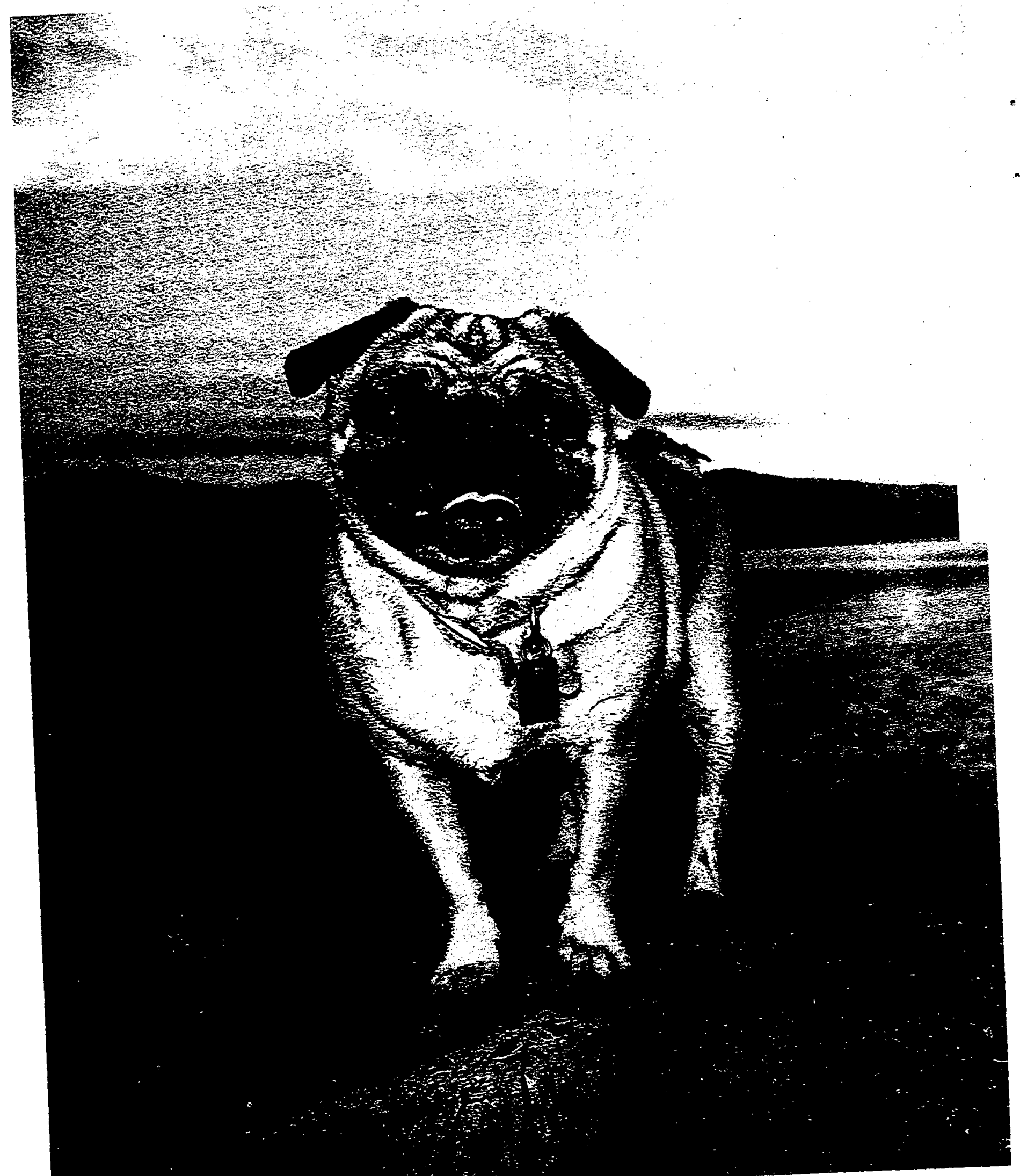




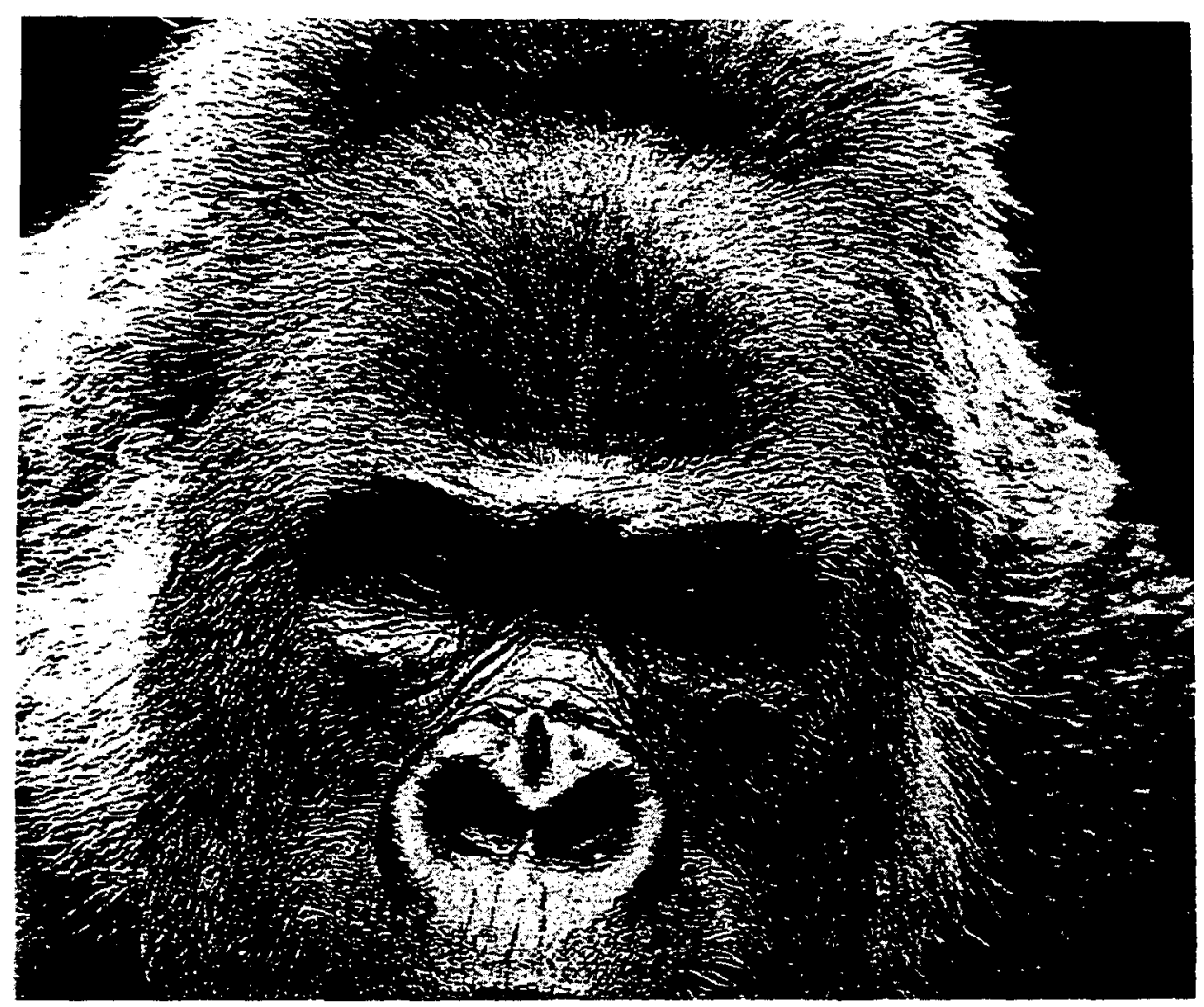




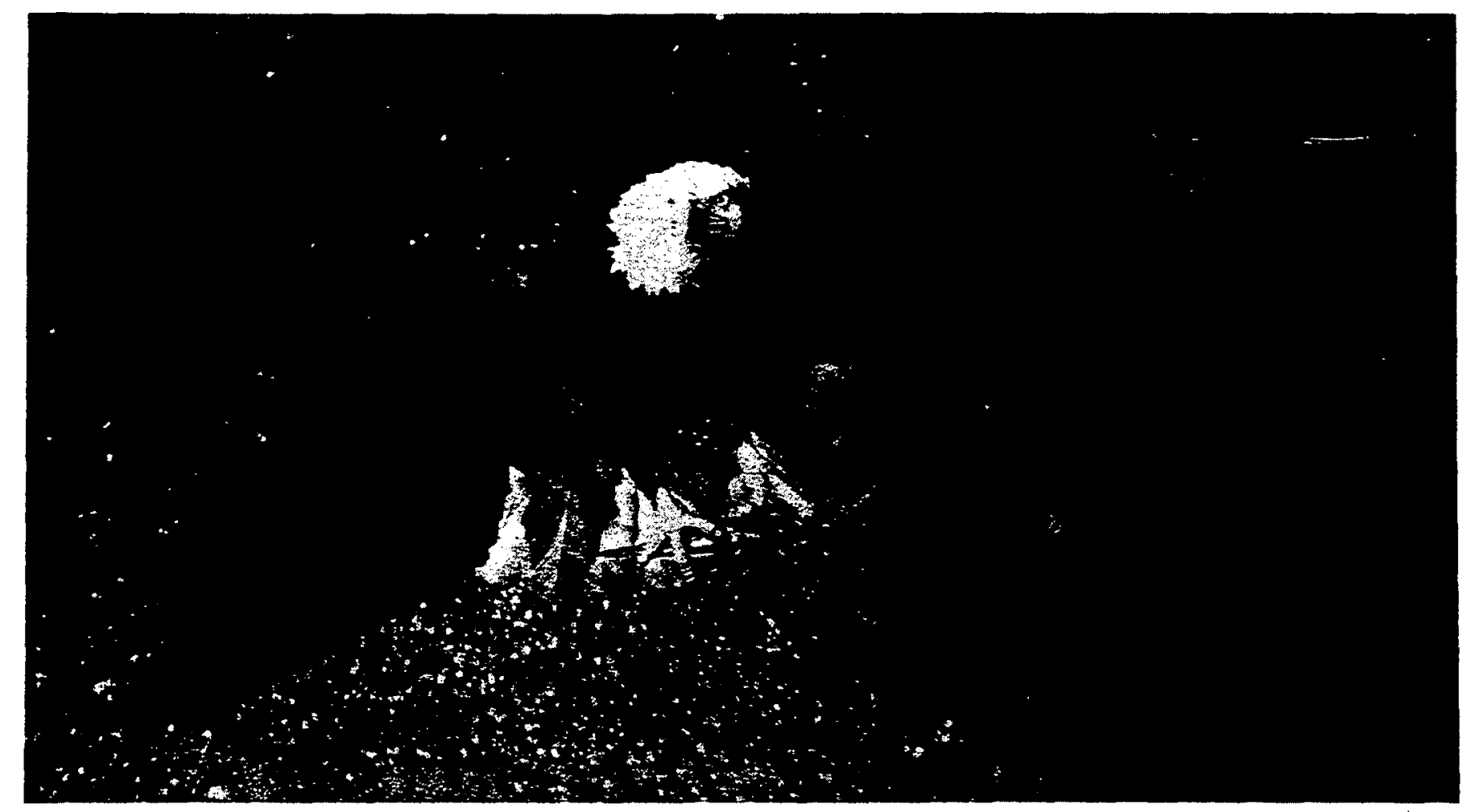




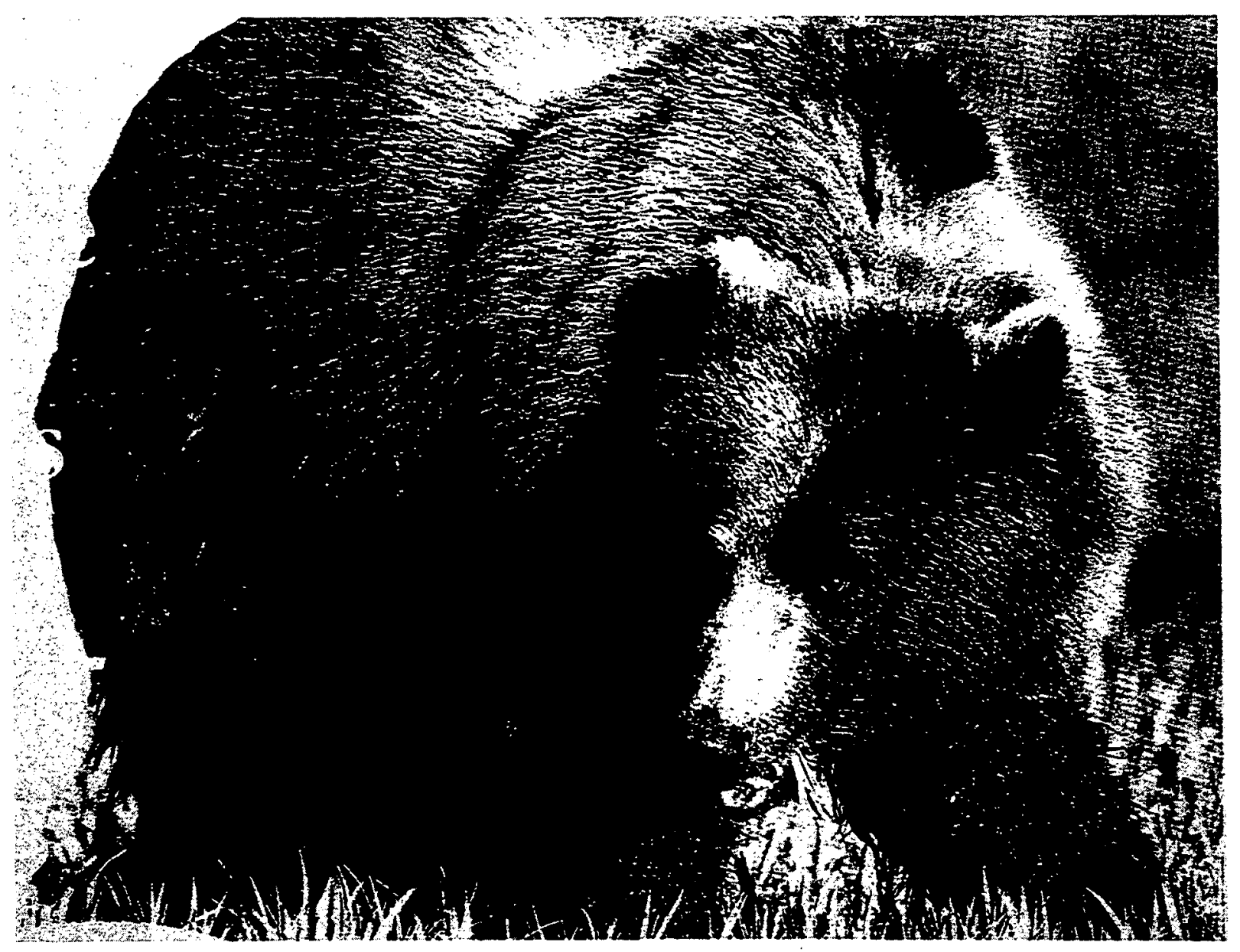




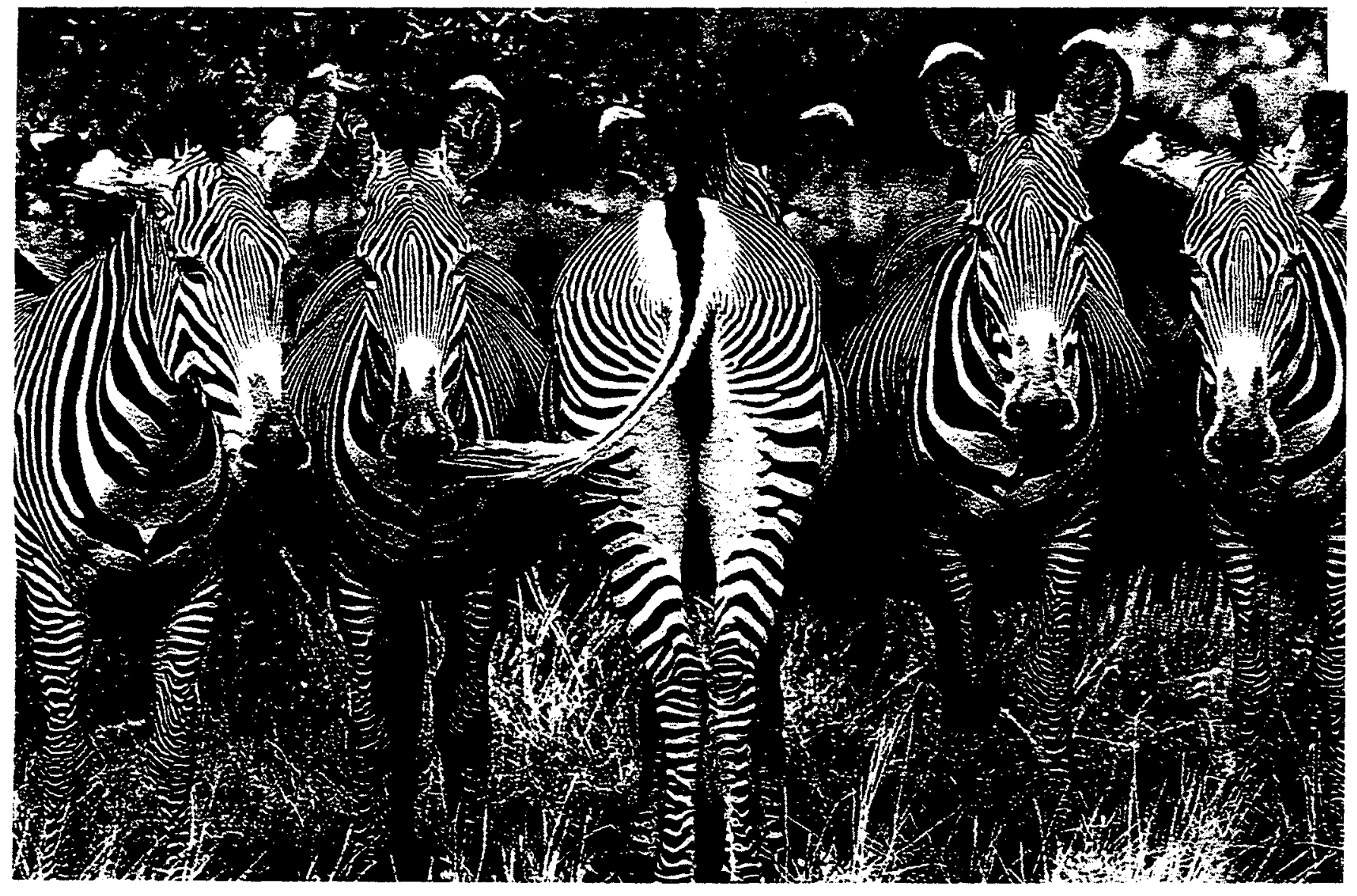




\section{APPENDIX D \\ FOCUS GROUP DETAILED SUMMARY}

\section{PURPOSE AND SCOPE}

This report presents the key findings of twelve focus groups among young people between the ages of 21 and 29, conducted by RIVA Market Research, Inc. for Pacific Institute. Four groups were conducted in each of three cities: Bethesda, Maryland; Palo Alto, California; and Madison, Wisconsin. In each city, two groups were conducted among women and two groups were conducted among men; the groups of women were moderated by Rebecca Day, a female moderator, and the male groups by Reyn Kinzey, a male moderator.

In general, the groups were undertaken to explore the perceptions, opinions, attitudes and beliefs of young people about drinking and driving. Many of the participants had previously been interviewed individually by Pacific Institute staff members: the focus groups were intended to clarify issues raised by those interviews. Specific topics investigated included:

1. Social Activities and the Role of Alcohol, including what participants do in their spare time; activities and situations that lead to greater or lesser amounts of drinking; the influence of friends and members of the opposite sex; problems associated with drinking; perceptions of drinking and driving, including perceived differences between drinking-and-driving and driving "drunk" or impaired, and perceptions of "limits;" situations where participants have driven impaired; and "preventive measures" participants use to avoid drinking and/or drinking and driving.

2. Attitudes towards Drinking, Not Drinking, and Staying in Control, including participants' experiences as designated drivers; reasons for being a designated driver; and images of people who never drink, people who drink but never drive impaired, people who drink and sometimes drive impaired, people who drink and drive "all the time," and people who are designated drivers.

3. Role Playing, including participants' perceptions of how they would deal with several scenarios: 1 . A friend becomes too drunk to drive; 2. A designated driver decides "one or two can't hurt;" 3. A designated driver becomes too drunk to drive; 4. People begin encouraging the designated driver to drink.

4. Friends and. Family, including participants' associations with the values of friendship and family; their associations with 
driving responsibly; and their ideas of how those associations might be related.

5. Final Considerations, including ways participants believe people can be encouraged to drive responsibly, and the relative effectiveness of "positive" approaches and "scare tactics" or guilt-ridden approaches.

A statement of METHODOLOGY follows this section, followed by an EXECUTIVE SUMMARY, outlining the most significant findings of the twelve groups. A more DETAILED SUMMARY OF FNDINGS for each of the three cities, broken down by female and male groups, follows the EXECUTIVE SUMMARY. A copy of the MODERATOR'S GUIDE is included as an appendix to the report, as are copies of the pictures used in the picture sort exercise. 


\section{METHODOLOGY}

The purpose of a focus group interview is to provide a more in-depth understanding of consumers' behavior, attitudes, and/or perceptions of products and services than can be gained by wider-scale consumer surveys. Typically, focus groups are used to explore more complex attitudes that cannot be determined by wide-scale surveys: for example, motivations for driving responsibly. A more in-depth understanding of consumers' motivations can be achieved because fewer people are interviewed, allowing more time for fuller responses, and respondents are free to elaborate on their responses and generate their own ideas. The moderator also has considerably more opportunity to ask follow-up questions than a telephone surveyor.

On the other hand, the smaller number of people involved in focus groups means that the behavior, attitudes, and perceptions expressed are not necessarily statistically representative of the entire population in a market area. Questions of past behavior or general levels of awareness of products and advertising within a target population are generally better answered by larger, more representative surveys. Further, the more in-depth understanding which can be gained through focus groups must sometimes be developed by analyzing both what is said and unsaid, by watching non-verbal signals (such as body signals), by judging the quickness of a response, or the emphasis placed on wording.

Focus groups are a valuable tool in marketing research, often allowing insights not possible from wider studies. However, the findings should not be taken as quantitative. Some care needs to be exercised with the analysis of the findings, but, used judiciously and, particularly in combination with quantitative surveys, they can help provide directions for marketing, product design, or advertising and public awareness campaigns.

\section{The Focus Groups}

Participants in all groups were between the ages of 21 and 29, and all indicated that they drink at least socially. Many, although not all, had already participated in individual interviews with Pacific Institute staff. In each city, two groups were conducted among women and two groups among men. In all groups, the sex of the moderator was matched to the sex of the group. This was done to promote greater openness and candor.

All participants were recruited by Pacific Institute.

The schedule of the groups is listed below:

\author{
Group A - Bethesda, MD \\ Group B - Bethesda, MD \\ Group C - Bethesda, MD \\ Group D - Bethesda, MD \\ Group E - Palo Alto, CA \\ Group F - Palo Alto, CA
}

6 pm December 1 (Women)

8 pm December 1 (Men)

6 pm December 2 (Women)

8 pm December 2 (Men)

6 pm December 10 (Men)

11 am December 11 (Women) 
Group G - Palo Alto, CA 2 pm December 11 (Men)

Group H - Palo Alto, CA 4 pm December 11 (Women)

Group I - Madison, WI 6 pm December 14 (Women)

Group J - Madison, WI 8 pm December 14 (Men)

Group K - Madison, WI 6 pm December 15 (Women)

Group L - Madison, WI 8 pm December 15 (Men)

The MODERATOR'S GUIDE used by the moderators was designed by the moderators, Rebecca Day and Reyn Kinzey, in consultation with Pacific Institute. A copy is included as an appendix to the report. 


\section{EXECUTIVE SUMMARY}

The findings from the focus groups generally support the findings from the individual interviews conducted by Pacific Institute, particularly:

1. Virtually all participants acknowledge that drinking and driving all the time is wrong and do not need further messages to convince them of this.

2. Respondents freely admit to driving while legally impaired.

3. The fear of potential arrest appears to be causing participants to alter their drinking and driving patterns.

4. The vast majority of participants have been designated drivers and have used other preventive measures to avoid drinking and driving, but they clearly need to develop better skills in using these behaviors.

5. Family and friends are very important values to these participants.

The findings also generally support the assumption that positive values might be used to develop countermeasures to reduce drunk driving. These values might include a stronger image for the designated driver as well as linking the value of friends, and perhaps family, to driving responsibly.

However, some of the key findings of the groups suggest that these issues need some clarification and modification.

\section{THE "ACCEPTABILITY" OF DRIVING IMPAIRED AMONG THESE PARTICIPANTS}

First, and perhaps the most important clarification, is whether or not participants truly believe drinking and driving is wrong. The answer clearly depends on what is meant by "drinking and driving." The issue is certainly not simply a semantic argument. If drinking and driving means driving after one or two drinks, then virtually none of the participants believe drinking and driving is wrong; most would not consider it drinking and driving at all. If drinking and driving means habitually driving while "drunk," (and this may be different from what is legally drunk) yes, virtually all of the participants would say that is wrong, bad and dangerous.

But what about drinking after three, four, or even six drinks? Most of the participants do not even have a term for this behavior: it is entirely a gray area. For many of them, four or five drinks is not yet "drunk." They do not use the word impaired, although some of them see it as a legal distinction. Most will admit to driving while legally impaired (finding \#2), and quite a few will admit to driving while "sloshed," but that, to them, appears to be morally different than driving drunk habitually. 
This can be seen most clearly in the picture sorts that were used to stimulate discussion of what images participants have of people who drink--or do not drink--and drive. When asked for words that describe people who sometimes drive impaired, they virtually always said, "average," or "that describes a lot of us." However when asked to describe people who drink and drive all the time, they generally used harsh, moralistic terms, such as "uncaring," "foolish," and "selfish."

It appears, then, that occasionally driving legally impaired does not violate these participants' sense of values. Some directly stated that people who drink and sometimes drive impaired are not "irresponsible" people, although they may occasionally act irresponsibly.

\section{FEAR OF ARREST IS REAL, BUT MAY BE LIMITED AS A DETERRENT}

This is not at all to say that the fear of being arrested for driving while legally impaired is not deterring some people from drinking and driving. Particularly men in Bethesda and men and women in Palo Alto expressed a great deal of concern over the possibility of arrest-particularly those who have been previously arrested (point 3 \#). However, for those who have not been arrested, the chance of being arrested is almost like a game; they repeatedly used the term "getting away with it." It is not a value-laden concern that they are likely to keep in their minds at 2:00 am, after a heavy night of drinking.

\section{THE SUBJECTIVITY OF LIMITS}

Again, participants have no ready term for driving after several drinks, and the issue is not merely a semantic one. Since they have no term for the "gray area," they have no real practical ways of dealing with the behavior. This is most clearly seen in the subjective "limits" they place on their drinking. Generally, only one or sometimes two participants in a group place any numerical limit on their drinking (generally, the limit seems reasonable, such as one or two drinks, but some have limits of six beers. One participant has one drink an hour, in an attempt to keep himself just below the legal limit). Most participants say their limits vary from night to night, according to how much they've eaten, how much stress they've been under, etc, so they judge whether or not they are all right to drive by physical sensations (numb lips, room tilting, inability to walk) or mental sensations (am I carrying the conversation okay; am I having to concentrate too hard; are my friends making sense?). One obvious problem with such judgements is that they are only made after the person is already intoxicated. Many participants who said they have driven drunk, also said they often don't realize how drunk they are until they are in the road or until the next morning.

\section{FAIURE TO PLAN AHEAD}

Of the many poor skills demonstrated in participants' attempt to avoid drinking and driving, the most pronounced seems to be a failure to plan ahead. One participant in Madison seemed to accurately assess the situation: 
"People do not intend to drive drunk. Their intention is to get drunk. And their intention is to drive, but... it's like they don't put the two together."

Most participants seem to have good intentions, but lack the skills to carry through on attempts to avoid driving after drinking. For example, the majority of participants report having been designated drivers, but most say the decision is an "informal" one, almost always made after the group has already gotten to the bar (which may mean several cars are already involved), and often made at the end of the evening, when "whoever is least drunk" becomes the designated driver. In fact, one of the reasons participants commonly give for driving drunk is that the designated driver was even more intoxicated.

\section{5. "NO ONE WANTS TO BE THE DESIGNATED DRIVER"}

Participants clearly have ambiguous feelings about designated drivers. When asked directly how they would describe designated drivers, most groups used adjectives such as "caring" and "responsible," and this positive response certainly seems to reflect their honest feelings: Participants overwhelmingly agree that having a designated driver is a good idea. However, they also occasionally used words such as "geeky" and "nerdy" to describe a designated driver. This ambiguity was particularly apparent in the picture sort. For example, almost all of the groups said the eagle would never drive and drink, or would be a designated driver because he is "proud," "majestic," and needs to be in control. However, others said that the kitten would be a designated driver because she is "timid." One participant said the pug would be a designated driver because he has no social skills and wouldn't be allowed to go out with the group if he wouldn't volunteer to be the designated driver.

Many participants directly said "no one wants to be a designated driver," because it's "no fun." One participant said the wolf would be a designated driver, because wolves are loners, and "you're a lonely son of a buck when you're the designated driver." Several said being a designated driver is only acceptable on a "taking turns" basis.

\section{AMBIGUITY ABOUT DRINKING IN GENERAL}

Many participants seem to have ambiguous feelings about drinking in general. Participants were screened to make sure that they are at least social drinkers, and it is not surprising that they said that drinking was "fun." In fact, the area of strongest agreement across all the groups was that of what they found good about drinking: virtually every group said drinking relaxes them, releases their inhibitions, helps them to socialize, and tastes good. However, virtually every group listed more problems associated with alcohol than good points (usually beginning with "hangovers" and, in many groups, going through addictions, accidents, and deaths (women were generally more likely to bring up accidents than men, and only women mentioned problems such as addiction and sexual and physical abuse). Further, during the picture sort, participants indicated some strongly ambiguous feelings about drinking: several said certain animals wouldn't drink because, in their words, "they're not up for that kind of 
Ironically, the groups that tended to voice these kinds of sentiments were the very groups that seemed composed of the heaviest drinkers (in Madison).

Participants in all cities talked about peer pressure and/or situational pressure to drink. Sometimes groups within a city seemed divided on the issue of whether or not this pressure was actually "peer pressure," because for some, it's not a matter of people actually pushing others to drink, but most seemed to agree, as it was stated in Palo Alto, "it's the nature of a party." "If everyone else is drinking, you tend to drink, too." Some participants in Bethesda and Madison argued that it is just plain peer pressure: "It's like there's something wrong with you if you don't drink."

\section{THE POSITIVE VALUES: "LIFE," "SAFETY" AND "RESPONSIBILITY"}

The initial interviews had already determined that family and friends were primary values to the participants, and the focus groups confirmed this. The groups also tried to determine if the values of friendship and family could be associated with the need to drive responsibly. The drawing exercise indicated that most participants could easily associate the three values together. The majority saw fairly straight-forward relationships: If you value your friends and family, you should drive responsibly. Many used words such as "interconnected" and "inter-related" to describe the connection between the three. Some participants had difficulty seeing how "family" could be associated with "friends" and "driving responsibly," although several of these participants said that they learned their values from their families, and they use these values when they drive responsibly.

Perhaps a more important finding is that, when the idea of a designated driver or driving responsibly is placed in the context of family and friends, participants moved very directly to the values of "life" and "safety:" Several used these words to describe the relationship of the three values. Significantly, in this context, not a single participant raised the issue of being pulled by the police or getting a ticket; again, this may indicate that, even though fear of getting a ticket is a practical concern, it may not be the kind of moral concern that has real, deep-seated "value" to the participants. They instead focused directly on the value of safety.

\section{PERCEIVED NEED FOR SCARE TACTICS}

The above findings suggest that countermeasures against drinking and driving might be successfully developed to elevate the image of the designated driver within the context of the values of safety, responsibility, families and, particularly, friends: as one participant put it, "Nobody wants to see his buddies in a ditch."

However, it must also be pointed out that many participants think that "scare tactics" are

more effective, or, at least, should also be used. Some even suggested using scare tactics exploiting the value of family and friends. Some talked about the need for showing the "grim realities." 


\section{REGIONAL, GENDER, AND INDIVIDUAL DIFFERENCES}

Finally the findings from the twelve focus groups in three different cities also indicate there are strong regional, gender, and individual differences in the way young people think--and act--about drinking and driving. In each city, not only were there differences between the male and female groups, but there were often fairly strong differences between the two groups of the same sex. Also, even though there are always differences among participants in any group, the differences within these groups seem to indicate a wide range of behaviors: people drink differently, and they deal with the problem of drinking and driving in different ways. This in itself suggests that a wide range of approaches might be necessary for countermeasures.

These regional and gender differences are evident in the detailed summaries which follow, which divide the findings both by city and gender. Some differences are not directly related to drinking and driving issues, but might be important for promotional campaigns: for example, dancing seems much more important in Bethesda than in the other cities; nature and environmental concerns are most important in Palo Alto. Other differences are much more directly related to drinking and driving Some of the most important of these are listed below:

* In general, women seem somewhat more willing to say they would not argue if friends told them they had had too much to drink and shouldn't drive (although even this cannot be taken too far: women in Madison say they have fooled their friends). Women also tend to plan ways of avoiding drinking and driving somewhat more than men do. Women are more likely than men to plan on having designated drivers and are more likely to suggest spending the night at a friend's apartment rather than drive home drunk.

* Women were more likely than men to list addiction and accidents as problems associated with alcohol (men were more likely to talk about hangovers).

* Men in Bethesda seem to plan ahead somewhat more than men in Palo Alto and Madison.

* Participants in Palo Alto seemed to be more reluctant than others to risk confrontations with friends who become too drunk to drive.

* Participants in Palo Alto seemed the most concerned about the possibilities of getting pulled over and given a ticket.

* Participants in Madison were the most likely to espouse traditional values, but they also seemed to be the heaviest 
drinkers. The women in Madison were the most likely to mention alcohol-related family problems and abuse. Participants in Madison also reported a great deal of peer pressure to drink.

* Since most participants in Madison say they can walk to bars, most say they do not worry very much about drinking and driving. Even so, most of the participants admitted that they had driven impaired.

* Generally, almost all participants said they drink less with members of the opposite sex. The women in Madison were a notable exception: several said they drink more.

Although this EXECUTIVE SUMMARY is intended to summarize the most important findings of the project, the ambiguity of the participants on these issues, their extreme subjectivity, and the regional and gender differences make it difficult to summarize all of the findings quickly. The DETALED SUMMARIES, which include statements in the participants' own language, is intended to provide a much fuller context for these key findings. 


\title{
DETAILED SUMMARY OF FINDINGS
}

\author{
BETHESDA, MARYLAND
}

\section{WOMEN}

\section{SOCLAL ACTIVITIES AND THE ROLE OF ALCOHOL}

\section{Leisure time activities}

Both groups of women in Bethesda, but particularly the first group, talked about the importance of dancing and music in their social lives. The first group seemed a little more social and talked more about going out to bars, dance clubs, and parties. The second group also talked about dancing and dating, but seemed somewhat more subdued. Both groups also talked about exercising; the second group seemed somewhat more sports-minded and talked about watching sports as well as playing sports.

Participants generally agreed that drinking helps them get over inhibitions and that it makes talking to other people easier.

"You open up a lot more. It gives you guts."

"It encourages socializing."

Participants also said that drinking relaxes them and relieves tension.

Activities and situations that lead to greater or lesser amounts of drinking

Both groups indicated that there is a strong link between dancing and drinking:

"You can dance longer."

"Sometimes better, sometimes worse."

"When I go out dancing, it's just part of the scene."

"Like if you have to dance with someone you don't like... (a drink helps you to get through it)."

Participants indicated that drinking is a social activity for them: many tend to drink more when they are in groups, rather than with one other person, and particularly at parties: 
"You drink more if you're at a good party. With one or two people, you don't drink so much."

"Dancing, with a lot of people (you drink more). With one other person, I don't start slamming drinks."

"If you're with one person, it's more for conversation."

Participants also talked about drinking with friends, with family, especially during the holidays, when going out, and when watching sports.

Participants said they did not drink when playing sports, exercising, or working.

The influence of friends and members of the opposite sex

Again, participants indicated that they drink more in larger groups, and it also seems to depend on who the people are. Some participants openly admitted the importance of peer pressure:

"Sometimes you drink just because you're with someone who expects you to."

Several participants said that "some guys just can't stand to see you without a drink in your hands." Even so, most said that they drink less when they are with members of the opposite sex, particularly someone they have just met:

"Someone you just met, you drink less."

"So you don't make a fool of yourself."

"If it's a first date, I wouldn't drink as much. I'd be worried about making a bad impression."

"I worry about doing something I wouldn't normally do. If I told them something..."

Participants did use phrases like "being taken advantage of," and they certainly seemed to be implying "in a sexual sense" (although they would not explicitly say so, even though they were given every opportunity), but it was also very clear that some of them were very concerned about disclosing something of themselves that they would normally not disclose. 


\section{Problems associated with drinking}

Both groups talked about problems with hang-overs, about "acting stupid" and "getting to hear about it the next day," and about health problems (both groups mentioned liver damage). Both groups said the worst problems are addiction and accidents: the first group seemed more concerned with addiction, while the second group was more concerned with accidents. Both groups mentioned "innocent victims" and the impact on families:

"The innocent people-- you always hear that the drunk walks away and the family of five is killed. The person who was drinking had a choice."

"The innocent victims..."

"It ruins a whole family. If someone dies, the whole family hurts for the rest of their lives."

Perceptions of.drinking and driving, including perceived differences between drinking-and-driving and driving "drunk" or impaired

Almost all participants said there is a difference between drinking-and-driving and driving drunk or impaired, but the distinction appears difficult to make. Most seemed to agree that "if you only drink one beer, that's okay," but few have any definite limits, and most seem to think "it depends..."

\section{Perceptions of "limits"}

Most participants have very subjective perceptions of "limits:"

"It depends..."

"It depends on the mood."

"If you've been eating..."

"You know if you're drunk."

"It's a person-to-person thing."

"You can feel it."

"I make it up."

"If you stand up to go to the bathroom, and you feel like you're 
going to fall over...I'll call my Dad."

A few participants sensed some problems with this subjective approach:

"But sometimes you don't feel it, and you shouldn't be driving.

You might be doing all right, but if you got pulled over, you

might be over the limit."

At least one participant said she abides by a strict numerical limit:

"I don't drink and drive any more. If I'm driving, I have a strict two drink limit, and I stick to it."

However, this participant seemed to be in the minority.

Situations where participants have driven impaired

Most participants seemed willing to admit that they had driven impaired, and some did not mind saying they had driven when they were "sloshed." Participants said they did so because "it's the easiest solution at the time." Several raised practical reasons why they felt they must get home: parental curfews, husbands, having to get the car back for someone else to use in the morning, having to get ready to go to work themselves. Some said they were simply tired and needed to go home to sleep. However, many simply said, they didn't know they were too drunk to drive:

"You don't know you're drunk."

"When you're drunk, you think you're okay."

"When you're drunk, you're ready to go."

Others added that, by the time they're drunk, so are the friends around them.

\section{"Preventive measures" participants use to avoid drinking and/or drinking and driving}

Virtually all the participants said they had been a designated driver at one time or another (but see discussion below). Others said they drink in bars close to home or close enough to take a taxi home: many participants said taxis are not a realistic preventive measure, because they are so expensive. Several also complained that public transportation doesn't work as a preventive measure because the Metro stops running at midnight. Several said that "sleeping over" is becoming more and more common. In general, the women in Bethesda seem to plan ahead to avoid drinking and driving more than the male participants. 
Several commented that, if they realize they have had too much to drink, they will "stop somewhere and get something to eat."

Participants in both groups realized that not drinking is a preventive measure in itself, but participants in the first group were not ready to consider it seriously. Some participants in the second group said they really don't have any problem not drinking at all: one participant said her family didn't drink so it wasn't hard for her not to drink; conversely, another said her family had experienced some problems with drinking, so she didn't have any problems not drinking.

\section{ATTITUDES TOWARDS DRINKING, NOT DRINKING, AND STAYING IN CONTROL}

\section{Experiences as designated drivers}

As noted in the section above, most participants report having been a designated driver. However, a "designated driver" to many can be a person who does not drink as much as the others (many seem to think two drinks are acceptable for a designated driver), or a person who "slows down around midnight" to sober up:

"We usually work it so that there's always a designated driver who slows down around midnight."

Other participants reported bad experiences with other designated drivers:

"I've had designated driver friends get drunk, so I'd have to drive when I didn't expect to. That's upsetting."

Several participants complain that men will not admit when they've had too much to drink--"It's a macho thing." Or, "they're too immature to admit it." Several feel that "women can be more honest about admitting weakness." Others complain that "wives are always driving-it's unfair."

One participant said she doesn't really drink, so her friends simply assume that she will be the designated driver. Another said she has a friend who doesn't like to drink, so he's usually the designated driver ("he'll just have a beer or two").

\section{Reasons for being a designated driver}

Participants in the first group were more likely than participants in the second group to say directly that they act as designated drivers out of concern for their friends:

"Because you care about your friends. You sacrifice one night of fun."

"Like a friend's birthday: You say I'll be there for you." 
Participants in this group were also more likely to say that nobody wants to be the designated driver all the time: "it's not as much fun." Many seem to take tums with roommates and close friends. driver:

Participants in the second group mentioned more personal reasons for being a designated

"I feel safer when I'm behind the wheel."

"To be in control."

"To be able to leave when you want to."

At least a couple of participants in this group had already said that they don't drink much and are usually, or often, designated drivers. However, others said that they wouldn't want to do it all the time, because "sometimes you want to drink." One or two participants in each group also complained, "you have to pick up sloppy friends when they're drunk." "It's like you're a baby-sitter."

\section{Images of people who never drink}

(Participants were shown photographs of animals and asked to imagine what the animals' drinking and driving behavior might be, if they were human. The actual choice of animal is not to be taken as overly significant, except in the verbal associations the participants raised. Copies of the pictures are included as an appendix to this report).

\section{People who never drink}

Several participants in both groups said they would imagine the kitten never drinks, because he looks "innocent." One said he wouldn't drink because he's satisfied with his life and likes to stay at home. Another participant indicated the lizard wouldn't drink because he's real "chilled," and doesn't look like he would want much stimulation.

Several participants in the second group said the penguins wouldn't drink because they were a family. They used expressions such as "love is more important than drinking," and "they wouldn't hurt the kid." Some participants argued that drinking is more of a single's activity, but others disagreed.

Several participants in the first group said the eagle would not drink because he is "wise," "learned," "old," "alert," "knowledgeable," "regal," and "needs to survive."

When asked directly (without the pictures) what images they held of people who never drink, participants had a more difficult time: in the first group, participants disagreed about whether non-drinkers are self-confident people or timid. Others said they might have had 
alcoholic parents, while others suggested they, themselves, might be in recovery. Participants in the second group said that there was no one particular characteristic non-drinkers shared: "people who just don't like it." However, some suggested they may be people who have had bad experiences with drinking.

People who drink but never drive impaired

Participants in the second group had similar associations with the eagle as the first group, and imagined he might drink but would never drive impaired: "he's flying, so he should have his senses." "He's proud, doesn't want to look foolish." They also said the tiger and the wolf looked "together," and wouldn't drive impaired, nor would the fox, because he is an "intelligent creature."

Participants in the first group said the gorilla wouldn't drive because he's "familyoriented," "protecting," and "intelligent." In a different vein, some said the sea otter looks "responsible, but a fun guy, too--too cute to be bad."

When asked directly (without the pictures) what images they held of people who drink but never drive impaired, participants in both groups used the word "responsible." Participants in the first group added "educated," "know their limits," and "cares about other people than himself." Participants in the second group added "aware" and "alert."

People who drink and sometimes drive impaired

All agreed that the dog wearing a snorkel would drink and sometimes drive impaired because he looks "playful," but participants disagreed about whether or not he might be a sloppy drunk (the first group generally seemed less harsh in their judgements). Some participants in the first group said the gorilla would sometimes drive impaired: one suggested that he was smart enough to know better, but would give in to peer pressure. Another said it'd be a "macho" thing:

"He'd say, 'I am the man, and I can drink and drive. And nobody can stop me."

When asked directly (without the pictures) what images they held of people who drink and sometimes drive impaired, both groups said "the average person." Most seemed to think that they are not irresponsible people, even though they sometimes make an irresponsible decision.

People who drink and drive "all the time"

Participants in the first group also seemed to associate over-drinking with aggressive, male characteristics. They suggested that the bear, the bull dog, the tiger, the wolf, and the shark would all "drink all the time." One participant then commented, "They're all very aggressive--all of them." Another commented: 
"The tiger, the bear, they remind me of men--arrogant, aggressive, male-oriented."

Participants in the second group agreed on the shark:

"He's a killer. He doesn't care. No concern for others."

However, they also indicated that others drive drunk out of sheer foolishness: they said the zebra is an "ass, really confused;" the otter is "pretty wasted;" and the dog with a snorkel is "just stupid."

When asked directly (without the pictures) what images they held of people who drink and drive impaired "all the time," participants made much harsher judgements than they did about people who sometimes drive impaired:

"Stupid."

"Jack-ass."

"Has problems."

"Serious problems, not just irresponsible."

"Uncaring."

"Short-sighted."

People who are designated drivers

Both groups suggested that the eagle could be a designated driver:

"A symbol--wise and responsible."

"He soars over and watches everybody."

"He takes care of himself, so he has to be responsible."

Others suggested the penguin, because of their family values and concern for others. Some said the tiger also looks "friendly" and "caring." Some said the iguana might be a designated driver because he's "passive and slow."

When asked directly (without the pictures) what images they held of people who are designated drivers, participants used the word "responsible," but they spent more time talking about personal characteristics of being caring, concerned, understanding and easy-going: 
"A caring, concerned person."

"A person who cares about friends."

"Even caring about strangers."

"Easy-going, understanding."

Participants in the second group also commented on mental and personal strengths:

"It comes with being aware."

"A very secure person, secure with yourself."

"A person who can stand up to a lot of pressure."

\section{ROLE PLAYING, INCLUDING PARTICIPANTS' PERCEPTION OF HOW THEY WOULD} DEAL WITH SEVERAL SCENARIOS:

\section{A. A friend becomes too drunk to drive}

Participants developed two solutions in this role playing scenario: both groups suggested having the driver stop drinking, get something to eat, and wait to sober up; the second group suggested having the person sleep over at the house of one of her friends.

The first group seemed to realize that the first suggestion is not necessarily the best, but it does seem to be a common practice. One participant commented, " Usually none of us want to drive, but usually one person comes through. It's not always the best, but..."

Participants in the second group said, "It's not a big deal to stay over," and the "driver" in the scenario said she would probably do it. However, she also said she might "start drinking water, hang out, and sober up." Other participants said sometimes they couldn't stay over, because they had to go to work the next day, and some expressed concern about leaving the car on the street: "If you have a nice car, it'll get stripped."

\section{B. A designated driver decides "one or two can't hurt"}

The groups responded somewhat differently to the second scenario: participants in the first group generally agreed that "one or two can't hurt: you have one or two, but no more." The general feeling was that most designated drivers do have one or two drinks. Most of the participants in the second group also agreed:

"I expect the designated driver to have one or two." 
"I would not fly into a panic."

However, a few expressed some concern, and some said they would stop drinking themselves if a designated driver started drinking (reactions in the second group were somewhat affected by the fact that the participant playing the role of the designated driver had said that she was a light drinker).

\section{A designated driver becomes too drunk to drive}

The responses of the two groups differed even more on the third scenario, where the designated driver became too drunk to drive. The first group indicated that they honestly wouldn't resolve the situation very well: they expressed some anger at the designated driver ("way to go," and "thanks a lot"); indicated that they wouldn't take a taxi, because it was too expensive; they probably wouldn't call someone else to come pick them up (they indicated they would think about that solution, and some said they would come pick up friends in similar situations, but at 3:30 am, they said it would be hard to think of people); and, finally, they commented on how easy it is to "talk people into believing you're okay."

The second group, however, indicated that they would call someone to come pick them up: "There's got to be somebody you can call." Several said they have called friends and brothers in similar situations.

Participants in the second group also said that "if you're driving, you ARE the designated driver: the two are one in the same," indicating that they are planning ahead to limit driving to one person.

\section{People begin encouraging the designated driver to drink}

Participants indicated that this scenario is "true:" people will pressure a designated drinker to drink. Participants in the first group again indicated that one or two drinks wouldn't hurt the designated driver, while participants in the second group said the designated driver should resist, or perhaps get a non-alcoholic beer.

\section{FRIENDS AND FAMILY}

Participants in the first group were asked directly about the influence of family and friends. They talked a great deal about peer pressure to drink, even when they are acting as designated drivers. They feel that friends should be dependable and trustworthy, but they aren't always, when drinking is involved.

They also readily accept that the family is important and no one should do anything to hurt their family, but they indicated that they didn't see that value as very relevant to drinking situations: "you don't think that far ahead;" and, "you don't think about the consequences." 
Participants in this group said that they felt some pressure from some family members to drink. However, several commented that they or their friends have family members, including parents, in recovery, which is an influence on them to drink more responsibly.

(Participants in the second group were asked to choose colors and draw shapes that somehow represented "friends," "family," and "driving responsibly." As with the animal photographs, the actual colors and shapes are not to be taken as overly significant, except in the verbal associations the participants raised).

Associations with the value of friendship

Several of the participants drew circles or hearts and talked about "inter-locking relationships. Many of them used adjectives such as "warm" "cozy," and "happy."

Associations with the value of family

Again, many participants drew circles or hearts. A few drew houses. They used adjectives such as "connection," and, again, "warm, cozy." However, some participants indicated that their families were not close, and a few specifically mentioned alcohol-related problems.

Associations with driving responsibly (designated driver)

Several participants drew shapes representing their idea of a designated driver. One drew a triangle and said being a designated driver was like separating parts of her personality-"wanting to have fun, but also staying in control." Another drew a straight line for a designated driver because "you know where you're going." Still another drew a "solid circle," because "you're a solid person." Two drew rectangles, one saying "you know where you are going, straight lines." However, the other said she's generally the designated driver, and she thinks people think she's "boring, a geek." Still another drew a red badge, and said, "You're proud, being the bold one in control."

How those associations might be related

One of the most important findings is that participants did easily associate the three images together in a number of ways, indicating that the values "fit together" in a way that makes emotional sense to them: several drew their circles or hearts "around everything--it's all together."

"I did the circle around everything. It's "interconnected," all related. If you want to be happy with friends and family, you're not going to screw it up with doing something stupid."

"It's all together. I love my family, I love my friends, and I love myself, so I'm not going to drink and drive." 
They were also asked to write down one word that describes the relationship between the three images. In addition to the word "interconnected," participants used the terms "secure," "responsible," and "compromise."

\section{Final Considerations}

Ways participants believe people can be encouraged to drive responsibly

Participants discussed the need for greater education and awareness, in the schools and in the homes. Several said the idea of the designated driver "grew up with us," and needs to be stressed with "kids." People need to be taught that one night's fun is a small sacrifice for friends.

The relative effectiveness of "positive" approaches and "scare tactics" or guilt-ridden approaches

Participants said that they believe "scare tactics" are more effective than an appeal to values, but they pointed out that it is possible to do both. 


\section{MEN (BETHESDA)}

\section{SOCIAL ACTIVITIES AND THE ROLE OF ALCOHOL}

\section{Leisure time activities}

Both male groups named sports as major leisure time activities (hockey, tennis, baseball, football, running, and hiking). The first group talked about clubs, concerts, and "girlfriends," while the second group mentioned "the babes."

Participants in the second group appeared much more socially-oriented and most appeared to be heavier drinkers than participants in the first group.

Activities and situations that lead to greater or lesser amounts of drinking

Participants at first said that "sports and drinking don't mix," but some then said they drink when they play some sports, such as softball, golf, and volleyball. Others said they drink after playing some sports. Several said they drink when watching sports.

Most drink most heavily when out at bars with friends or at parties (particularly when the drinks are free). Participants also tend to drink more heavily at clubs:

"Clubs make you feel like drinking more. I feel more comfortable because of the setting and the people I'm with."

"Especially if you don't like the music--it doesn't sound so bad after you drink."

"Dancing--the more you drink, the less you care."

Conversely, one participant said he didn't drink at concerts, because he's more interested in the music."

Participants in both groups mentioned the same reasons for drinking as the women in Bethesda: it's relaxing; it relieves stress; it "facilitates conversation."

The influence of friends and members of the opposite sex

v Most said they drink less when they are with girlfriends, particularly when they are first getting to know someone:

"If she doesn't drink, you don't swill down the brews."

"You don't want to get sloppy with women." 
Others said that they were more likely to drink wine when out to dinner on a date.

Both groups indicated that drinking was a social activity, something that you do with groups of friends. However, the participants in the first group referred to "peer pressure" throughout the course of the discussion. They first mentioned this in a relatively positive way, "you drink because everyone else is," but, by the end of the session, several had indicated serious concern about the situation.

\section{Problems associated with drinking}

Both groups mentioned hang-overs. The second group also talked about "forgetting what you did," "doing stupid things," and "waking up next to somebody strange." The first group, however, mentioned the problems with driving immediately, and indicated a fear of legal consequences, including going to jail (a concern they returned to later in the evening).

Perceptions of drinking and driving, including perceived differences between drinking-and-driving and driving "drunk" or impaired

Some participants in both groups said they thought the drinking and driving problem "is getting better." However, some disagreed, saying, "People are more discreet now. We drink in Slurpee cups now (while driving)." Another said, "People are more aware now, but I still have friends who drink and drive.

Participants in both groups had very different perceptions of what "driving impaired" means: some said that even one sip of an alcoholic drink "impairs" a person to some extent, while others seem to think that people begin to become impaired after two or three beers, although they usually don't realize it.

Participants sometimes use the phrase "drinking and driving" to mean literally drinking while behind the wheel. Most participants seemed to make a distinction between driving responsibly after a few drinks and driving while intoxicated. Many seemed to be think that driving after two or three drinks is acceptable, but perceptions of "personal limits" varied greatly.

\section{Perceptions of "limits"}

Several participants mentioned a personal limit of two or three drinks for driving:

"I' $m$ a designated driver and I have two drinks and I'm safe to drive."

"We decide at the beginning (who will be the designated driver)-limited to two or three max." 
However, as with the women, many have much higher limits, or said that it varies, or depends on how they feel:

"I never get too drunk. I set limits--six or seven or eight beers."

"After I feel a buzz, I say that's it."

"I drink in the beginning until I feel a buzz, and then I taper off."

"I know what it feels like when I shouldn't. If things feel fuzzy, I don't drive."

"It changes according to the situation."

"We used to drink and drive. Now we moderate it. Or, by the time we go home, we're sober."

"This is your own personal limit: how you relate to your own drunkenness."

Situations where participants have driven impaired

Most of the participants in the second group admitted that they sometimes drive impaired. For them, it seems to be mostly a matter of not always realizing how impaired they are. However, participants in both groups seem to be taking measures to cut down or eliminate the times they do drive impaired. Several said they have been more careful as they have gotten older and more experienced.

"Preventive measures" participants use to avoid drinking and/or drinking and driving

Most participants have been designated drivers at some point. Many also mentioned "waiting it out:" stopping their drinking at a club at midnight and waiting until two o'clock to drive home. Several participants in the second group make a point of walking to close-by bars (one said he had to drive, "but it's only a couple of blocks"). One participant said he regularly takes the metro when he knows he's going to be drinking. Others agreed that public transportation is a good option, but that the Metro closes too early. Some have taken taxis, but many commented on how expensive they are. alternative.

Men were much less likely than women to mention sleeping at a friend's house as an 
When asked how they might avoid drinking altogether, participants in the second group suggested "drinking responsibly." (sic, despite the contradiction in logic). They also said "you could not go out at all," but they quickly said, "that's not really an option."

\section{ATTITUDES TOWARDS DRINKING, NOT DRINKING, AND STAYING IN CONTROL}

\section{Experiences as designated drivers}

Most participants have been designated drivers. One who had not had recently moved to the Washington area from Manhattan, and he commented that no one ever needs to be a designated driver in New York City because of the public transportation and the taxis.

At least one participant commented, "If you're married, you have a built-in dd."

Another directly said, "Whoever is the least drunk is the dd."

\section{Reasons for being a designated driver}

Participants in both groups said that they take turns with their friends. Participants in the second group said some people might be "on the wagon" or might not "feel like drinking," but they seemed to be talking about people other than themselves. On the other hand, participants in the first group -- the same participants who had earlier talked about the peer pressure to drink-

- made similar comments, and seemed to be talking about themselves:

"Some people don't like to drink. Being a designated driver relieves them of the pressure."

"People like to have an excuse not to drink."

Images of people who never drink

(Participants were shown photographs of animals and asked to imagine what the animals' drinking and driving behavior might be, if they were human. The actual choice of animal is not to be taken as overly significant, except in the verbal associations the participants raised).

Participants in both groups said that the kitten would never drink because it looks innocent. Participants in the first group also said the zebra wouldn't drink because he is "standoffish" and "doesn't want to be associated with others" (the zebra is pictured as being standing in the opposite direction of the other zebras).

Participants in the second group said the penguin would not drink or would be a designated driver because of their concern with their family. The second group also said the tiger would not drink because he is "wise." Participants in the second group also said the eagle would never drink, or, at least, would never drink and drive because he "has to fly to live," and needs 
to be "sharp" and "in control."

When asked for their image of people who never drink (without reference to pictures), participants in the first group said "committed," because "it's easier to drink than not to drink."

People who drink but never drive impaired

Some participants said the shark would drink but not drive impaired, because "he wants some beers, but he wants to be alert." Some said he would not drink at all, for the same reason. Some participants also saw the shark as "a leader," in strong contrast to the two groups of women.

Again, some saw the eagle as someone who would drink, but never drive impaired, because he needs to be in control.

Participants in the first group said that people who drink but never drive impaired are "responsible," but they also suggested that they are "afraid of the consequences."

People who drink and sometimes drive impaired

Participants in the second group said the fox would drink and drive impaired and get away with it because he's "sly, smooth."

One participant suggested that the penguin would sometimes drive impaired: he interpreted the picture of the two adult penguins and one infant penguin as being a father, who was arguing that he could still drive, and a mother, who was arguing that he shouldn't. The participant said she was going to win the argument "because she has the child."

Participants in the first group said that people who drink and sometimes drive impaired are "normal:" "that describes a lot of us."

People who drink and drive "all the time"

Participants in both groups said the bear drinks and drives all the time, because he's "big," "dumb," "doesn't care." Participants in both groups thought both dogs would drink and drive all the time because the pug "looks like he's about to fall over" and the dog with the snorkel "looks flaky." (However, some disagreed and said the dog with the snorkel is just "playful" or a "risk-taker;" they thought he would drive impaired sometimes).

Interestingly, both groups said the wolf would drink and drive all the time, but for opposite reasons: participants in the first group (again, the group concerned about peer pressure) said the wolf would drink all the time because "he's hanging out, running with the pack--it's a pack thing." Participants in the second group said the opposite: the wolf would drive drunk all the time because he's "a loner, doesn't care what he does." 
One participant said the iguana was a drunk driver because "his reflexes are gone."

Participants in the first group described people who drive impaired all the time as "irresponsible," "reckless," "dangerous," and "selfish."

People who are designated drivers

The first group said the kitten would be a designated driver because he looks "timid," but others said the eagle would be the designated driver because he's "bold," "a leader," his "wings are all-encompassing--he's taking care of something." "He takes responsibility."

Participants in the second group said the penguin would be a designated driver because he's "a family man." However, they also said the gorilla because he's "the leader," a "good example."

3. ROLE PLAYING, INCLUDING PARTICIPANTS' PERCEPTION OF HOW THEY WOULD DEAL WITH SEVERAL SCENARIOS:

A. A friend becomes too drunk to drive

Participants in the first male group began as the women did, by asking the driver how he or she felt, and whether or not he or she thought he could still drive. However, the male participants indicated that, once they were convinced their friend could not drive, they would take more physically aggressive action: they said they would "physically take the keys away from him," or disconnect the battery." The driver in the first group said he felt "challenged, like I had to argue." (In contrast, one woman had to be encouraged by the moderator to insist that she could drive, to keep the role playing going. She actually said that she would not argue at all if her friends told her she was too drunk to drive).

Participants in the second male group said they would try to gauge whether or not their friend could drive, and then, if they thought he couldn't, they would suggest "getting some food in him" and "waiting it out." This male driver also insisted that he was all right to drive.

B. A designated driver decides "one or two can't hurt"

Most participants agree that "one or two can't hurt" (it is the limit many of them set for themselves as designated drivers). One or two said they might stop drinking themselves.

C. A designated driver becomes too drunk to drive

Since most of the participants agreed that one or two can't hurt, the second scenario was allowed to run into the third, to see at what point friends would get concemed about a designated driver's drinking. Some participants began to show some concern at the third drink: 
"At the third, I'd switch to beer."

Participants showed even more concern at four drinks: participants in the second group said, "That's where I'd pull out the 'dude," as in "Hey, Dude," to "guilt-trip" the friend: "I can't get hammered now that you've had four."

One participant in the first group said, "If he started to drink six or seven, I'd smack him over the head."

\section{People begin encouraging the designated driver to drink}

Participants agreed that this scenario does occur: "It seems real: If someone buys you a beer, you drink it." In both groups, participants insisted that the driver had to take control, but in the actual role-playing, the participants playing the role of friends took active measures to control the situation, in one case, pretending to take the beer from in front of the designated driver.

\section{FRIENDS AND FAMILY}

Participants in the first group again talked about peer pressure, which they see as a conflict: "Peer pressure to drink is not good.". One said that at birthday parties, there is often nothing non-alcoholic to drink. Others talked about friends in recovery, which seem to encourage them to moderate their own drinking.

Participants said that they take turns with their friends being designated driver, which is a way of "looking out for each other," despite what they see as an "inconvenience." (However, one participant said he and his friends help each other by "looking out for the cops" when they drink and drive).

As with the women groups, male participants said that family members sometimes act as a moderating influence by positive example (parents who don't drink) and sometimes by negative example (older brothers with drinking problems).

Participants expressed a concern that, if they were paralyzed or seriously injured in an automobile accident, their parents would have to take care of them.

(Participants in the second group were asked to choose colors and draw shapes that somehow represented "friends," "family," and "driving responsibly." As with the animal photographs, the actual colors and shapes are not to be taken as overly significant, except in the verbal associations the participants raised). 
Associations with the value of friendship

Most participants choose bright colors (red, yellow, and orange). Several drew circles, but others drew something solid, such as a rock or a box with a lid. They used adjectives such as "comfortable," "soothing," "warm," "reliable," and "bright--makes you smile."

Associations with the value of family

Several drew circles or hearts ("hearts signify love"), but several drew houses (rectangle: "four walls mean security") and one drew a pyramid ("wherever you tum, someone will be there").

Associations with driving responsibly

Participants responded very differently when asked to draw a shape that they associated with a designated driver. Three themes emerged:

1. A "straight arrow"--"true blue"

2. Black tombstones and skulls -- "finality,"

3. Gray/purple -- "confusion, a confusing issue," "muddled"

Participants talked about the line as being a choice or decision: "you're on one side or another." They also talked about the line in terms of being "steady," "knowing where you are going."

One of the participants who chose black and drew a skull later said that he had had a family member killed by a drunk driver. The one who drove the tombstone said, "If you don't have a designated driver it will catch up to you."

How those associations might be related

Participants generally literally put things together: family and friends in a house, lines down the middle of the pyramid. They used words such as "trust," "security," "complete," "together," but also "circumstance" ("could be good or bad").

\section{Final Considerations}

Ways participants believe people can be encouraged to drive responsibly

When asked to develop ways to encourage people to drive responsibly, both groups suggested better "education." However, participants in the first group tended to suggest more practical and more enforcement methods: they suggested stricter penalties, more enforcement, breathalizers in cars that would prevent the car's starting if the driver is impaired, breathalizers in bars "for educational purposes," and better Metro hours and lower taxi fares on weekend 
nights. However, when asked directly about positive measures, participants suggested promoting that it takes leadership not to drink and to stay in control.

In contrast, the second group suggested "more caring," knowledge," and "better priorities:" "Is your friendship worth one night of getting plastered?" Even so, participants in this group said that "scare tactics work."

The relative effectiveness of "positive" approaches and "scare tactics" or guilt-ridden approaches

When asked directly, participants said both "positive" and "scare tactics" should be used. Even though some said they personally react negatively to negative approaches, they think some people need them. Participants in the first group compared the situation of drinking and driving to the campaign against smoking, and participants in the second group compared it to the campaign to educate people about the consequences of AIDS. 
DETAILED SUMMARY OF FINDINGS

PALO ALTO, CALIFORNIA

WOMEN

\section{SOCIAL ACTIVITIES AND THE ROLE OF ALCOHOL}

\section{$\underline{\text { Leisure time activities }}$}

Female participants in Palo Alto mentioned many of the same leisure time activities as women in Bethesda, including going out to clubs and socializing. However, women in Palo Alto more often mentioned sports and outdoor activities, such as hiking, camping, biking, and going to the beach. Three participants in the two groups play rugby and another plays Ultimate frisbee. Both groups mentioned going out to clubs, but the second group did not specifically mention dancing (although the first group did). Participants in both groups mentioned sleeping as an important leisure time activity. One participant in the second group mentioned sex as "sometimes" a recreational activity, and a few other participants agreed.

Participants mentioned the same reasons for drinking as participants in Bethesda: "It relaxes you;" "It makes you more sociable;" "You lose your inhibitions."

\section{Activities and situations that lead to greater or lesser amounts of drinking}

Participants in both groups said they drink the most at parties, clubs, and at bars:

"Huge parties--everyone's expected to stay all night."

"At parties--it's the nature of a party."

"I'd put clubs in the same category--the environment, people drink more."

"At a bar, that's a given."

The rugby players and Ultimate frisbee player talked about the importance of drinking beer at toumaments. In both groups, participants used the identical saying, "if you can't beat them on the field, beat them at the party." Participants in the first group talked about drinking at tailgate parties before football games, at drive-in movies, and at the beach.

Participants said they did not drink at work. Several of the athletes said they did not drink as much when they were in training. 
Participants mentioned generally the same reasons for drinking as participants in Bethesda: it's relaxing; it's an escape; it tastes good; and it can create warmth and interaction.

The influence of friends and members of the opposite sex

Several participants in the first group commend on direct peer pressure to drink, but others said it wasn't so much direct pressure as the "environment:" "Like if it's a superbowl party and everybody else is drinking, you do, too." Or, again, "It's the nature of a party."

Some participants said that they drink less with members of the opposite sex, particularly if it is someone they just met, and they gave the same reasons as the participants in Bethesda: "If I've just met someone, I want to be in control."

However, other participants said they actually drink more with members of the opposite sex:

"I drink more. I don't know why. The awkwardness goes away--you don't care what you say."

"It's more social."

"To get the conversation going."

"It gives you something to do--something to do with your hands.

Something to hang on to."

In the first group, one participant asked if they were to assume that "people are drinking to get drunk." She then said that she personally doesn't set out to get drunk. Several others agreed that they usually don't intend to get drunk but "sometimes it just happens."

\section{Problems associated with drinking}

Participants in both groups said one of the problems with drinking is that "it makes you lose control." Both groups mentioned doing things they later regret (including, in the first group, "waking up with someone you don't remember meeting"). Participants in the second group mentioned alcoholism. Participants in the second group specifically mentioned "driving and accidents," and one participant in the first group said specifically, "Sometimes I drive when I think I'm okay, but I really shouldn't."

Perceptions of drinking and driving, including perceived differences between drinking-and-driving and driving "drunk" or impaired

Some participants perceive "driving impaired" and driving "drunk" as very similar. Most seem to agree that there is an acceptable level of drinking and driving. "Impaired" implies the 
alcohol is affecting the driver "too much."

Perceptions of "limits"

Perceptions of "limits" were, as they were in Bethesda, very subjective, or seem to be applied only after the person has already had too much to drive:

"That's a judgement call."

"You can feel it."

"It's a mental thing. I can't think as clearly. Things get fuzzy.

But sometimes you can't tell and drive anyway."

"When I'm walking crooked (I've had too much)."

"If you're fumbling for your keys, you should get someone else to drive."

"It's hard for people to tell."

Situations where participants have driven impaired

Participants admitted that they have sometimes driven when they should not have. Several said they had do so because, at the time, they honestly didn't realize they were impaired. Several complained about designated drivers getting drunk, implying that they had found themselves in situations where they drove because they were "less drunk" than the designated driver. Others talked about the need to get home: "You can't just stay at the club." Several agreed that they would not take taxis because they are too expensive. Others said that it is difficult to call someone to pick them up at two o'clock in the morning.

One participant said she had signed a "contract" with her father, as part of a high school program, saying that she could call him and he would come pick her up, no questions asked, but she was afraid to use it: "That man would beat me."

"Preventive measures" participants use to avoid drinking and/or drinking and driving

Participants have used designated drivers, although not always with success (as noted before, several participants complained about designated drivers getting too drunk to drive them home). Others talked about "waiting it out," eating food, and drinking coffee. Some participants in the second group seemed to think that trying to drive very carefully when they've had too much to drink is something of a precautionary measure: they said they tried not to drive too far or too fast. 
Women in Palo Alto were the most likely of all the groups to report "staying over" as a means they actually use to avoid drinking and driving. The comment about "huge parties" where "everybody is expected to spend the night" has already been quoted. Others talked about going to parties were the host and hostess collect keys at the beginning of the evening; one participant who had lost a friend in a motorcycle accident said her friends always make arrangements for people to spend the night when they have a party.

When asked to develop preventative measures in small groups, participants suggested that if people found themselves too impaired to drive, they should:

1) walk or spend the night where they are

2) appoint responsible designated drivers

3) take taxis

4) call someone to get them.

Participants in Palo Alto seemed more willing to entertain the possibility of not drinking at all than participants in the first female group in Bethesda. They suggested:

1) not going to places that serve alcoholic beverages

2) associate with people who don't drink

3) getting involved in activities that are not associated with

drinking, including exercising and sports

4) drinking non-alcoholic beers

5) simply not drinking

\section{ATTITUDES TOWARDS DRINKING, NOT DRINKING, AND STAYING IN CONTROL}

\section{Experiences as designated drivers}

Most participants in both groups have been designated drivers. Some said they have been designated drivers as an excuse not to drink. At least one person in each group said that her friends always appointed a designated driver at the beginning of the evening and that person did not drink at all. However, for the majority, the experience seems to be much less formal.

\section{$\underline{\text { Reasons for being a designated driver }}$}

Participants in the first group talked about more positive reasons for being a designated driver: "protecting yourself and your friends" (the participant had two friends who were killed), and "out of respect for my friends." Several mentioned taking turns with friends. Participants in the second group said that they didn't trust others (incidentally, it was the first group which complained more about designated drivers getting too drunk to drive them home). Again, some participants in the first group said they sometimes volunteered to be the designated driver so that they would have an excuse not to drink. 
However, participants in both groups said that being a designated driver was "not fun." Not only does the designated driver have to limit her drinking, but she has to take care of drunken friends who can be loud and obnoxious.

\section{Images of people who never drink}

(Participants were shown photographs of animals and asked to imagine what the animals' drinking and driving behavior might be, if they were human. The actual choice of animal is not to be taken as overly significant, except in the verbal associations the participants raised).

Participants in the first group suggested that the kitten would never drink because she is "calm," "peaceful." However, they also used the adjectives "boring" and "too sedate." Others said the iguana would never drink because he's "boring," "slow, methodical--just sits there all day," "really indifferent, and doesn't have "much opportunity to go anywhere."

Several participants said the wolf would not drink because he's "a loner," "by himself," and "kind of serious." However, some said he might be a designated driver because he's "responsible to the pack."

Several participants said the gorilla would never drink because he's "content with himself, doesn't need to drink," and "a pretty serious guy--drinking's too frivolous for him."

Participants agreed that the eagle would never drink:

"Alert--has to be."

"Control freak--too high an altitude."

"On a natural high."

"Above everything, looking down on everyone. Proud, wouldn't risk making a fool of himself in front of others."

When asked directly (without the picture) what images they held of people who never drink, participants said "self-sufficient" and "confident," but they also said, "boring," "a person in recovery," and "careful--maybe had a bad experience in their family."

People who drink but never drive impaired

Although many participants said the bear was a "stupid drunk," (and generally identified the bear as male) one participant in each group said the bear was female and would not drive impaired because she needs to protect her cubs. 
When asked directly (without the picture) what images they held of people who drink, but never drive impaired, participants immediately said "responsible," and "mature," but also "anal."

\title{
People who drink and sometimes drive impaired
}

Participants in the first group generally thought the dog with the snorkel would sometimes drive impaired because he's a "risk taker," "a fun guy," "nice," a "party animal." They also said the fox would sometimes drive impaired because he's "sly," a "frat boy," a "party fox." One participant in the second group said he looked like a "weekend partier." The pug was also seen as a person who would sometimes drive impaired or possibly a person who drinks and drives all the time because he "looks like a frat boy to me;" "happy-go-lucky, sometimes gets carried away:" and "would be drinking beer watching the ball game on t.v., but he'd drive down to the 7 - 11 if he ran out of beer."

When asked directly (without the picture) what images they held of people who drink and sometimes drive impaired, participants said, as did participants in Bethesda, "human," "most people," "people with good intentions, but sometimes you find yourself the least drunk."

People who drink and drive "all the time"

Many participants in the second group said the dog with the snorkel would drink and drive "all the time," because he's "so goofy." Participants in the second group were also much more critical of the fox than the first group, saying he would drink and drive all the time because he is a "sly, creepy type of guy," "the kind of guy who comes over and slobbers on you," the kind of guy who "thinks he's being witty and clever but is really out of control."

Most participants in both groups said the shark would drink and drive all the time, because "he doesn't care;" "he thinks he can do anything he wants;" "he drinks and drives all the time--on a Harley." (One participant in the first group said the shark would never drive impaired because "he takes care of himself").

When asked directly (without the picture) what images they held of people who drink and drive all the time, participants again, as they did in Bethesda, made much harsher judgements than they did about people who sometimes drive impaired:

\author{
"Stupid." \\ "Uneducated." \\ "Dangerous.". \\ "Has a problem." \\ "Doesn't care."
}


"Reckless."

People who are designated drivers

Several said the tiger could be a designated driver because he "can take control," "responsible," "climb on my back-I'll take care of you." Others said that he would never drive impaired because he's "wise," "in control," "strong." Others said the sea otter might be a designated driver because he's "older, alert." However, others said he would be the designated driver because he "looks like the one who gets picked on."

Many said the penguins would be designated drivers because "they're organized;" "they're prepared;" "they have a kid;" and, "they have a lot to live for." like a dad."

One participant said the gorilla would be a designated driver because he's "responsible,

Although many participants said the zebra drinks and drives all the time, several said he might be a designated driver because he's a non-conformist.

When asked directly (without the picture) what images they held of designated drivers, participants said:

"A pal."

"Responsible."

"Conscientious."

"Generally, someone who gives a __ about everyone there."

However, one participant did comment, "A party-pooper."

3. ROLE PLAYING, INCLUDING PARTICIPANTS' PERCEPTION OF HOW THEY WOULD DEAL WITH SEVERAL SCENARIOS:

\section{A. A friend becomes too drunk to drive}

Participants developed essentially the same two solutions as the female groups in Bethesda: having the friend "wait it out" or spend the night at a friend's house. As in Bethesda, participants seem truly concerned about leaving a car on the street or in a parking lot.

One participant who played the role of the drunk friend said that she would quickly acquiesce to her friends if they told her she shouldn't drive. However, several participants said that friends often insist that they are all right to drive when they are not; others admitted that 
they had "fooled other people" on occasions. Participants seemed willing to defer to the driver's own judgement.

\section{B. A designated driver decides "one or two can't hurt"}

Generally, participants expressed no concem at all if a designated driver had one drink. Some began to ask her if she was "all right" after she ordered the second drink, but participants generally did not intervene until the third drink.

Several participants in the second group said they probably would not have kept track of how many drinks a designated driver had had.

\section{A designated driver becomes too drunk to drive}

In both groups, one of the other role players stopped drinking after the designated driver ordered her third drink. Several participants said they would prefer to stop drinking themselves rather than risk a confrontation with a friend. Another participant commented, "You try to find solutions that don't single out the designated driver who is failing in her responsibility."

On the other hand, one participant did comment, "Last time I hang out with you, and other participants laughed. Participants in the second group, who "solved" the situation by deciding to take a taxi home, said they would be a little angry at having to pay taxi fare.

D. People begin encouraging the designated driver to drink

Unlike participants in Bethesda, participants in Palo Alto said that this scenario did not generally occur: people do not encourage designated drivers to drink.

\section{FRIENDS AND FAMILY}

(Participants were asked to choose colors and draw shapes that somehow represented "friends," "family," and "driving responsibly." As with the animal photographs, the actual colors and shapes are not to be taken as overly significant, except in the verbal associations the participants raised).

\section{Associations with the value of friendship}

Again, several participants drew circles or hearts and talked about interlocking relationships, warmth, comfort, and wholeness.

\section{Associations with the value of family}

A few participants also drew circles for their families, although more drew rectangles and houses. Many used brown and talked about being rooted, basic, and "earth-colored." Most 
talked about being connected and happy; some talked about going off in different directions, but remaining connected. However, one participant commented that people go off in different directions, ending in dysfunction.

Associations with driving responsibly (designated driver)

Several participants drew straight lines or rectangles or squares and talked about designated drivers being "even," "balanced," "sturdy," and "a structure you can lean against." Three participants drew tree trunks and talked about being "big," "solid," and "supportive," "looking over people." Several used brown, and again talked about being "rooted," down to earth.

However, one person drew a brown stick figure of a person sitting very straight in a chair, and indicated that "brown is not fun."

How those associations might be related

Participants in the first group had very little difficulty putting the symbols together in ways that they found meaningful, although a few of the participants in the second group did: a couple indicated that the idea of a designated driver was not emotionally important enough to really be associated with friends and family.

Several showed the designated driver supporting the friends and family. Several participants in the first group used the word "life" to describe the relationship, and others used the word "safe." Another used the word "love" and still another used the word "one," because the friends are connected to the family, and the designated driver is behind in support, all one."

Participants in the second group used the words, "caring," "responsibility," "steady," "dependent" (a pregnant woman, the symbol of the family "dependent" on the designated driver for the life of her child), "inter-connected," and "support." However, the participants who weren't sure how the images fit together used the words "periphery," "fracture," and "juggling."

\section{Final Considerations}

Ways participants believe people can be encouraged to drive responsibly

Participants suggested providing practical alternatives for getting people home, such as Tipsy-taxis, which would take people home for free. Some suggested putting breathalizers in bars so that people could learn to gauge the alcohol content in their blood.

The relative effectiveness of "positive" approaches and "scare tactics" or guilt-ridden approaches

Generally, participants agreed that both "positive" approaches and scare tactics are necessary: 
"Different people, so need both."

"Some people need scare tactics. (but) Some people are turned off by negative approaches."

Participants in the second group agreed that the designated driver needs to be shown in a positive light, but "we (also) need to change the whole cultural idea of what a party is."

MEN (PALO ALTO)

1. SOCLAL ACTIVITIES AND THE ROLE OF ALCOHOL

Leisure time activities

The men in Palo Alto mentioned some of the same sports as did the men in Bethesda, but they were somewhat less likely than the men in Bethesda to mention clubs and going out. Instead, some mentioned gardening, cooking and reading. One mentioned fantasy role playing and collecting reptiles. One participant in the first group mentioned "nudie bars" and "the gun range." This participant, a mechanic, was one of the few participants in the two male groups who had no association with the university, and he made some initial comments that indicated that he felt somewhat out of place.

\section{Activities and situations that lead to greater or lesser amounts of drinking}

Participants said they drink the greatest amounts when they "go out with the guys," at family celebrations over the holidays, and at celebrations with friends, including birthday parties. Several said they drink more heavily at other people's houses because it's cheaper.

Participants in Palo Alto and, later, participants in Madison (the two sets of groups with heavy concentrations of students) said they drink heavily after exams.

Some participants mentioned drinking at concerts, but others said they drink less at concerts because they want to be more "mellow" in public, and because lines are long and drinks are expensive.

Several participants in the first group said they do not drink much when they are listening to music and dancing: they are more likely to smoke pot. They say the alcohol dehydrates. (Participants in different cities were generally not asked about their drug use, since the subject was outside the scope of the study, but participants in Palo Alto raised the subject on their own. The first group of men discussed drugs most, although the second group raised the issue of mixing alcohol and drugs. One or two women in Palo Alto also raised this issue). participants:

Male participants listed the same reasons for drinking as other male and female 


\author{
"It relaxes you." \\ "Your inhibitions go away." \\ "It creates a social context." \\ "The taste."
}

The influence of friends and members of the opposite sex

For the most part, male participants in Palo Alto agreed that they drink less with members of the opposite sex, if it's "someone you trying to get to know." However, a few participants insisted that they have women friends (the implication was Platonic) they drink with, and in those situations, a person's sex "doesn't change anything." Another participant mentioned going out with "women who slam them."

\title{
Problems associated with drinking
}

In both groups, participants immediately mentioned hangovers and other physical problems (feeling bloated and dehydrated). People also talked about acting foolish and saying things they didn't really mean, especially in a romantic relationship (one participant did mention waking up in strange beds).

Participants in the first group did not directly raise the issue of drinking and driving, but the second group did. One talked about having a tire blow out when he was driving under the influence. Another said once he encountered an accident in the road ahead of him while he was driving after drinking; he said, "Nothing happened, but it could have."

Perceptions of drinking and driving, including perceived differences between drinking-and-driving and driving "drunk" or impaired

Participants in Palo Alto, as participants in other cities, see the difference in driving "when you're all right" and when you are driving under the influence as individual and subjective: for example, the first group, generally agreed that "two glasses of wine could be impaired, drunk, or not, depending on the person," and they discussed issues such as body weight, time within which the drinks were consumed, and so on.

However, one difference between the men in Palo Alto and the men in other cities was that they expressed much more concern about being pulled over and convicted of driving under the influence. Several participants in both groups have been arrested, or have had bad experiences, and those experiences seem to have affected them greatly:

"I was pulled over and convicted. For me, if I've had anything to drink in the past hour, I don't drive." 
"I drove and hit a pole. I stay away from hard alcohol--I'll have a couple of beers."

"I drove after $\mathrm{x}$ amount of beers and didn't drive for 12 hours. I drove and ran off the road. The car flipped three times. I've been psychologically shaken."

Participants seem to believe that California enforces drinking and driving laws more harshly than some other states. A couple of participants also said they don't even talk about drinking and driving in a normal conversation: "It's a stigma thing when you're talking about drinking and driving."

\section{Perceptions of "limits"}

Again, because of some bad experiences, some participants report fairly strict limits, such as the participant who will not drive if he's had anything in the past hour. Another reported a two beer limit, and another says he will not drink and drive: he uses a designated driver. Still, for the most part, participants reported very subjective limits:

"I just ask myself if I'm capable. Sometimes I am, sometimes I'm not."

"You draw the line and just stop. (But) I let myself drive a little looser than I should."

"I get up. (Ask myself) How much am I carrying the conversation? I get up and walk around to see (how) I'm doing."

"It's if I'm cloudy or sharp."

"Around 12, I stop drinking."

"I have a two part system. I sit at the bar and wait for the room to tilt. If it doesn't, I pass phase I. Then I walk to the door. If I don't fall over, I'm okay."

\section{Situations where participants have driven impaired}

Some participants said they have driven home impaired because their parents expected them to come home for the night. However, most seem to drive home because it's simply more convenient than anything else. Others simply think they're okay at the time. Some of the participants who have been convicted still insist they were capable of driving, including one who tested at $1.9 \%$ blood alcohol. 
"Preventive measures" participants use to avoid drinking and/or drinking and driving

Most participants have been or have used designated drivers (including wives and girlfriends). However, most seem to judge their own limits and "wait it out."

When asked to suggest ways to discourage drinking and driving, the first group tended to suggest scare tactics:

"Televise the results of drinking and driving. Show the gore."

"List the names of people in the paper. Increase the stigma factor--public shame."

"Have cars from drunk driving wrecks on display."

The second group suggested breathalizers in bars, even requiring people to pass a breathalizer test to get their keys (some also talked about breathalizers hooked up to ignition systems to prevent people from starting their cars). They also suggested a shuttle system run by the bars or a "party van" that will pick up people at bars.

Both groups said it was not realistic to try to encourage people not to drink at all.

\section{ATTITUDES TOWARDS DRINKING, NOT DRINKING, AND STAYING IN CONTROL}

\section{Experiences as designated drivers}

Most participants report having been designated drivers, but many say it's very informal, often sorted out at the bar, after drinking. Some say they rely on their wives or girlfriends. One participant said that he and his friends always decide before the night begins, and the designated driver does not drink at all. Most participants said they think it is all right for a designated driver to "have a drink or two."

\section{Reasons for being a designated driver}

Several participants said they were sometimes designated drivers on nights that they "didn't feel like drinking that much." Some said they would take the responsibility, and at least one said he would do it because he knew his friends would be drinking, and he didn't want to ride with them. Another said, "You get stuck. It's your turn."

Images of people who never drink

(Participants were shown photographs of animals and asked to imagine what the animals' drinking and driving behavior might be, if they were human. The actual choice of animal is not 
to be taken as overly significant, except in the verbal associations the participants raised).

Some said the kitten would never drink because she is "shy" and "innocent," although others said she wouldn't drink because she's "too smart," "independent" and "clever."

Several participants said the wolf would never drink because:

"He's back to nature."

"Gets his jollies in a different way--doesn't need alcohol."

"A new age wolf who respects his body and doesn't drink."

Some also said the tiger would never drink, because he is "fierce, has pride, is in control."

Some also said the gorilla would never drink because he has "nobility," "power," he's "not out of control." Others said he could be a designated driver because gorillas care for their young and have a sense of responsibility.

Many participants said the eagle would never drink or would be a designated driver:

"A nature thing--he doesn't need to drink."

"Take care of yourself."

"Looks serious."

"Powerful."

"Has to hunt."

"Has to be up in the air."

When asked directly for their image of a person who never drinks (without the pictures) participants said "restrained, reserved."

People who drink but never drive impaired

Some participants said the iguana would drink a lot, but never drive, because he "never wants to go anywhere--people can come to him." Another said the iguana "would not risk anything."

When asked directly for their image of a person who drinks but never drives impaired (without the pictures) participants said "rational, responsible." 
People who drink and sometimes drive impaired

Participants in both groups said the dog with the snorkel would sometimes drive impaired because "he's a little crazy," or because "he's immature--a kid, not a bad kid." (One or two thought he would drink and drive all the time because he's "wild and crazy").

Even though several participants said the wolf would never drink, one participant said, "He's wild, a trickster. Of course he would."

Similarly, some participants said the fox would never drink because "he needs his wits," but more said he would drive impaired: "He's sly--impaired, but covers it up well." "He thinks he can get away with it."

When asked directly for their image of a person who drinks and sometimes drives impaired (without the pictures) participants said "normal" (similar to other groups), but they also said, "risky."

People who drink and drive "all the time"

Some participants in the first group said the tiger would drink and drive all the time: "He's got that fat guy look -- in his Cadillac." Others said the sea otter would, because he seems "irresponsible, foolish."

Several said the shark drinks and drives all the time:

"Does nothing but drink."

"Doesn't give a __."

"Does whatever he wants."

(However, some said the shark would never drink because he's "strong," "clean," and needs to "keep the system clear").

The pug was also considered a "repeat offender--looks like a chronic alcoholic," because he looks like he has no brains," "not caring."

When asked directly for their image of a person who drinks and drives "all the time" (without the pictures) participants said "foolish, stupid, brainless, not thinking."

\section{People who are designated drivers}

One participant said the dog with a snorkel is "goofy, a clown" and "would get pushed to be the designated driver." Some said the kitten would be the designated driver because she 
"looks timid," "not out-going."

As in some other groups, participants said the zebra could either be a designated driver or a drunk driver, because he's a non-conformist: "the only one in the crowd."

When asked directly for their image of a person who is a designated driver (without the pictures) participants said "generous, selfless, compassionate."

\section{ROLE PLAYING, INCLUDING PARTICIPANTS' PERCEPTION OF HOW THEY WOULD DEAL WITH SEVERAL SCENARIOS:}

A. A friend becomes too drunk to drive

Participants in both groups suggested having the person wait it out, as did men in Bethesda. However, in both groups in Palo Alto, participants offered to let the person stay at their apartment.

In both groups, some participants said they would physically take the keys from a friend who had had too much to drink. However, in one group, a couple of participants said they "would never tell anyone they've had too much to drink." "It's insulting."

B. A designated driver decides "one or two can't hurt"

In general, participants indicated that they would not even react if a designated driver had one drink. Some indicated they would begin to feel some concern, but would not really react until the third.

C. A designated driver becomes too drunk to drive

Participants did react to a designated driver ordering a third drink:

"Okay, Dude. How long since your last drink?"

"Next week, I'll be dd and have one or two, but not three."

Participants' reacted more vigorously to the fourth drink:

"You're not driving, Dude. Keys, please."

However, after the role playing, several participants said the situation would be much more difficult in real life: "In real life, it's not so easy. He might take offense." A few said that they would stop drinking themselves rather than risk the confrontation. 


\section{People begin encouraging the designated driver to drink}

Some participants said they found this scenario difficult to distinguish from the others, because, in real life, they would have one or two drinks as the designated driver. So, the real life scenario would move along the lines of scenarios "B" and "C."

\section{FRIENDS AND FAMILY}

(Participants were asked to choose colors and draw shapes that somehow represented "friends," "family," and "driving responsibly." As with the animal photographs, the actual colors and shapes are not to be taken as overly significant, except in the verbal associations the participants raised).

\section{Associations with the value of friendship}

Virtually all of the participants in both groups drew circles of some kind. Most talked about connections and being "all encompassing." Many also used the word "warmth." Several mentioned associations with nature and the outdoors.

Associations with the value of family

The majority of participants continued to draw circles or hearts, and a few drew rectangles or cubes, including symbols of the house or table. Most talked about loyalty and support, and a sense of belonging, although some commented that they had difficulty with their families.

\section{Associations with driving responsibly}

Over half of the participants drew pyramids or triangles, and used words such as "directed, well-grounded, strong, balanced, stable, sturdy, supporting, and "very well defined." Two drew blue stars for "guidance" and "security." Two drew arrows: "you have to be straight." Another drew a hard hat for "control."

How those associations might be related

Participants had some difficulty seeing how the three images might be related: Some had problems seeing the relationship between driving responsibility and their families, and others had trouble seeing a relationship between their friends and their families. However, several of them said that they learned their values about drinking responsibly from their families:

"My family gave me values to care about other people. I'd drive people I don't know to save them."

"I had trouble putting family in there, except for the values." 
"I learned values from my family. When my friends and I go out, I don't drink."

Even so, participants used words such as "foundation," "connect," "integration," and "unified" to describe their désigns. Others used words such as "care," "security," "responsibility," "duty," "life" and "love."

\section{Final Considerations}

Ways participants believe people can be encouraged to drive responsibly

Participants in the second group stressed the importance of developing the image of the designated driver in a positive way, as a leader.

The relative effectiveness of "positive" approaches and "scare tactics" or guilt-ridden approaches

The groups were somewhat divided on the issue of positive approaches vs. scare tactics. Both groups seemed to prefer positive approaches. However, participants in the first group said they weren't sure if either approach really works. The second group said they believed positive approaches could work, particularly developing the image of the designated driver. However, they also said that scare tactics are "necessary at a young age," and can be effective: they pointed to the anti-smoking campaign and the reduction of smoking among people they know. 


\title{
DETAILED SUMMARY OF FINDINGS
}

\author{
MADISON, WISCONSIN
}

\section{WOMEN}

\section{SOCLAL ACTIVITIES AND THE ROLE OF ALCOHOL}

Leisure time activities

Women in Madison listed sports, including skiing and biking, but also watching sports, crafts, cooking, movies, television, and reading as leisure time activities. The first group did not initially mention bars, clubs, or concerts, although the second group did. They said they usually went to bars in groups of three to four or up to five to ten people.

Participants 'mentioned generally the same reasons for drinking as other groups: It's relaxing; it's a fun thing; it helps to socialize and celebrate occasions; it reduces inhibitions; it tastes good. Participants in both groups said alcohol is good for your health because it reduces cholesterol.

\section{Activities and situations that lead to greater or lesser amounts of drinking}

Participants in the first group particularly talked about drinking with friends at happy hours, at the end of the week or "the end of a long stressful day" (four participants in this group are married). Participants in the second group talked more about nights, weekends, holidays, and dinner parties. Several talked about drinking games at bars and at parties and feeling obligated to drink.

The influence of friends and members of the opposite sex

Participants specifically said, "Things you do by yourself, you tend not to drink. You drink more when you are with other people." Participants in the second group talked about peer pressure to drink:

"At dinner parties, they keep filling up your glass, even if you don't want to drink that much."

"Different people push you to drink more."

"(At birthday parties) The shots keep coming and you feel obligated." 
"My family's house, they really want you to drink to take part in the holiday."

"My family celebrates everything with a lot of alcohol. I don't drink that much. I'm the outcast."

"My husband's family is not satisfied until I drink something."

In contrast to groups in other cities, many of the women in Madison said that they drink more with members of the opposite sex, because drinking in bars is a common thing to do on dates:

"Since I've gotten married, we don't drink much at all, or we drink fast and get real drunk. When we were dating, we drank a lot: that's what we did--drank and danced."

"Same for me."

"It was six months before we had a daytime date. So we always met at night and there was alcohol."

"You keep talking and ordering drinks."

"If I'm not comfortable, I'll drink more to loosen up and relax."

Problems associated with drinking

Women in Madison mentioned some of the same problems associated with alcohol as other participants, including hangovers, health problems, and the expense. As in some other groups, they mentioned the problems of drinking and driving. However, women in Madison were more likely than women in other cities to talk about family problems, violence, and sexual abuse:

"It breaks up families."

"It destroys families."

"My boyfriend's daughter's mother is an alcoholic. It's really hard on the kids."

"Violence. Abuses children or breaks things."

"In high school, a girl passed out at a party, and boys were going in and out of the room taking advantage." 
Participants also mentioned the recent situation at the Wisconsin football game, where several young people were trampled.

Perceptions of drinking and driving, including perceived differences between drinking-anddriving and driving "drunk" or impaired

As in other cities, participants in Madison seemed not to have very clear definitions for these terms. One participant said, "If you've had anything, you're driving impaired." However, most seemed to feel that the term drinking and driving should not be applied to the casual social drinker:

"Drinking and driving is when you know you're losing perception. One or two beers and socializing and then driving is not drinking and driving."

On the other hand, participants see driving drunk as a somewhat undefined, and fairly extreme state. One participant said she knows that .1 is legally drunk, but she also asked, "How many times do you know your own blood alcohol level?" Another said, "Driving drunk is past the point of the buzz," and another, "If you're really drunk, you won't remember driving home."

Participants also were unsure what "driving impaired" actually means. Some said it could include other things, such as drugs, or even stress. A couple of participants said they know people who mix alcohol with drugs.

Perceptions of "limits"

Again, most participants have a very subjective sense of their own limits, or use their physical feelings to judge:

"It's a fine line. Sometimes I can have two drinks and whew!

Sometimes I can have two and not feel anything."

"It's the feeling. Your face gets hot, cheeks get pink, your fingers tingle."

"You can feel it."

"I know if I stand up and don't feel coordinated enough to walk." 


\section{Situations where participants have driven impaired}

All of the participants in the first group and most in the second said they have driven when they have had too much to drink. Some said they did not want to leave their cars at the bars; others said they didn't realize until they were halfway home that they shouldn't be driving; some said they didn't think about it until the next day. One participant said she knows that there was no real reason why she had to be home--"just plain stupidity."

One participant said she had to get home:

"When you have kids, you have to get home because of the baby sitter."

Several said they drove because the designated driver "fell through:"

"You relax and depend on someone else, and they get drunk, and you end up driving. It isn't the person who is sober who drives home; it's the person who is least drunk."

"If someone tells me I can't drive, then I'm going to drive. I know I'm in better condition than the person slurring words in my face asking for my keys."

"Preventive measures" participants use to avoid drinking and/or drinking and driving

Participants talked a lot about designated drivers, although there seems to be some disagreement about how effective designated drivers are. One participant said:

"Designated drivers have caught on quite a bit here. I used to be a bartender. A lot of people stay sober. They're responsible for getting others home."

But another said:

"We check on people before they drive, but if they are the designated driver, no one else is in better shape to drive. People are more aware, but the actions have drastically changed."

Several talked about taking turns with their husbands or "significant other," although some of them admitted that they usually end up driving.

Others talked about walking to bars, taking taxis or buses (even biking), calling a friend to pick them up, and spending the night somewhere. 
When asked to develop solutions for encouraging people to drive more responsibly, participants suggested breathalizers in bars and/or in cars and having a service to pick people up. Individuals should consider and calling someone to pick them up, taking taxis, or staying there. Some suggested making legal penalties stronger.

When asked to develop solutions for encouraging people to avoid drinking, participants said people could focus on non-drinking activities, such as movies. They said people could also provide more non-alcoholic drinks; several said that often at parties, there are no non-alcoholic drinks available except water. Finally, people said you could eliminate bars, but added, that's not a real option in Wisconsin.

\title{
2. ATTITUDES TOWARDS DRINKING, NOT DRINKING, AND STAYING IN CONTROL
}

\section{Experiences as designated drivers}

All of the participants in the first group and over half of the participants in the second group have been designated drivers.

\section{Reasons for being a designated driver}

The two groups gave almost identical reasons for being a designated driver:

\author{
"Some nights you don't want to drink." \\ "You've experienced a ride with a horrible driver when they're \\ drunk."
}

"Concern for your family and friends. You want them to get home in one piece."

"No one else wants to be the designated driver--someone takes the responsibility."

"You take turns."

Participants in the two groups also gave identical reasons for not wanting to be the designated driver:

"Boring."
"Not as much fun."

"Don't want any limitations--the mission is to get drunk." 
"You've been doing it too frequently."

One participant also mentioned not wanting drunks in her car.

Images of people who never drink

(Participants were shown photographs of animals and asked to imagine what the animals' drinking and driving behavior might be, if they were human. The actual choice of animal is not to be taken as overly significant, except in the verbal associations the participants raised).

Participants in the two groups agreed that the iguana never drinks: "very zen--wouldn't want to be bothered with a hangover." However, they also said, "He's too lazy to drink," and "No friends."

Some people said the penguins would not drink, or at least wouldn't drive drunk, because they're "a family, taking care of each other." (However, like the men in Madison, some of the women said they would be social drinkers, because of their "tuxedo" outfits).

Many participants agreed that the eagle would never drink:

"Smart, majestic, wouldn't do something stupid."

"Very pure. Wouldn't need to drink to have fun."

"Up above watching over everyone, in control."

"A symbol of America and the American dream."

"Rare, almost extinct."

When asked directly (without the pictures) what images they have of a person who never drinks, participants used the words "smart," "pure," "serious," "Christian," "happy with themselves," and "well adjusted," but also "boring," "square," and "geeky."

People who drink but never drive impaired

Some said the tiger would never drive impaired because he looks "in control," a "leader."

Some said the bear would drink but not drive impaired because he "reminds me of a teddy bear--fun, cuddly, but also caring and responsible."

When asked directly (without the pictures) what images they have of a person who drinks, but never drives impaired, participants used the words "responsible," "in control," and "doesn't buckle under pressure." 


\section{People who drink and sometimes drive impaired}

The groups agreed that the sea otter would drink and drive impaired, although the first group said he would only drive impaired sometimes, while the second group said he would all the time. The difference seems to have been that the first group saw him as "fun-loving:" "He might not intend for it to happen, but it might." The second group saw him as "all wet and sloppy."

When asked directly (without the pictures) what images they have of a person who drinks and sometimes drives impaired, participants said "us," "average."

\section{People who drink and drive "all the time"}

Most participants identified the dog with a snorkel as someone who would drink and drive all the time, because he's "silly," "crazy," a "risk taker." However, some said he might only drive impaired sometimes, but he is somewhat responsible.

Most of the participants also identified the pug as someone who drinks and drives all the time: "Look at that face. People who drink all the time are ugly and have bad breath."

Several said the wolf would drink all the time, because he's "crazy," "howling at the moon." However, one participant said he would drink all the time because he is a "symbol of freedom--no restrictions."

Some said the fox "drinks and drives all the time and is happy he got away with it." Others commented that he's "sly, tries to get by."

Several said the shark would also drink and drive all the time, because he looks like "a guy who is drunk and on the prowl, aggressive," and because, "he wouldn't care about the police or anything--out to kill."

Some participants said the gorilla would be a "a mean drunk who drives a big truck. Drinking and driving is part of his macho."

Some participants said the zebra would drink all the time because he's "the ham," "the clown," "he's mooning the camera."

When asked directly (without the pictures) what images they have of a person who drinks and drives all of the time participants used the words "carefree," "reckless," and "lots of problems." 


\section{People who are designated drivers}

Some respondents said the kitten would be a designated driver because she is "very serious." However, they also added that she is "not having a good time." Some also said the wolf was a designated driver, because he is "lonely," "by himself."

Some said the tiger is a designated driver because he "looks serious" and "sets the rules."

Even though most participants identified the pug as a heavy drinker, one participant said he would be a "guaranteed designated driver, otherwise he'd never get to go out. He wants to be part of the group, but has no social skills."

Some participants said the gorilla would be a designated driver because they are "caring and gentle with their young." Others commented that the gorilla looks "very controlled."

When asked directly (without the pictures) what images they have of a designated driver, participants used the words "responsible," "caring," and "dedicated."

\section{ROLE PLAYING, INCLUDING PARTICIPANTS' PERCEPTION OF HOW THEY WOULD DEAL WITH SEVERAL SCENARIOS:}

\section{A. A friend becomes too drunk to drive}

The two groups differed somewhat in response to the first scenario. In the second group, the participant playing the role of the person becoming too drunk to drive agreed right away to let someone else drive her home, and several others said they would not argue with their friends if they told them they shouldn't drive. When asked what they would do if the role player didn't quickly agree, the other role playing participants offered to take the person who had had too much to drink to their home for the night and bring her back to get the car the next day. Some said they have done this.

In the first group, even though role players offered to give the person drinking too much a ride, they were not as sympathetic to the person, and said that in real life, their friends would not be sympathetic:

"I'm not driving you home. Be an adult."

"My friends would not be real sympathetic. They'd say, you made your bed."

"It's a mind your own business thing. You don't want to mother-hen your friends." 


\section{B. A designated driver decides "one or two can't hurt"}

As in other cities, most participants agreed that one or two drinks can't hurt a designated driver, so most participants did not respond until the third drink:

"If I were the designated driver, I'd drink a beer."

"If one or two turns into three or four, then I'd say something, but being the designated driver doesn't mean that person doesn't drink."

However, within this general agreement, there were some variations. One participant did say she would rather not drink herself than have the designated driver drink. On the other extreme, one woman said that she would drink four beers as a designated driver.

As in other cities, participants indicated that designated drivers are not selected at the beginning of the evening, and some even used negative language to describe the designated driver:

"Nobody is designated at the beginning of the evening."

"It's more of a comment in passing, rather than a formal decision."

"A designated driver may not be designated before you start drinking. He is someone who is thought of as kind of nerdy. No one wants to be the designated driver."

One participant had a novel way of forcing others to become the designated driver:

"When I get drunk, I beg people for a ride, or I puke and then anyone will drive me to get me out of there."

\section{A designated driver becomes too drunk to drive}

Most participants began to say something to the designated driver at the third drink, and they discussed other ways to get home. In the first group, the designated driver suggested calling her husband to come get them; in the second group, they decided to take a taxi.

\section{People begin encouraging the designated driver to drink}

The two groups also responded differently to this scenario. Participants in the second group said it was unrealistic: they might have two or three drinks as a designated driver, but no one would pressure them. However, participants in the first group reported peer pressure, or at 
least social pressure, to drink:

"Happy hour, my supervisor wants everybody to drink. He'll buy shots for everyone. He's real insistent, so I drink just to get rid of him."

"At parties, they just pass out drinks."

"Co-workers and people know what I drink, and they just buy me drinks."

"It's not real pressure, more the situation. People think they're doing you a favor--make you lighten up."

\section{FRIENDS AND FAMILY}

(Participants were asked to choose colors and draw shapes that somehow represented "friends," "family," and "driving responsibly." As with the animal photographs, the actual colors and shapes are not to be taken as overly significant, except in the verbal associations the participants raised).

Associations with the value of friendship

Several participants in the first group drew circles, and talked about being "connected," "a circle of friends." Another drew a pentagon: "An enclosed group of friends; the points are the individuals." Two others drew figures of people holding hands.

Participants in the second group drew hearts and flowers and Shamrocks (her best friend is Irish), and talked about warmth. Two drew rectangles for tables and talked about communication.

\section{Associations with the value of family}

In the first group, half of the participants drew houses and talked about growing up with love and acceptance. However, others talked about conflict. One drew a jagged red line; she said her dad died at three, and the red was for anger. Another drew a red diamond and said, "We all go to different points." Another drew concentric circles, and said "As we get older, we go away, go apart and the togetherness isn't there.

Some participants in the second group also indicated family conflict: one drew a misshapen heart, "because there has been a lot of miscommunication, and my family has caused a lot of pain; another drew a black sheep with the head backwards, because "I feel like the black sheep." One drew a coin: "My dad gavẽ it to me. It represents five years of sobriety. It's a 
big accomplishment."

Associations with driving responsibly (designated driver)

Participants in the first group drew fairly straight-forward symbols for the designated driver: several drew straight lines and talked about being straight, although one commented that the designated driver is geeky; one drew a black "V," like a bird watching over, like the eagle, doesn't need drinking for the night; several used yellow, the highway sign color.

Two participants in the second group drew a star and talked about "looking up;" one drew a brown peace symbol, and another drew a "no drinking" symbol; and two drew representations of a person driving a car.

How those associations might be related

The second group generally combined the symbols and talked easily about the relationship of friends, family, and the designated driver: that if you care for your friends and family, you should drive responsibly. They used words such as "life," "good," "caring," (several participants) "responsible," home," and "connectedness."

On the other hand, the first group had difficulty placing the family in this context, partially, they said, because they had never discussed drinking and driving with their families:

"I wasn't sure what to do with "family." Drinking and driving wasn't an issue we discussed."

"I didn't use my family because I don't drink with my family."

"My family never discusses the designated driver. We all drink and drive. But $I$ do discuss it with my friends."

"My family talked a lot about values and principles, (but) drinking and driving is not a value we talked about."

\section{Final Considerations}

Ways participants believe people can be encouraged to drive responsibly

The relative effectiveness of "positive" approaches and "scare tactics" or guilt-ridden approaches

Participants in both the female groups in Madison agreed that scare tactics are more effective. Some recommended using the values of family and friendship, but as part of scare tactics: 
"Scare tactics are effective--if you see a crash and a skeleton, that has more effect than a value-based one."

"The scare tactics affect me."

"Scare tactics are effective."

"Scare tactics work. Someone can scare you subtly."

"We thought scare tactics were more effective, like the

commercial showing the glasses breaking on the graves they

show on television."

"The graduation scene with the boy or girl missing."

\section{MEN (MADISON)}

\section{SOCIAL ACTIVITIES AND THE ROLE OF ALCOHOL}

Leisure time activities

Male participants in Madison mentioned some of the same sports as men in Bethesda and Palo Alto, including volleyball, football, basketball, golf, and racquetball. More participants mentioned skiing in Madison than in the other cities. The men also mentioned fishing, swimming, and hiking. Shooting pool and darts seem to be more popular activities in bars than dancing; participants said dancing was not very important in Madison, although there are some clubs where people dance.

Participants also mentioned drawing, reading, rebuilding cars, computers, and Nintendo. One participant mentioned sex, and there was a lot of laughter in agreement.

Participants in Madison generally listed the same reasons for drinking as other male participants, although they seemed more likely to talk openly about using alcohol as a means of escape:

"It's fun. For the buzz."

"It's a release."

"It reduces inhibitions. It reduces anxiety."

"It's a way to socialize."

"It's a good excuse (to do what you want to do)." 


$$
\begin{aligned}
& \text { "Short-term memory loss." } \\
& \text { "No one remembers (what you did)." } \\
& \text { "It makes you do things." } \\
& \text { "It's an escape." }
\end{aligned}
$$

One participant also said, "It gives you confidence if you want to hit on a certain someone."

In general, the male participants in Madison clearly seemed to be the heaviest drinkers among the male participants. They, of course, would have no way of comparing themselves to other participants, and they did not claim to be heavy drinkers, but the way they described their drinking suggested heavy consumption (for example, they complained about hang-overs lasting not only into the next morning but into the "whole first part of the week)." They also commented in general that Wisconsin is known for its heavy consumption of beer.

\section{Activities and situations that lead to greater or lesser amounts of drinking}

Participants said they drink most going out to bars with friends, going out with friends on weekends, Sunday afternoons watching football games, on weekends in general, and celebrations, such as birthday parties, and after exams. Participants in the first group are all from families that drink, and they report drinking heavily at holiday celebrations at home.

Bars seemed more important to these participants than to the male participants in Bethesda and Palo Alto. They said that there is a great deal of difference between bars on campus and bars off campus (the majority of participants were students). They said that on-campus bars are almost exclusively patronized by students, who generally live within walking distance. Several participants said that they generally drink the same amount at bars or clubs, but the differences between drinking in bars and clubs varies according to age and to time of night. People under the legal drinking age generally drink more in people's houses, but many participants (who were all at least 21) said that they, too, generally drink at homes before $10 \mathrm{pm}$; then, in bars between $10 \mathrm{pm}$ and $2 \mathrm{am}$; and then again in houses after $2 \mathrm{am}$.

\section{The influence of friends and members of the opposite sex}

Some participants in Madison, like those in Palo Alto, said that they sometimes drink as heavily with women who are (Platonic) friends as with their male friends, but most agreed that they drink most heavily when they go out with their male friends. One participant made the comment, "You don't want to make an ass out of yourself in front of women, but you do want to make an ass out of yourself in front of your friends." Others said they drink less with women because they want "to conserve your energy for later" (with obvious sexual implications). 
Most participants said they generally drink most with six or more friends, who they described as "your good friends."

\section{Problems associated with drinking}

Participants, like male participants in other cities, immediately listed hangovers as a problem associated with drinking. As mentioned before, some complained about losing not only the next day but being "cloudy" for the first part of a week: one participant said he was once cloudy for two weeks, but most participants found that extreme.

Despite some of the things they said about the positive values of alcohol as an escape, participants admitted that making an ass of yourself, short-term memory loss, and "doing things you'll regret later" are negative effects of drinking.

Participants also complained about the cost of alcohol.

Some participants said that alcohol can also affect your performance in sports, and other things (with obvious sexual implications).

However, participants in both groups agreed that the most serious problem with drinking was the "loss of control" and the potential "of doing something dumb--hurting yourself or other people... it doesn't happen to many people, but still, the next day, you think, 'what if'...."

Perceptions of drinking and driving, including perceived differences between drinking-and-driving and driving "drunk" or impaired

When asked if drinking and driving was a concern for them, participants in the first group immediately said "yes," but then, almost immediately, said, "But you don't think about it until the next day:"

"People don't plan on going out and drinking too much, but then it just happens, and they don't think about it until the next day."

Participants in the first group discussed whether or not people ever intentionally drove drunk. Some said that some people do, but one participant seemed to express the situation in a very plausible, if illogical way:

"Their intention is to get drunk. And they intend to drive, but...it's like they don't make the connection."

Participants in the second group openly said that drinking and driving wasn't much of a concern to them because they can walk to all the bars on campus (one participant in the first group said one of the problems with drinking was the walk home--"if you can walk home)." 
When asked about the terms "drinking and driving," "driving impaired," and "drunk driving," participants in both groups indicated that they do NOT use the term driving impaired, although some said it sounded like a legal term. Some would not use the term drinking and driving, "because that could mean driving after one drink, and that's nothing." Others see "drinking and driving as a euphemism for "drunk driving:"

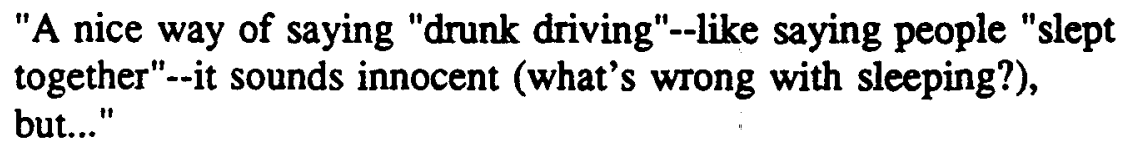

In general, participants don't seem to have a term for any drinking and driving behavior that falls in the "gray area" between "nothing" and "drunk driving." One participant said that he wouldn't use any of these terms to apply to a person who had had two or three drinks over an evening. Even if the person had four drinks, the participant said, "Still, I wouldn't use the term 'impaired,' because I don't think even a cop or a judge would call that blameworthy." However, at six drinks, the participant admitted, "That would put him about .1--legally drunk. But it depends on when he has the drinks." At twelve drinks, the participant admitted, " He's in bad shape."

\section{Perceptions of "limits"}

As in other cities, only one or two participants had definite numerical limits. All the others apply very subjective limits:

"My limit is--my lip gets numb. If my lip gets numb, I stop (drinking)."

"(Agreeing) My lips get numb, time to chill and eat."

"Everybody's different."

"Sometimes you set limits, but you get going along, and you forget your limits."

Participants in the second group argued that their limits could depend on the situation (and so are not "limits" in any real sense of the word):

"It depends on how inconvenient it is to have an alternative route."

"Realistically, you're in the middle of nowhere, no one else is going to drive you."

"It depends on who you're with..." 


\title{
Situations where participants have driven impaired
}

Most participants admitted that they have driven drunk, or at least have driven when they think they would have failed a breathalizer test. This was just as true in the second group, even though those participants had said they don't worry about drinking and driving because they can walk to bars. Most say that they simply don't think about it or rationalize it:

\author{
"You'se so drunk, you don't even think about it." \\ "You just think you're not going to get caught." \\ "You can rationalize it if it's only a short drive." \\ "My friends were even drunker, so I convinced myself it was \\ okay."
}

"Preventive measures" participants use to avoid drinking and/or drinking and driving

Again, many participants try to walk to bars. Most have used designated drivers in various ways. However, many seem to be using subjective limits, "pacing themselves," and stopping drinking around midnight when they know they have to drive.

When asked to develop methods for encouraging people not to drink and drive, participants generally talked about providing alternative ways of getting people home, either by cars or vans, or by a taxi system: apparently the university will pay for students to take a taxi home, but participants seemed very confused about how it works (or doesn't work). Some think that the service is not intended for people who have been drinking (there is some perception that the service began as an escort service for women traveling alone).

As in other cities, participants said the problem with getting a person home is that, if they have driven in the first place, they are not going to want to leave their cars on the street or in the parking lot of a bar. Participants said this was partially a legitimate concern over the security of the vehicle, but also a "macho" or "possessiveness" thing.

Participants also suggested breathalizers in the bars, so people can see how drunk they are (and possibly collecting keys and not returning to them to anyone who cannot pass a breathalizer test).

\section{ATTITUDES TOWARDS DRINKING, NOT DRINKING, AND STAYING IN CONTROL}

\section{Experiences as designated drivers}

Virtually all participants have been designated drivers, but people use the concept in different ways. Some say they sometimes decide before they go to the bar, or during the first 
round, but some admit that it's much less formal: " A lot of times, it just ends up who's the least drunk."

Some participants said that they don't drink at all when they are designated drivers, but others said they'll have a beer or two. One participant said he makes sure he stays under the legal limit: "one drink per hour."

\section{Reasons for being a designated driver}

People in the first group particularly made the point that they don't like being the designated driver, although they are willing to take turns:

"There's a lot of arguing. Really. People are having a good time. Nobody wants to stop. But someone comes through, because nobody wants to see his buddies in a ditch."

"l'm willing to do it if someone else will next time--take turns."

"When people are on a mission, somebody's just got to do it."

Some participants in the second group seemed more willing to be a designated driver, but not necessarily for altruistic reasons:

"I feel more comfortable, because I feel more in control if I haven't been drinking so much. I'd rather drive than have someone who's drunk driving."

"I've got one set of friends I know I can't trust...A lot of people say they're going to be the designated driver, but the first thing you know, they're hanging under the bar."

Images of people who never drink

(Participants were shown photographs of animals and asked to imagine what the animals' drinking and driving behavior might be, if they were human. The actual choice of animal is not to be taken as overly significant, except in the verbal associations the participants raised).

Many participants said the tiger would never drink because he's "strong, self-confident, pure." One participant said, "He has no time for that stuff; he has more important things to do." Another said, "He has no need to put on any front--no false sense of superiority." However, one participant said a tiger could be a drunk, because "they feel they have no superiors; they can do whatever they want." 
For completely different reasons, many participants said the iguana would never drink: "He's lazy and conservative." "A mellow guy." "Laid back." "Low excitement level." However, some participants suggested he could drink a lot, "because he just hangs out at the bar all day-even has his own bar stool."

Participants in the first group said the shark would never drink because he's "an athlete, in control, a leader, but pretty dangerous." Some participants said the same thing about the gorilla:

"Same as the shark. He's not up for that kind of __. Doesn't
want to divert his attention."

"He's strong. He takes care of himself. Eats right. People respect him."

"He has the confidence. Doesn't need to drink."

Some participants in the second group said the gorilla might drink all the time, "just because he doesn't want to take anything from anybody, but if he never wants to drink, that's okay with me, too." Some said he might be a designated driver because he's "over-powering, the guy that people look up to."

Participants in both groups immediately agreed that the eagle would never drink:

"Definitely a \#1 (the number used to identify the non-drinker)."

"Sharp, athletic."

"Majestic."

"Pure."

"A deity."

"Our national symbol."

"A symbol of high morals."

People who drink but never drive impaired

Many participants said the kitten would never drive impaired because she is "cautious." Several used the word "cute." Some said she would never drink at all, because she's "too shy, timid," but others said she was "a little sly," so could drink and get away with it. 
People who drink and sometimes drive impaired

The fox was the one animal that seemed most identified by male participants in Madison as a person who would drink and sometimes drive impaired, and their main reason was that the fox would be sly and "get away with something:"

"Sneaky, aggressive, devious--getting away with something."

"If he's drunk, he'll get himself home and no one will know.

He's that sly"

"Sly enough to get away with it."

People who drink and drive "all the time"

Like participants in other cities, male participants in Madison thought the dog with the snorkel would drink and drive all the time, or at least sometimes drive impaired, because he's "goofy," "somebody who's out of control." They also said the pug would be "with the dog with the snorkel." "Man, he's a lush." "He'd start the brawl in the bar." (from both groups).

Participants in the second group also tended to identify the wolf as someone who drinks and drive all the time, because he "looks blitzed," "(like) he drinks a lot and is proud of it-telling the world, howling."

Participants in the first group identified the bear as a "Green Bay drunk" (a factory worker from Green Bay who goes into bars and gets into fights): "Anything gets in his way, he'll knock it over." Participants in the second group were somewhat divided whether the bear would drink and drive all the time or only sometimes.

Participants in the second group said the otter would drink all the time because it "seems like they drink and flop around on their backs all day; kind of goofy and out of control." Participants in the first group generally agreed, but suggested he'd only drive impaired sometimes: "He's a crazy guy out in the water, a little out of control, but not completely."

Participants in the second group said the shark would drink and drive all the time because he "doesn't take anything from anybody; he does what he wants to do."

People who are designated drivers

Even though many participants identified the wolf as a drinker, some said he would be a designated driver because "they're intelligent. They tend to go in go in groups; they have a leader." However, one participant said, "He's a dd, because you're a lonely son of a buck if you're the dd." 
Many participants, particularly in the first group, said the penguins would be designated drivers "because of the family thing," although some said they would drink but never drive because their "tuxedo" outfits mark them as social drinkers.

Although participants in both groups agreed that the eagle would never drink, they were divided on whether or not he would also be a designated driver. Participants in the first group said that he would, because he is "someone who is looking out for others," "responsible," "altruistic." However, participants in the second group seemed to think "he wouldn't want to get involved."

As did participants in other cities, participants in Madison said the zebra could be either a designated driver or a drunk, because "he's going against the norm."

\section{ROLE PLAYING, INCLUDING PARTICIPANTS' PERCEPTION OF HOW THEY WOULD DEAL WITH SEVERAL SCENARIOS:}

\section{A. A friend becomes too drunk to drive}

Participants in both groups were divided about how "physical" and direct they would be with a friend who became too drunk to drive. In the second group, one of the role players immediately insisted, "Give me your keys. You're not driving. You want to go to jail?" Even though this was one of the most direct approaches seen in the six male groups, one participant said it was much too polite: "In real life, people would be much more rowdy."

In both groups, other role players took more indirect approaches, offering to give their friend a ride home and even trying to "guilt trip him." Several participants said that "guilt trip" approaches often work, and some said overly direct approaches don't:

"If everyone came at me, I'd back off, get away from them."

"I don't like aggressive people. That would put me off."

"I'd take that (a direct approach) as a dare."

"I'd say, '___ you, dude.'"

However, even some participants who said they'd try a more polite approach first also said that, if that failed, they would go on to a more physical approach and physically take the keys away. Some did admit, "with some people, nothing works." One participant said that all he can do with one of his friends is to wait until he passes out, so he can throw him in the back of the car. 


\section{B. A designated driver decides "one or two can't hurt"}

As in other cities, participants in Madison seem to believe that one or two beers really can't hurt. Few would seriously react to a designated driver having one beer. However, some said that they would make some comment such as, "remember you're responsible for all of us tonight." Some said they wouldn't say anything to a designated driver if he ordered a second drink, but they would start talking to the other people in their party about how to handle the situation.

\section{A designated driver becomes too drunk to drive}

Role playing participants did react to a third drink. In the first group, several participants said they would stop drinking themselves. They said they would rather stop drinking than risk a confrontation with a friend: "I don't know if you want to get into an argument with one of your best buddies."

In the second group, participants went directly to the "guilt trip: "Christ, what the are you doing? What the is your problem?"

In the first group, participants reacted very directly to a fourth drink. They said they would take the drinks away if the person persisted. One participant added, "In my group, it's the biggest guy--the strongest guy--that goes over and approaches him."

Several participants said that the scenario was a little unrealistic, in that they seldom order individual drinks: they tend to order beer by the pitcher. Also, they tend to wander off to throw darts or shoot pool, so it's difficult to know how much a designated driver might be drinking.

\section{People begin encouraging the designated driver to drink}

The two groups responded very differently to this scenario. The first group found the situation very realistic:

"Welcome to Wisconsin."

"The weirdest peer pressure I've ever seen. It's like if you don't drink, there's something wrong with you.",

"Let's face it: Wisconsin is infamous nation-wide for its beer consumption."

Participants in the second group said they could not imagine the people with a designated driver encouraging him to drink, but participants in both groups agreed that a lot of pressure to drink comes from other people in the bar, some of whom may not realize that the person is supposed to be the designated driver. 


\section{FRIENDS AND FAMILY}

(Participants were asked to choose colors and draw shapes that somehow represented "friends," "family," and "driving responsibly." As with the animal photographs, the actual colors and shapes are not to be taken as overly significant, except in the verbal associations the participants raised).

Associations with the value of friendship

Again, the majority of participants drew circles and talked about completeness, fullness, connectedness. Many used the word "warmth." Many had associations with nature and the outof-doors. One person drew three vertical lines supporting a horizontal line, saying that friends "are a group of people supporting one thing." Another drew an abstract design of two arms shaking hands.

Associations with the value of family

Again, for the family, several drew circles, and others drew squares or diamonds. One drew a circle with a square around it and a triangle on top: "It's a house." One drew a star, but explained it somewhat as others explained circles: "Points around a center, all tied to one point." Two drew green trees: "Family tree, coming from one place but branching off." Most talked about the family as being "forever there, whether you love them or hate them." Several talked about the family being "really strong," "valuable," but one mentioned "rough edges, but with a smooth part, too," and another drew a red explosion and said, "We fight a lot--violent, mad."

Associations with driving responsibly (designated driver)

Several participants drew straight lines or arrows and talked about "straight and narrow," being "unwavering," and "motion, getting you there." Others drew obviously positive symbols, such as peace sign ("It gives you peace. The peace sign is cliched now, but that doesn't make it less of a good idea."), a "plus" sign ("good idea"), and an orange light bulb ("bright idea").

However, several clearly have mixed feelings about being a designated driver:

"I drew a vertical line. It's up-right, single, because when I'm a designated driver, I figure I might as well sit in my corner until my friends are ready to leave--a loner, basically."

"I drew a brown horizontal line. Brown's a neutral color. I respect a dd, but you'd have to be neutral that night, lay low that night."

"I drew a yellow abstract design of a strong torso--responsible, but yellow, because he's really afraid of the cops." 
"A green line with irregular shapes surrounding it--steady when everybody else is being chaotic, but green because envious, because everybody else is having a good time."

How those associations might be related

Participants in Madison said they found it easy to put their symbols together, although they weren't sure how much meaning it had, and a few said they weren't sure the idea of a designated driver related to their concept of family. Many used words such as "interconnected," "connections" and "link" to describe what they done. They talked about the designated driver supporting or protecting family and friends. One participant used the words "family values" to describe his design, saying that the family is "one of the places where you learn the protective values that you have when you're being the designated driver."

Other participants used the words "care," "safety," "security," "trust," "prudence," "balance," and "order" to describe what they had done.

\section{Final Considerations}

Ways participants believe people can be encouraged to drive responsibly

The relative effectiveness of "positive" approaches and "scare tactics" or guilt-ridden approaches

Participants in Madison generally wanted to say that positive approaches would work, particularly showing the role of a designated driver in a more positive way ("make it seem cool to be a designated driver"). Some said scare tactics, such as the movies in drivers' education courses, clearly have not worked. However, many seemed pessimistic:

"People are immature, and as long as getting drunk is seen as cool, these people are going to be immature."

A few said that, unfortunately, sometimes people only leam from bad experiences. 